\title{
Augmenting the Activity of Macrolide Adjuvants Against Acinetobacter baumannii
}

Authors: Veronica B. Hubble†; Kyle R. Bartholomew†; Alexander W. Weig†; Sara M.

Brackett†; Samantha L. Barlock†; Anne E. Mattingly†; Ansley M. Nemeth†; Roberta J. Melander†; and Christian Melander*†

$\dagger$ Department of Chemistry and Biochemistry, University of Notre Dame, Notre Dame, Indiana 46556, United States

†Department of Chemistry, North Carolina State University, Raleigh, NC, 27695, United States

*Correspondence: Christian Melander, cmelande@nd.edu 


\section{Table of contents}

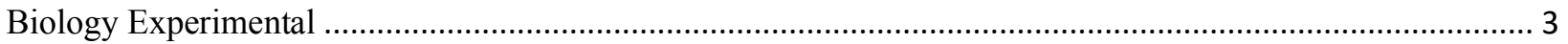

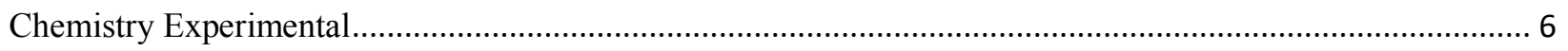

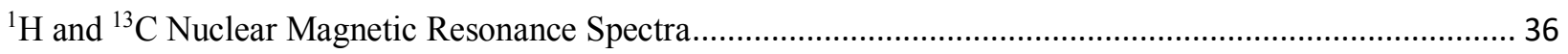

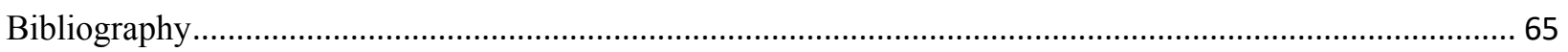




\section{Biology Experimental}

Bacterial Strains and Antimicrobial Agents. Acinetobacter baumannii clinical isolate 5075 was obtained from Dr. Colin Manoil at the University of Washington. Colonies were grown on lysogeny broth (LB) agar. Cation-adjusted Mueller-Hinton Broth (CAMHB) (catalog number 212322) were purchased from BD Diagnostics. LB broth was purchased from Fisher Scientific (catalog number BP9722-2). Clarithromycin (catalog number C2220) was purchased from TCI. Colistin sulfate salt (catalog number C4461) was purchased from Sigma Aldrich. All assays were completed in duplicate and repeated at least two separate times. All compounds were dissolved as their $\mathrm{HCl}$ salts in molecular biology grade DMSO as 10 or $100 \mathrm{mM}$ stock solutions and stored at $-20{ }^{\circ} \mathrm{C}$. Colistin was dissolved in sterile water while clarithromycin was dissolved in molecular biology grade DMSO.

Broth microdilution method for MIC determination. Day cultures (6 h) of each bacterial strain in cation adjusted Mueller Hinton II broth (CAMHB, Fisher Scientific U.S.) were subcultured to $5 \times 10^{5} \mathrm{CFU} / \mathrm{mL}$ in CAMHB. Aliquots $(1 \mathrm{~mL})$ were placed in culture tubes and compound was added from $10 \mathrm{mM}$ stock samples in DMSO, such that compound concentration equaled highest concentration tested $(200 \mu \mathrm{M})$. Samples were then aliquoted $(200 \mu \mathrm{L})$ into the first wells of a $96-$ well plate, with all remaining wells being filled with $100 \mu \mathrm{L}$ of initial bacterial subculture. Row one wells were mixed five times, before $100 \mu \mathrm{L}$ was transferred to row two. Row two was then mixed five times, and $100 \mu \mathrm{L}$ was transferred to row three. This process was repeated until the final row had been mixed; this served to serially dilute the compound. Plates were then covered with GLAD Press n' Seal and incubated under stationary conditions at $37^{\circ} \mathrm{C}$ for $16 \mathrm{~h}$. MIC values were then recorded as the lowest concentration at which no bacterial growth was observed. 
Broth microdilution method for antibiotic potentiation. Day cultures $(6 \mathrm{~h})$ of bacteria in CAMHB were subcultured to $5 \times 10^{5} \mathrm{CFU} / \mathrm{mL}$ in CAMHB. Aliquots $(4 \mathrm{~mL})$ were placed in culture tubes and dosed with compound from $10 \mathrm{mM}$ stock samples to give the desired concentration of the compound to be tested against the particular bacterial strain; this insured non-toxic DMSO concentrations $\leq 0.3 \%$ in each well. $1 \mathrm{~mL}$ of the resulting solution was placed in a separate culture and dosed with antibiotic at the highest concentration to be tested. Bacteria treated with antibiotic alone served as the control. Row one of a 96-well plate was filled with $200 \mu \mathrm{L}$ of the antibiotic/2AI solution, and rows 2-12 were filled with $100 \mu \mathrm{L}$ each of the remaining $4 \mathrm{~mL}$ of bacterial subculture containing adjuvant at the desired concentration, except for the control lane which contained only bacterial subculture. Row one was then mixed five times, and $100 \mu \mathrm{L}$ was transferred to row two, which was then mixed five times before being transferred to row three. This process was repeated until all rows had been mixed, except for row twelve which would have only 2-AI to serve as a control to monitor potential toxicity. The 96 -well plate was then covered in Glad Press n' Seal and incubated under stationary conditions at $37^{\circ} \mathrm{C}$ for $16 \mathrm{~h}$. MIC values were determined as the lowest concentration at which no bacterial growth was observed, and fold reductions were determined by comparison to antibiotic control lane.

Dose-response of Adjuvant Assay. The procedure for 'broth microdilution method for antibiotic potentiation' was followed using $4 \mathrm{~mL}$ aliquots of adjuvant at various concentrations: $0,5,7.5,10$, $15,20,25$, and $30 \mu \mathrm{M}$. 
Evolution of Clarithromycin Resistance in A. baumannii. A. baumannii 5075 was grown in CAMHB overnight then subcultured $\left(5 \times 10^{5} \mathrm{CFU} / \mathrm{mL}\right)$ in $6 \mathrm{~mL}$ of fresh CAMHB. Adjuvant was added into this 6-mL subculture at either 10 or $30 \mu \mathrm{M}$ concentrations. Aliquots of $1 \mathrm{~mL}$ were taken and placed into five individual culture tubes and clarithromycin was added at concentrations of 2and 4-fold MIC greater than and also 2- and 4-fold less than reported clarithromycin MIC values with adjuvant, with the middle tube representing the clarithromycin MIC value. After $24 \mathrm{~h}$ of shaking at $37^{\circ} \mathrm{C}$, bacterial growth was evaluated and the highest clarithromycin concentration with growth was carried forward and MICs determined every two days. This was serially repeated for a period of nine days. 
Table S1. CLR potentiation against AB5075 for compounds with varying aryl tails.

\begin{tabular}{cccccccc}
\hline Compound & $\begin{array}{c}\text { MIC } \\
(\mu \mathrm{M})\end{array}$ & $\begin{array}{c}\text { Concentration } \\
\text { Tested }(\mu \mathrm{M})\end{array}$ & $\begin{array}{c}\text { CLR } \\
\text { MIC } \\
(\mu \mathrm{g} / \mathrm{mL})\end{array}$ & $\begin{array}{c}\text { Compound } \\
(\mu \mathrm{M})\end{array}$ & $\begin{array}{c}\text { Concentration } \\
\text { Tested }(\mu \mathrm{M})\end{array}$ & $\begin{array}{c}\text { CLR } \\
\text { MIC } \\
(\mu \mathrm{g} / \mathrm{mL})\end{array}$ \\
\hline- & - & - & 32 & - & - & - & 32 \\
$\mathbf{4 a}$ & $>200$ & 30 & 16 & $\mathbf{4 n}$ & 25 & 7.5 & 2 \\
$\mathbf{4 b}$ & $>200$ & 30 & 32 & $\mathbf{4 o}$ & 100 & 15 & 0.5 \\
$\mathbf{4 c}$ & $>200$ & 30 & 32 & $\mathbf{4 p}$ & 50 & 15 & 0.5 \\
$\mathbf{4 d}$ & 200 & 30 & 1 & $\mathbf{4 q}$ & $>200$ & 30 & 8 \\
$\mathbf{4 e}$ & $>200$ & 30 & 16 & $\mathbf{4 r}$ & 100 & 30 & 0.5 \\
$\mathbf{4 f}$ & $>200$ & 30 & 32 & $\mathbf{4 s}$ & 100 & 30 & 0.5 \\
$\mathbf{4 g}$ & $>200$ & 30 & 16 & $\mathbf{4 t}$ & $>200$ & 30 & 4 \\
$\mathbf{4 h}$ & $>200$ & 30 & 4 & $\mathbf{4 u}$ & $>200$ & 30 & 2 \\
$\mathbf{4 i}$ & $>200$ & 30 & 1 & $\mathbf{4 v}$ & 100 & 30 & 1 \\
$\mathbf{4 j}$ & $>200$ & 30 & 8 & $\mathbf{4 w}$ & $>200$ & 30 & 32 \\
$\mathbf{4 k}$ & $>200$ & 30 & 4 & $\mathbf{4 x}$ & $>200$ & 30 & 4 \\
$\mathbf{4 l}$ & 50 & 15 & 8 & $\mathbf{4 y}$ & 200 & 30 & 0.25 \\
$\mathbf{4 m}$ & $>200$ & 30 & 2 & $\mathbf{4}$ & - & - & - \\
\hline
\end{tabular}


Table S2. Minimum inhibitory concentration data against AB isolates.

\begin{tabular}{|c|c|c|c|}
\hline $\begin{array}{l}\text { A. baumannii } \\
\text { strain }\end{array}$ & $\begin{array}{l}\text { Compound } \mathbf{1 5 b} \\
(\mu \mathrm{M})\end{array}$ & $\begin{array}{l}\text { Compound 20a } \\
(\mu \mathrm{M})\end{array}$ & $\begin{array}{c}\text { CLR MIC } \\
(\mu \mathrm{g} / \mathrm{mL})\end{array}$ \\
\hline 3560 & 50 & 25 & 32 \\
\hline 3785 & 200 & 50 & 64 \\
\hline 3806 & 200 & 25 & 16 \\
\hline 3927 & $>200$ & 100 & 32 \\
\hline 4025 & 100 & 100 & 64 \\
\hline 4026 & 100 & 50 & 64 \\
\hline 4027 & 200 & 50 & 64 \\
\hline 4052 & $>200$ & 50 & 32 \\
\hline 4269 & $>200$ & 50 & 32 \\
\hline 4448 & $>200$ & 100 & 32 \\
\hline 4456 & 50 & 25 & 32 \\
\hline 4490 & $>200$ & 100 & 32 \\
\hline 4498 & 100 & 50 & 64 \\
\hline 4795 & 100 & 25 & 32 \\
\hline 4857 & 50 & 50 & 64 \\
\hline 4878 & 200 & 50 & 32 \\
\hline 4957 & $>200$ & 50 & 32 \\
\hline 4991 & $>200$ & 50 & 32 \\
\hline 5001 & $>200$ & 50 & 32 \\
\hline 5197 & $>200$ & 25 & 64 \\
\hline 5256 & $>200$ & 25 & 32 \\
\hline 5711 & $>200$ & 25 & 64 \\
\hline 8967 & $>200$ & 100 & 16 \\
\hline
\end{tabular}


Table S3. Clarithromycin potentiation data against AB isolates using lead aryl 2-AI adjuvants $\mathbf{1 5 b}$ and 20a.

\begin{tabular}{|c|c|c|}
\hline $\begin{array}{l}\text { A. baumannii } \\
\text { strain }\end{array}$ & $\begin{array}{c}\text { CLR MIC }(\mu \mathrm{g} / \mathrm{mL}) \\
+ \\
\mathbf{1 5 b}(10 \mu \mathrm{M})\end{array}$ & $\begin{array}{c}\text { CLR MIC }(\mu \mathrm{g} / \mathrm{mL}) \\
+ \\
\mathbf{2 0 a}(7.5 \mu \mathrm{M})\end{array}$ \\
\hline 3560 & 2 & 1 \\
\hline 3785 & 4 & 1 \\
\hline 3806 & 0.5 & 0.25 \\
\hline 3927 & 2 & 0.5 \\
\hline 4025 & 1 & 1 \\
\hline 4026 & 4 & 1 \\
\hline 4027 & 1 & 1 \\
\hline 4052 & 1 & 0.5 \\
\hline 4269 & 2 & 2 \\
\hline 4448 & 2 & 0.5 \\
\hline 4456 & 2 & 1 \\
\hline 4490 & 2 & 1 \\
\hline 4498 & 2 & 2 \\
\hline 4795 & 2 & 0.5 \\
\hline 4857 & 1 & 0.5 \\
\hline 4878 & 2 & 0.5 \\
\hline 4957 & 4 & 0.5 \\
\hline 4991 & 2 & 0.5 \\
\hline 5001 & 4 & 1 \\
\hline 5197 & 2 & 1 \\
\hline 5256 & 1 & 0.25 \\
\hline 5711 & 4 & 1 \\
\hline 8967 & 1 & 0.25 \\
\hline
\end{tabular}


Table S4. Dose-response of active aryl tails for colistin potentiation against AB5075.

\begin{tabular}{|c|c|c|}
\hline Compound & $\begin{array}{l}\text { Concentration Tested } \\
\qquad(\mu \mathrm{M})\end{array}$ & $\begin{array}{c}\text { Colistin MIC } \\
(\mu \mathrm{g} / \mathrm{mL})\end{array}$ \\
\hline- & - & 0.5 \\
\hline $4 h$ & 30 & 0.5 \\
\hline $4 i$ & 30 & 1 \\
\hline $4 k$ & 30 & 1 \\
\hline $4 m$ & 30 & 0.5 \\
\hline $4 n$ & 7.5 & 1 \\
\hline 40 & 15 & 1 \\
\hline \multirow{2}{*}{$4 p$} & 15 & 1 \\
\hline & 10 & 0.5 \\
\hline $4 r$ & 30 & 4 \\
\hline $4 s$ & 30 & 0.25 \\
\hline $4 u$ & 30 & 0.5 \\
\hline \multirow[t]{2}{*}{$4 v$} & 30 & 1 \\
\hline & 30 & 4 \\
\hline \multirow[t]{2}{*}{$4 y$} & 20 & 4 \\
\hline & 10 & 4 \\
\hline \multirow{2}{*}{$6 a$} & 30 & 1 \\
\hline & 20 & 0.5 \\
\hline \multirow{2}{*}{$\mathbf{6 b}$} & 30 & 4 \\
\hline & 20 & 1 \\
\hline $10 \mathrm{a}$ & 30 & 1 \\
\hline
\end{tabular}




\begin{tabular}{ccc}
\hline & 20 & 0.5 \\
$\mathbf{1 0 d}$ & 30 & 8 \\
& 20 & 2 \\
& 10 & 1 \\
$\mathbf{1 0 e}$ & 30 & 4 \\
& 20 & 1 \\
$\mathbf{1 5 a}$ & 30 & 4 \\
\hline $\mathbf{1 5 b}$ & 30 & 8 \\
& 20 & 8 \\
\hline $\mathbf{1 7 a}$ & 10 & 2 \\
\hline $\mathbf{1 7 b}$ & 15 & 2 \\
\hline $\mathbf{2 0 a}$ & 15 & 2 \\
\hline $\mathbf{2 0 b}$ & 15 & 4 \\
\hline
\end{tabular}


Table S5. CLR potentiation data for the evolution assay using CLR-alone exposure to AB5075 over the course of nine consecutive days.

\begin{tabular}{cc}
\hline Day & CLR MIC $(\mu \mathrm{g} / \mathrm{mL})$ \\
\hline 0 & 32 \\
2 & $\geq 128$ \\
4 & 128 \\
6 & 512 \\
\hline 8 & 512 \\
\hline
\end{tabular}

Table S6. CLR potentiation data with parent compound $\mathbf{1}$ for the evolution assay using serial passage of CLR-adjuvant $\mathbf{1}$ (at $30 \mu \mathrm{M})$ to AB5075 over the course of nine consecutive days.

\begin{tabular}{ccc}
\hline Day & $\begin{array}{c}\text { Compound } \mathbf{1} \text { Concentration } \\
\text { Tested }(\mu \mathrm{M})\end{array}$ & CLR MIC $(\mu \mathrm{g} / \mathrm{mL})$ \\
\hline 2 & 0 & 0.25 \\
4 & 30 & 32 \\
\hline 6 & 0 & 0.25 \\
& 30 & 32 \\
8 & 0 & 0.25 \\
\hline 10 & 30 & 32 \\
\hline & 0 & $\leq 0.5$ \\
\hline
\end{tabular}




\section{Chemistry Experimental}

All reagents used for chemical synthesis were purchased from commercially available sources (VWR U.S., Fisher Scientific U.S., or Sigma Aldrich U.S.) and used without further purification. Flash chromatography was performed using $60 \AA$ mesh standard grade silica gel from Sorbetch. NMR solvents were obtained from Cambridge Isotope Labs and used as is. All ${ }^{1} \mathrm{H}$ NMR (400 or $500 \mathrm{MHz})$ were recorded at $25^{\circ} \mathrm{C}$ on Bruker AVANCE III HD spectrometers. All ${ }^{13} \mathrm{C}$ NMR $(100$ or $125 \mathrm{MHz}$ ) spectra were recorded at $25^{\circ} \mathrm{C}$ on Bruker AVANCE III HD spectrometers. Chemical shifts $(\delta)$ are given in parts per million (ppm) relative to the respective NMR solvent; coupling constants $(\mathrm{J})$ are in hertz $(\mathrm{Hz})$. Abbreviations used are s, singlet; bs, broad singlet; d, doublet; dd, doublet of doublets; $\mathrm{t}$, triplet; $\mathrm{dt}$, doublet of triplets; $\mathrm{tt}$, triplet of triplets; m, multiplet. Highresolution mass spectrometry measurements were obtained at either Notre Dame Department of Chemistry Mass Spectrometry and Proteomics Facility, or in part by the Molecular Education, Technology and Research Innovation Center (METRIC) at NC State University, which is supported by the State of North Carolina. Infrared spectra were obtained on a Bruker Alpha II FTIR spectrophotometer $\left(v_{\max }\right.$ in $\left.\mathrm{cm}^{-1}\right)$. UV absorbance was recorded on a Genesys 10 scanning $\mathrm{UV} /$ visible spectrophotometer $\left(\lambda_{\max }\right.$ in $\left.\mathrm{nm}\right)$. The purities of the tested compounds were all verified to be $\geq 95 \%$ by LC-MS analysis on an Advion LC-MS 2020 with Kinetex, $2.6 \mathrm{~mm}, \mathrm{C} 1850 \times 2.10$ $\mathrm{mm}$.

General procedure for alloc protection. The corresponding aniline (17 mmol, 1 eq) was dissolved in a 1:1 ratio of $\mathrm{H}_{2} \mathrm{O}: 1,4$-dioxane $(45 \mathrm{~mL}: 45 \mathrm{~mL})$ at room temperature. DIPEA (33 mmol, 2 eq) and $\mathrm{NaHCO}_{3}(50 \mathrm{mmol}, 3 \mathrm{eq})$ were added to the reaction mixture. The reaction mixture was cooled to $0^{\circ} \mathrm{C}$ and allyl chloroformate $(17 \mathrm{mmol}, 1 \mathrm{eq})$ was added dropwise to the reaction mixture, and the reaction was allowed to stir for $16 \mathrm{~h}$. Upon completion, the reaction mixture was cooled to 
$0{ }^{\circ} \mathrm{C}$ and quenched with $1 \mathrm{~N} \mathrm{HCl}(70 \mathrm{~mL})$, at which point white solid crashed out of solution. The precipitate was vacuum filtered and collected as desired aniline product.

General procedure for saponification. Methyl ester analogs (1 eq, $1.34 \mathrm{mmol})$ were dissolved in a 1:1 mixture of $\mathrm{MeOH}: \mathrm{H}_{2} \mathrm{O}(16 \mathrm{~mL})$ to which a $5 \mathrm{M}$ solution of sodium hydroxide $(4 \mathrm{~mL})$ was added at room temperature. The reaction solution was stirred for $3 \mathrm{~h}$. After completion, the $\mathrm{MeOH}$ was removed under reduced pressure. The remaining aqueous solution was cooled to $0{ }^{\circ} \mathrm{C}$, and 12 $\mathrm{N} \mathrm{HCl}$ was added until the $\mathrm{pH}$ reached $\sim 2$. The resulting precipitate was then isolated using vacuum filtration and allowed to dry under high vacuum for $2 \mathrm{~h}$.

General procedure for acid chloride formation. To a solution of anhydrous DCM (20 mL) was added the benzoic acid analogs $(1 \mathrm{eq}, 5.1 \mathrm{mmol})$, followed by the dropwise addition of commercially available oxalyl chloride $(1.1 \mathrm{eq}, 5.6 \mathrm{mmol})$ and catalytic amount of DMAP (0.01 eq, $0.05 \mathrm{mmol}$ ) at $0{ }^{\circ} \mathrm{C}$. The reaction was stirred at $0{ }^{\circ} \mathrm{C}$ for $1 \mathrm{~h}$, then solvent was removed under reduced pressure and the crude was allowed to dry under high vacuum for $0.5 \mathrm{~h}$ and immediately used in the general procedure for $\alpha$-bromo-ketone production.

General procedure for $\boldsymbol{\alpha}$-bromo-ketone production. In a flame dried round bottom under $\mathrm{N}_{2}$ atmosphere was added the corresponding alloc-protected benzoic acid $(6.0 \mathrm{mmol}, 1 \mathrm{eq})$ dissolved in anhydrous DCM $(20 \mathrm{~mL})$. The reaction mixture was cooled to $0{ }^{\circ} \mathrm{C}$ and oxalyl chloride $(6.6$ mmol, 1.1 eq) was added dropwise followed by the addition of a catalytic amount of DMF (6.5 $\mu$ mol, $0.0001 \mathrm{eq})$. The reaction mixture was allowed to stir for $2 \mathrm{~h}$, at which point the solution was concentrated under reduced pressure to yield corresponding desired acid chloride. The acid 
chloride product $(10 \mathrm{mmol}, 1 \mathrm{eq})$ was dissolved in anhydrous DCM $(20 \mathrm{~mL})$ and added dropwise to a distilled solution of diazomethane $(50 \mathrm{mmol}, 5 \mathrm{eq})$ in ether at $0{ }^{\circ} \mathrm{C}$ and stirred for $1.5 \mathrm{~h}$. TLC analysis was used to verify consumption of acid chloride starting material, at which point concentrated $\mathrm{HBr}(50 \mathrm{mmol}, 5 \mathrm{eq})$ was added dropwise at $0{ }^{\circ} \mathrm{C}$ and stirred an additional $30 \mathrm{~min}$. Upon reaction completion via TLC analysis, the reaction solution was quenched with $\mathrm{NaHCO}_{3}$ $(200 \mathrm{~mL})$ and the reaction was extracted with DCM $(3 \times 300 \mathrm{~mL})$. The combined organic layers were rinsed with brine $(1 \times 30 \mathrm{~mL})$ and dried with $\mathrm{MgSO}_{4}$. The solvent was removed under reduced pressure, and the residue was rinsed three times with $\mathrm{Et}_{2} \mathrm{O}$ to remove undesired impurities. The remaining residue was collected and dried on high vacuum as the corresponding desired $\alpha$-bromoketone and used without further purification in the 'general procedure for Boc-guanidine cyclization'.

General procedure for Boc-guanidine cyclization. The corresponding $\alpha$-bromo-ketone ( $2 \mathrm{mmol}$, $1 \mathrm{eq})$ and boc-guanidine $(6 \mathrm{mmol}, 3 \mathrm{eq})$ were dissolved in anhydrous THF $(20 \mathrm{~mL})$ and stirred for $3 \mathrm{~h}$ at $56^{\circ} \mathrm{C}$. The reaction solvent was removed under reduced pressure to yield a crude residue. The crude residue was purified by flash chromatography ( $5-100 \%$ EtOAc/hexanes) to afford desired 2-aminoimidazole compounds.

General procedure for alloc deprotection. The corresponding alloc-protected compound (1.5 mmol, 1 eq) was dissolved in 200-proof EtOH $(20 \mathrm{~mL})$. Next, the reaction solution was cooled to $0{ }^{\circ} \mathrm{C}$ and tetrakis(triphenylphosphine)palladium $(0)(0.035 \mathrm{mmol}, 0.02 \mathrm{eq})$ and sodium borohydride ( $3.0 \mathrm{mmol}, 2 \mathrm{eq})$ were added to the reaction mixture and allowed to stir for $4 \mathrm{~h}$. After completion, the reaction was extracted with EtOAc $(2 \times 30 \mathrm{~mL})$ and washed with deionized water $(10 \mathrm{~mL})$. 
The combined organic layers were rinsed with brine $(10 \mathrm{~mL})$ and dried with $\mathrm{MgSO}_{4}$, then concentrated under reduced pressure. The residue was then purified using flash chromatography (30\% EtOAc in hexanes) to yield the corresponding aniline product.

General procedure for amide formation. To a solution of anhydrous THF (10 mL) was added the aniline intermediate $(1 \mathrm{eq}, 1.20 \mathrm{mmol})$ and $\mathrm{K}_{3} \mathrm{PO}_{4}(1.5 \mathrm{eq}, 1.79 \mathrm{mmol})$ at $0{ }^{\circ} \mathrm{C}$, followed by the dropwise addition of commercially available 3,5-dichlorobenzoyl chloride (1 eq, $1.20 \mathrm{mmol}$ ). The reaction was warmed to room temperature and stirred for $16 \mathrm{~h}$. Water $(10 \mathrm{~mL})$ was added to the reaction solution and the desired product was extracted with EtOAc $(3 \times 30 \mathrm{~mL})$, followed by the organic layers being rinsed with brine $(2 \times 10 \mathrm{~mL})$. The organic layers were combined and dried with $\mathrm{MgSO}_{4}$, then concentrated under reduced pressure. Final product was purified using flash chromatography ( $0-50 \%$ EtOAc in hexanes).

General procedure for amide formation using EDC coupling. A solution of commercially available carboxylic acid (4.4 mmol, $1.5 \mathrm{eq})$, EDC (17.7 mmol, 6 eq), DMAP (1.5 mmol, $0.5 \mathrm{eq})$, and commercially available aniline $(3.0 \mathrm{mmol}, 1 \mathrm{eq})$ was made in anhydrous DCM $(50 \mathrm{~mL})$. The reaction was refluxed at $40^{\circ} \mathrm{C}$ under an atmosphere of nitrogen and allowed to stir for $16 \mathrm{~h}$ at room temperature. After completion, the reaction was allowed to cool to room temperature and water $(30 \mathrm{~mL})$ was added to the flask. The desired product was extracted with DCM $(3 \times 50 \mathrm{~mL})$, washed with $1 \mathrm{~N} \mathrm{HCl}(2 \times 20 \mathrm{~mL})$, then rinsed with brine $(2 \times 20 \mathrm{~mL})$. The organic layers were combined and dried with $\mathrm{MgSO}_{4}$, then concentrated under reduced pressure. Final product was purified using flash chromatography $(0-50 \%$ EtOAc in hexanes $)$. 
General procedure for Boc deprotection. The corresponding Boc-protected 2-AI (1.3 mmol, 1 eq) was dissolved in DCM (1 mL) and TFA $(2 \mathrm{~mL})$ was added dropwise into the reaction vessel. The reaction was stirred at room temperature for $3 \mathrm{~h}$. Once reaction reached completion via TLC analysis, the solvent was removed under reduced pressure. The resulting TFA salt was dissolved in $\mathrm{MeOH}(10 \mathrm{~mL})$ then spiked with $6 \mathrm{M} \mathrm{HCl}(0.5 \mathrm{~mL})$ and solvent was removed to yield their corresponding $\mathrm{HCl}$ salts.

\section{Previously Reported Compounds}<smiles>Nc1nc(-c2ccc(NC(=O)c3cc(Cl)cc(Cl)c3)cc2)c[nH]1</smiles>

\section{$N$-(4-(2-amino-1 $H$-imidazol-4-yl)phenyl)-3,5-dichlorobenzamide hydrochloride (1):}

Compound $\mathbf{1}$ was prepared following a previously published protocol ${ }^{1}$ to obtained as a white solid in 64\% yield. ${ }^{1} \mathrm{H}$ NMR (400 MHz, DMSO-d $\left.)_{6}\right) 12.63(\mathrm{~s}, 1 \mathrm{H}), 11.99(\mathrm{~s}, 1 \mathrm{H}), 10.55(\mathrm{~s}, 1 \mathrm{H}), 7.99$ $(\mathrm{d}, J=1.9 \mathrm{~Hz}, 2 \mathrm{H}), 7.90(\mathrm{t}, J=1.9 \mathrm{~Hz}, 1 \mathrm{H}), 7.83(\mathrm{~d}, J=8.7 \mathrm{~Hz}, 2 \mathrm{H}), 7.66(\mathrm{~d}, J=8.7 \mathrm{~Hz}, 2 \mathrm{H})$, 7.47 (bs, 2H), $7.36(\mathrm{~s}, 1 \mathrm{H})$.<smiles>Nc1nc(-c2ccc(NC(=O)c3ccc(Br)cc3)cc2)c[nH]1</smiles>

$N$-(4-(2-amino-1H-imidazol-4-yl)phenyl)-4-bromobenzamide hydrochloride (4h): 
Compound $\mathbf{4 h}$ was prepared following a previously published protocol ${ }^{1}$ to obtained as a white solid in $72 \%$ yield. ${ }^{1} \mathrm{H}$ NMR (400 MHz, Methanol- $\left.d_{4}\right) \delta 7.86(\mathrm{~d}, J=8.6 \mathrm{~Hz}, 1 \mathrm{H}), 7.82(\mathrm{~d}, J=8.8$ $\mathrm{Hz}, 1 \mathrm{H}), 7.70(\mathrm{~d}, J=8.5 \mathrm{~Hz}, 1 \mathrm{H}), 7.58(\mathrm{~d}, J=8.7 \mathrm{~Hz}, 1 \mathrm{H}), 7.14(\mathrm{~s}, 1 \mathrm{H})$.<smiles>Nc1nc(-c2ccc(NC(=O)c3ccc(F)cc3)cc2)c[nH]1</smiles>

\section{$N$-(4-(2-amino-1H-imidazol-4-yl)phenyl)-4-fluorobenzamide hydrochloride (4j):}

Compound $\mathbf{4} \mathbf{j}$ was prepared following a previously published protocol ${ }^{1}$ to obtained as a tan solid in $57 \%$ yield. ${ }^{1} \mathrm{H}$ NMR (400 MHz, DMSO- $\left.d_{6}\right) \delta 12.84(\mathrm{~s}, 1 \mathrm{H}), 12.08(\mathrm{~s}, 1 \mathrm{H}), 10.44(\mathrm{~s}, 1 \mathrm{H}), 8.06$ $(\mathrm{dd}, J=8.7,5.6 \mathrm{~Hz}, 2 \mathrm{H}), 7.86(\mathrm{dd}, J=8.8,2.1 \mathrm{~Hz}, 2 \mathrm{H}), 7.65(\mathrm{~d}, J=8.7 \mathrm{~Hz}, 2 \mathrm{H}), 7.46(\mathrm{~s}, 2 \mathrm{H})$, $7.38(\mathrm{t}, J=8.8 \mathrm{~Hz}, 2 \mathrm{H}), 7.34(\mathrm{~s}, 1 \mathrm{H})$.<smiles>Nc1nc(-c2ccc(NC(=O)c3ccc(C(F)(F)F)c(F)c3)cc2)c[nH]1</smiles>

\section{$N$-(4-(2-amino-1H-imidazol-4-yl)phenyl)-3-fluoro-4-(trifluoromethyl)benzamide hydrochloride (4p):}

Compound $\mathbf{4 p}$ was prepared following a previously published protocoll ${ }^{1}$ to obtained as a tan solid in $36 \%$ yield. ${ }^{1} \mathrm{H}$ NMR (400 MHz, DMSO- $\left.d_{6}\right) \delta 12.69(\mathrm{~s}, 1 \mathrm{H}), 12.02(\mathrm{~s}, 1 \mathrm{H}), 10.65(\mathrm{~s}, 1 \mathrm{H}), 8.07$ $(\mathrm{d}, J=11.4 \mathrm{~Hz}, 1 \mathrm{H}), 8.00(\mathrm{~d}, J=5.9 \mathrm{~Hz}, 2 \mathrm{H}), 7.85(\mathrm{~d}, J=8.8 \mathrm{~Hz}, 2 \mathrm{H}), 7.67(\mathrm{~d}, J=8.7 \mathrm{~Hz}, 2 \mathrm{H})$, $7.46(\mathrm{bs}, 2 \mathrm{H}), 7.36(\mathrm{~s}, 1 \mathrm{H})$. 
<smiles>Nc1nc(-c2ccc(NC(=O)c3cccc(Cl)c3Cl)cc2)c[nH]1</smiles>

$N$-(4-(2-amino-1H-imidazol-4-yl)phenyl)-2,3-dichlorobenzamide hydrochloride (4q):

Compound $\mathbf{4 q}$ was prepared following a previously published protocoll ${ }^{1}$ to obtained as a tan solid in 55\% yield. ${ }^{1} \mathrm{H}$ NMR $\left(400 \mathrm{MHz}\right.$, Methanol- $\left.d_{4}\right) \delta 7.79(\mathrm{~d}, J=8.8 \mathrm{~Hz}, 2 \mathrm{H}), 7.68(\mathrm{dd}, J=7.9,1.7$ $\mathrm{Hz}, 1 \mathrm{H}), 7.59(\mathrm{~d}, J=8.7 \mathrm{~Hz}, 2 \mathrm{H}), 7.51(\mathrm{dd}, J=7.6,1.7 \mathrm{~Hz}, 1 \mathrm{H}), 7.44(\mathrm{t}, J=7.8 \mathrm{~Hz}, 1 \mathrm{H}), 7.15$ (s, $1 \mathrm{H})$.<smiles>Nc1nc(-c2ccc(NC(=O)c3c(F)c(F)c(F)c(F)c3F)cc2)c[nH]1</smiles>

$N$-(4-(2-amino-1H-imidazol-4-yl)phenyl)-2,3,4,5,6-pentafluorobenzamide hydrochloride (4x):

Compound $\mathbf{4 x}$ was prepared following a previously published protocoll ${ }^{1}$ to obtained as a tan solid in $61 \%$ yield. ${ }^{1} \mathrm{H}$ NMR (400 MHz, DMSO- $\left.d_{6}\right) \delta 12.77(\mathrm{~s}, 1 \mathrm{H}), 12.07(\mathrm{~s}, 1 \mathrm{H}), 11.21(\mathrm{~s}, 1 \mathrm{H}), 7.83$ - $7.60(\mathrm{~m}, 4 \mathrm{H}), 7.47(\mathrm{bs}, 2 \mathrm{H}), 7.37(\mathrm{~s}, 1 \mathrm{H})$.

\section{Novel Compound Characterization}




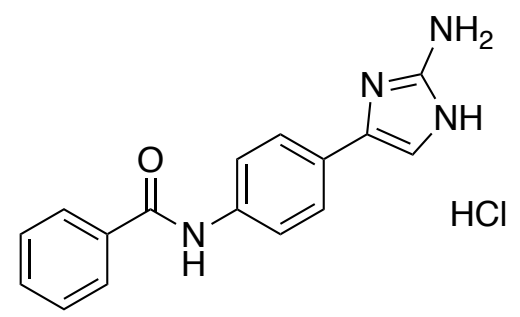

\section{$N$-(4-(2-amino-1H-imidazol-4-yl)phenyl)benzamide hydrochloride (4a):}

To a solution of anhydrous DCM ( $5 \mathrm{~mL})$ was added the aniline intermediate 3 ( 1 eq, $0.23 \mathrm{mmol})$ and trimethylamine ( $3 \mathrm{eq}, 0.72 \mathrm{mmol}$ ) at room temperature, followed by the dropwise addition of commercially available benzoyl chloride $(1.7 \mathrm{eq}, 0.39 \mathrm{mmol})$. The reaction was stirred at $25^{\circ} \mathrm{C}$ for $16 \mathrm{~h}$. The reaction solution was washed with water $(2 \times 10 \mathrm{~mL})$ and the desired product was extracted with DCM (2 x $20 \mathrm{~mL})$, followed by the organic layers being rinsed with brine $(2 \times 10$ $\mathrm{mL}$ ). The organic layers were combined and dried with $\mathrm{MgSO}_{4}$, then concentrated under reduced pressure. The crude material was purified using flash chromatography $(0-15 \%$ EtOAc in hexanes). After purification, the general procedure for Boc deprotection was utilized to obtain 4a as a tan solid in $40 \%$ yield. ${ }^{1} \mathrm{H}$ NMR $\left(400 \mathrm{MHz}\right.$, Methanol- $\left.d_{4}\right) \delta 7.99-7.92(\mathrm{~m}, 2 \mathrm{H}), 7.87-7.81$ $(\mathrm{m}, 2 \mathrm{H}), 7.64-7.49(\mathrm{~m}, 5 \mathrm{H}), 7.14(\mathrm{~s}, 1 \mathrm{H}) .{ }^{13} \mathrm{C}$ NMR (101 MHz, Methanol- $\left.d_{4}\right) \delta$ 168.9, 149.3, $140.4,136.1,133.1,129.7,128.9,128.7,126.1,124.9,122.5,109.5 . \mathrm{UV}(\lambda \max \mathrm{nm}): 312 ; \mathrm{IR}\left(v_{\max }\right.$ $\mathrm{cm}^{-1}$ ) 3259, 3134, 3027, 1676, 1641, 1447; HRMS (ESI) calcd for $\mathrm{C}_{16} \mathrm{H}_{15} \mathrm{~N}_{4} \mathrm{O}[\mathrm{M}+\mathrm{H}]^{+}:$279.1240, found: 279.1234 .<smiles>Nc1nc(-c2ccc(NC(=O)c3cccc(Cl)c3)cc2)c[nH]1</smiles>

4-(2-Amino-3H-imidazol-4-yl)phenyl]-3-chlorobenzamide hydrochloride (4d): 
To a solution of anhydrous THF $(5 \mathrm{~mL})$ was added the aniline intermediate 3 (1 eq, $0.20 \mathrm{mmol})$ and triethylamine ( $1 \mathrm{eq}, 0.20 \mathrm{mmol}$ ) at $-78^{\circ} \mathrm{C}$, followed by the dropwise addition of commercially available 3-chlorobenzoyl chloride ( 1 eq, $0.20 \mathrm{mmol})$. The resulting solution was then stirred at $78{ }^{\circ} \mathrm{C}$ for $0.5 \mathrm{~h}$ and quenched with $\mathrm{MeOH}(1 \mathrm{~mL})$ before being concentrated under reduced pressure and purified by flash column chromatography (5-50\% EtOAc/hexanes) to obtain $92 \mathrm{mg}$ (75\%) of the Boc-protected 2-AI product a white solid. After purification, the general procedure for Boc deprotection was utilized to obtain $\mathbf{4 d}$ as a tan solid in $95 \%$ yield. ${ }^{1} \mathrm{H}$ NMR (400 MHz, Methanol- $\left.d_{4}\right) \delta 7.94(\mathrm{t}, J=1.9 \mathrm{~Hz}, 1 \mathrm{H}), 7.87(\mathrm{~d}, J=7.6, \mathrm{~Hz}, 1 \mathrm{H}), 7.83-7.78(\mathrm{~m}, 2 \mathrm{H}), 7.61-7.54$ (m, 3H), $7.50(\mathrm{t}, J=7.9 \mathrm{~Hz}, 1 \mathrm{H}), 7.12(\mathrm{~s}, 1 \mathrm{H}) .{ }^{13} \mathrm{C} \mathrm{NMR}\left(101 \mathrm{MHz}\right.$, Methanol- $\left.d_{4}\right) \delta$ 165.7, 147.8, 138.6, 136.6, 134.3, 131.5, 129.9, 127.4, 127.3, 125.7, 124.6, 123.6, 121.0, 108.; HRMS (ESI) calcd for $\mathrm{C}_{16} \mathrm{H}_{14} \mathrm{ClN}{ }_{4} \mathrm{O}[\mathrm{M}+\mathrm{H}]^{+}$: 313.0851 , found: 313.0846 .

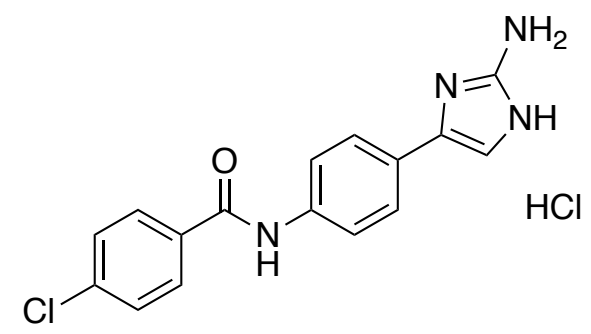

\section{4-(2-Amino-3H-imidazol-4-yl)phenyl]-4-chlorobenzamide hydrochloride (4i):}

The above compound was synthesized in a similar manner to compound $\mathbf{4 d}$, followed by using the general procedure for Boc deprotection to obtain $4 \mathbf{i}$ as a white solid in $97 \%$ yield. ${ }^{1} \mathrm{H}$ NMR (400 MHz, Methanol- $\left.d_{4}\right) \delta 7.92(\mathrm{~d}, J=8.9 \mathrm{~Hz}, 2 \mathrm{H}), 7.83-7.78(\mathrm{~m}, 1 \mathrm{H}), 7.60-7.55(\mathrm{~m}, 4 \mathrm{H}), 7.55-7.50$ (m, 1H), $7.13(\mathrm{~s}, 1 \mathrm{H}) .{ }^{13} \mathrm{C}$ NMR (101 MHz, Methanol- $\left.d_{4}\right) \delta 166.2,154.6,138.8,137.7,133.3$, 129.0, 128.4, 127.3, 124.7, 123.5, 121.0, 108.1; HRMS (ESI) calcd for $\mathrm{C}_{16} \mathrm{H}_{13} \mathrm{ClN}_{4} \mathrm{O}[\mathrm{M}+\mathrm{H}]^{+}$: 313.0851, found 313.0852 . 


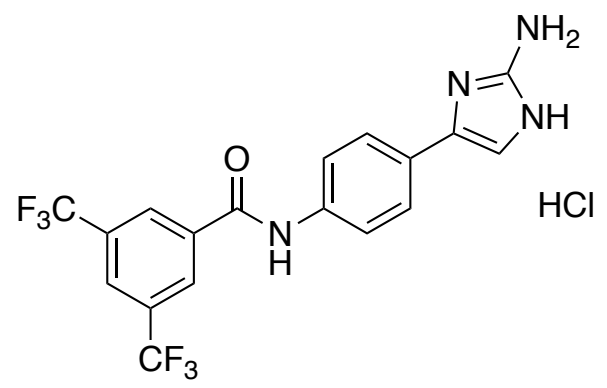

4-(2-Amino-3H-imidazol-4-yl)phenyl]-3,5-(bistrifluoromethyl)benzamide hydrochloride (4I):

The above compound was synthesized in a similar manner to compound $\mathbf{4 d}$, followed by using the general procedure for Boc deprotection to obtain $\mathbf{4 l}$ as a white solid in 99\% yield. ${ }^{1} \mathrm{H}$ NMR (400 MHz, DMSO-d6) $\delta 13.03(\mathrm{~s}, 1 \mathrm{H}), 12.18(\mathrm{~s}, 1 \mathrm{H}), 8.63(\mathrm{~s}, 1 \mathrm{H}), 8.35(\mathrm{~s}, 1 \mathrm{H}), 7.91-7.81(\mathrm{~m}, 3 \mathrm{H})$, 7.72-7.62 (m, 2H), $7.47(\mathrm{~s}, 2 \mathrm{H}), 7.35(\mathrm{~d}, J=1.3 \mathrm{~Hz}, 1 \mathrm{H}) .{ }^{13} \mathrm{C}$ NMR $\left(101 \mathrm{MHz}, \mathrm{DMSO}-d_{6}\right) \delta 163.0$, $148.1,138.6,138.5,137.3,131.1,130.7,130.4,126.6,125.1,124.9,124.1,122.2,121.3,121.2$ 109.4; HRMS (ESI) calcd for $\mathrm{C}_{18} \mathrm{H}_{12} \mathrm{~F}_{6} \mathrm{~N}_{4} \mathrm{O}[\mathrm{M}+\mathrm{H}]^{+}: 415.0988$, found 415.0988.

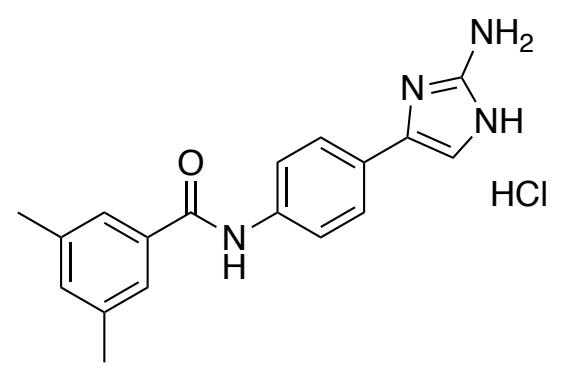

\section{$N$-(4-(2-amino-1H-imidazol-4-yl)phenyl)-3,5-dimethylbenzamide hydrochloride (4m):}

The above compound was synthesized in a similar manner to compound $\mathbf{4 a}$, followed by using the general procedure for Boc deprotection to obtain $\mathbf{4 m}$ as a tan solid in 94\% yield. ${ }^{1} \mathrm{H}$ NMR (400 MHz, Methanol- $\left.d_{4}\right) \delta 7.82(\mathrm{~d}, J=8.8 \mathrm{~Hz}, 2 \mathrm{H}), 7.60-7.53(\mathrm{~m}, 4 \mathrm{H}), 7.25(\mathrm{~s}, 1 \mathrm{H}), 7.14(\mathrm{~s}, 1 \mathrm{H}), 2.40$ $(\mathrm{s}, 6 \mathrm{H}) .{ }^{13} \mathrm{C}$ NMR $(101 \mathrm{MHz}$, Methanol-d 4$) \delta 169.3,149.2,140.4,139.6,136.0,134.5,128.9$, 
126.4, 126.1, 124.8, 122.4, 109.5, 21.3. UV ( $\lambda \max \mathrm{nm}): 312$; IR $\left(v_{\max } \mathrm{cm}^{-1}\right) 3260,3134,3005$, 2917, 2744, 1673, 1515; HRMS (ESI) calcd for $\mathrm{C}_{18} \mathrm{H}_{19} \mathrm{~N}_{4} \mathrm{O}[\mathrm{M}+\mathrm{H}]^{+}:$307.1553, found: 307.1534 .<smiles>Nc1nc(-c2ccc(NC(=O)c3ccc(C(F)(F)F)c(Cl)c3)cc2)c[nH]1</smiles>

\section{4-(2-Amino-3H-imidazol-4-yl)phenyl]-3-chloro-4-(trifluoromethyl)benzamide hydrochloride (4n):}

The above compound was synthesized in a similar manner to compound $\mathbf{4 d}$, followed by using the general procedure for Boc deprotection to obtain $\mathbf{4 n}$ as a tan solid in $98 \%$ yield. ${ }^{1} \mathrm{H}$ NMR (400 MHz, Methanol- $\left.d_{4}\right) \delta 8.15(\mathrm{~d}, J=1.6 \mathrm{~Hz}, 1 \mathrm{H}), 8.06-7.97(\mathrm{~m}, 1 \mathrm{H}), 7.92(\mathrm{~d}, J=8.2 \mathrm{~Hz}, 1 \mathrm{H}), 7.87-$ $7.78(\mathrm{~m}, 2 \mathrm{H}), 7.61-7.54(\mathrm{~m}, 2 \mathrm{H}), 7.14(\mathrm{~s}, 1 \mathrm{H}) .{ }^{13} \mathrm{C}$ NMR (101 MHz, Methanol- $\left.d_{4}\right) \delta 164.2,147.8$ $139.8,138.4,130.4,127.8,127.7,127.2,126.2,124.7,124.0,123.8,121.0,108.2$; HRMS (ESI) calcd for $\mathrm{C}_{17} \mathrm{H}_{12} \mathrm{ClF}_{3} \mathrm{~N}_{4} \mathrm{O}[\mathrm{M}+\mathrm{H}]^{+}: 381.0728$, found 381.0715.<smiles>Nc1nc(-c2ccc(NC(=O)c3ccc(Cl)c(C(F)(F)F)c3)cc2)c[nH]1</smiles>

\section{4-(2-Amino-3H-imidazol-4-yl)phenyl]-3-(trifluoromethyl)-4-chlorobenzamide hydrochloride (4o):}

The above compound was synthesized in a similar manner to compound $\mathbf{4 d}$, followed by using the general procedure for Boc deprotection to obtain $\mathbf{4 o}$ as a yellow solid in $95 \%$ yield. ${ }^{1} \mathrm{H}$ NMR (400 
MHz, Methanol- $\left.d_{4}\right) \delta 8.37-8.32(\mathrm{~m}, 1 \mathrm{H}), 8.21-8.15(\mathrm{~m}, 1 \mathrm{H}), 7.86-7.80(\mathrm{~m}, 1 \mathrm{H}), 7.77(\mathrm{~d}, J=8.3$ $\mathrm{Hz}, 2 \mathrm{H}), 7.61-7.54(\mathrm{~m}, 2 \mathrm{H}), 7.15(\mathrm{~d}, J=8.2 \mathrm{~Hz}, 1 \mathrm{H}) .{ }^{13} \mathrm{C}$ NMR (101 MHz, Methanol- $\left.d_{4}\right) \delta 164.5$, $147.8,138.5,135.1,133.9,132.3,131.7,127.3,126.8,126.8,124.6,123.7,121.0,108.2$; HRMS (ESI) calcd for $\mathrm{C}_{17} \mathrm{H}_{12} \mathrm{ClF}_{3} \mathrm{~N}_{4} \mathrm{O}\left(\mathrm{M}^{+}\right) 381.0728$, found 381.0725 .<smiles>Nc1nc(-c2ccc(NC(=O)c3c[nH]c(Cl)c3)cc2)cc(Cl)c1Br</smiles>

\section{$N$-(4-(2-amino-1 $H$-imidazol-4-yl)phenyl)-4-bromo-3,5-dichlorobenzamide hydrochloride}

(4y):

The above compound was synthesized in a similar manner to compound $\mathbf{4 a}$, followed by using the general procedure for Boc deprotection to obtain $\mathbf{4 y}$ as a tan solid in $11 \%$ yield. ${ }^{1} \mathrm{H}$ NMR (400 MHz, Methanol- $\left.d_{4}\right) \delta 8.08(\mathrm{~s}, 2 \mathrm{H}), 7.83(\mathrm{~d}, J=8.8 \mathrm{~Hz}, 2 \mathrm{H}), 7.58(\mathrm{~d}, J=8.8 \mathrm{~Hz}, 2 \mathrm{H}), 7.15(\mathrm{~s}, 1 \mathrm{H})$. ${ }^{13} \mathrm{C}$ NMR $\left(101 \mathrm{MHz}, \mathrm{DMSO}-d_{6}\right) \delta 162.2,147.6,138.3,135.7,135.5,128.0,126.2,126.1,124.7$, 123.6, 120.7, 109.0. UV ( $\lambda \max \mathrm{nm}): 330$; IR $\left(v_{\max } \mathrm{cm}^{-1}\right) 3238,3217,3149,3034,1683,1518$; HRMS (ESI) calcd for $\mathrm{C}_{16} \mathrm{H}_{12} \mathrm{BrCl}_{2} \mathrm{~N}_{4} \mathrm{O}$ [M+H] $]^{+}$: 424.9566, found: 424.9566 .<smiles>COc1cc(-c2c[nH]c(N)n2)ccc1NC(=O)c1cc(Cl)cc(Cl)c1</smiles> 


\section{$N$-(4-(2-amino-1H-imidazol-4-yl)-2-methoxyphenyl)-3,5-dichlorobenzamide hydrochloride}

(6a):

To a solution of anhydrous DCM $(20 \mathrm{~mL})$ was added the benzoic acid analog 5a (1 eq, $5.1 \mathrm{mmol})$, followed by the dropwise addition of commercially available oxalyl chloride (1.1 eq, $5.6 \mathrm{mmol})$ and catalytic amount of DMAP $(0.01 \mathrm{eq}, 0.05 \mathrm{mmol})$ at $0{ }^{\circ} \mathrm{C}$. The reaction was stirred at $0{ }^{\circ} \mathrm{C}$ for $1 \mathrm{~h}$, then solvent was removed under reduced pressure and the crude was allowed to dry under high vacuum for $0.5 \mathrm{~h}$ and immediately used in the general procedure for $\alpha$-bromo-ketone production. The corresponding $\alpha$-bromo-ketone was obtained as a white solid in $63 \%$ yield. The corresponding $\alpha$-bromo-ketone was used in the general procedure for Boc-guanidine cyclization to obtain the corresponding mono-Boc-protected 2 -aminoimidazole as a green solid in $92 \%$ yield. To a solution of anhydrous THF $(10 \mathrm{~mL})$ and $10 \% \mathrm{Pd} / \mathrm{C}(0.040 \mathrm{~g})$ was charged the mono-Bocprotected 2-aminoimidazole. Air was removed from the system, and the reaction was back flushed with hydrogen. This process was repeated three times before the reaction was placed under a hydrogen balloon at room temperature for $16 \mathrm{~h}$. After that time, the reaction was filtered to remove the catalyst. The filtrate was concentrated under reduced pressure and corresponding aniline product was obtained in $100 \%$ yield as an orange solid. To a solution of anhydrous THF (10 mL) was added the aniline intermediate $(1 \mathrm{eq}, 1.20 \mathrm{mmol})$ and $\mathrm{K}_{3} \mathrm{PO}_{4}(1.5 \mathrm{eq}, 1.79 \mathrm{mmol})$ at $0{ }^{\circ} \mathrm{C}$, followed by the dropwise addition of commercially available 3,5-dichlorobenzoyl chloride ( 0.9 eq, $1.08 \mathrm{mmol})$. The reaction was warmed to room temperature and stirred for $16 \mathrm{~h}$. Water (10 $\mathrm{mL})$ was added to the reaction solution and the desired product was extracted with EtOAc $(3 \times 30$ $\mathrm{mL})$, followed by the organic layers being rinsed with brine $(2 \times 10 \mathrm{~mL})$. The organic layers were combined and dried with $\mathrm{MgSO}_{4}$, then concentrated under reduced pressure. The crude material was purified using flash chromatography $(0-50 \%$ EtOAc in hexanes). After purification, the 
general procedure for Boc deprotection was utilized to obtain $6 \mathbf{a}$ as a tan solid in $95 \%$ yield. ${ }^{1} \mathrm{H}$ NMR (400 MHz, Methanol- $\left.d_{4}\right) \delta 8.03(\mathrm{~d}, J=8.3 \mathrm{~Hz}, 1 \mathrm{H}), 7.89(\mathrm{~d}, J=1.9 \mathrm{~Hz}, 2 \mathrm{H}), 7.70(\mathrm{t}, J=1.9$ $\mathrm{Hz}, 1 \mathrm{H}), 7.30(\mathrm{~d}, J=1.9 \mathrm{~Hz}, 1 \mathrm{H}), 7.23(\mathrm{~s}, 1 \mathrm{H}), 7.20$ (dd, $J=8.3,1.9 \mathrm{~Hz}, 1 \mathrm{H}), 3.99$ (s, $3 \mathrm{H}) .{ }^{13} \mathrm{C}$ NMR (101 MHz, DMSO-d $d_{6} \delta 162.7,152.3,147.6,137.6,134.4,131.0,126.5,126.3,125.9,125.8$, 125.5, 116.0, 109.7, 107.8, 56.2. UV ( $\lambda \max \mathrm{nm}): 320$; IR $\left(v_{\max } \mathrm{cm}^{-1}\right) 3416,3261,3064,3009$, 2958, 2776, 2549, 1681, 1634, 1285, 1225, 768; HRMS (ESI) calcd for $\mathrm{C}_{17} \mathrm{H}_{15} \mathrm{Cl}_{2} \mathrm{~N}_{4} \mathrm{O}_{2}[\mathrm{M}+\mathrm{H}]^{+}$: 377.0567, found: 377.0561 .<smiles>Cc1cc(NC(=O)c2cc(Cl)cc(Cl)c2)ccc1-c1c[nH]c(N)n1</smiles>

$N$-(4-(2-amino-1 $H$-imidazol-4-yl)-3-methylphenyl)-3,5-dichlorobenzamide hydrochloride (6b):

The above compound was synthesized in a similar manner to compound $\mathbf{6 a}$, followed by using the general procedure for Boc deprotection to obtain $\mathbf{6 b}$ as a white solid in $93 \%$ yield. ${ }^{1} \mathrm{H}$ NMR (400 MHz, DMSO-d 6 ) $\delta 12.48$ (bs, 1H), $12.18(\mathrm{bs}, 1 \mathrm{H}), 10.54(\mathrm{~s}, 1 \mathrm{H}), 8.01(\mathrm{~d}, J=2.0 \mathrm{~Hz}, 2 \mathrm{H}), 7.89$ (t, $J=1.9 \mathrm{~Hz}, 1 \mathrm{H}), 7.77-7.69(\mathrm{~m}, 2 \mathrm{H}), 7.49-7.34(\mathrm{~m}, 3 \mathrm{H}), 7.02(\mathrm{~s}, 1 \mathrm{H}), 2.38(\mathrm{~s}, 3 \mathrm{H}) .{ }^{13} \mathrm{C} \mathrm{NMR}$ $\left(101 \mathrm{MHz}, \mathrm{DMSO}-d_{6}\right) \delta 162.8,147.2,138.6,137.9,135.9,134.4,131.1,128.4,126.6,124.9$, 123.0, 122.5, 118.0, 111.1, 21.1. UV ( $\lambda \max \mathrm{nm}): 224$; IR $\left(v_{\max } \mathrm{cm}^{-1}\right) 3239,3138,3077,2960$, 2760, 1680, 1512, 708; HRMS (ESI) calcd for $\mathrm{C}_{17} \mathrm{H}_{15} \mathrm{Cl}_{2} \mathrm{~N}_{4} \mathrm{O}[\mathrm{M}+\mathrm{H}]^{+}: 361.0617$, found: 361.0627 . 
<smiles>C=CCOC(=O)Nc1ccc(C(=O)O)cc1C</smiles>

\section{4-(((allyloxy)carbonyl)amino)-3-methylbenzoic acid (8a):}

Using the general procedure for alloc protection, compound 8a was obtained as a white solid in 91\% yield. ${ }^{1} \mathrm{H}$ NMR (500 MHz, Chloroform- $d$ ) $\delta 11.18(\mathrm{~s}, 1 \mathrm{H}), 8.11(\mathrm{~d}, J=8.6 \mathrm{~Hz}, 1 \mathrm{H}), 7.98$ (dd, $J=8.6,2.1 \mathrm{~Hz}, 1 \mathrm{H}), 7.91(\mathrm{~d}, J=1.3 \mathrm{~Hz}, 1 \mathrm{H}), 6.72(\mathrm{~s}, 1 \mathrm{H}), 5.99(\mathrm{ddt}, J=17.1,10.4,5.9 \mathrm{~Hz}, 1 \mathrm{H})$, $5.40(\mathrm{dq}, J=17.2,1.5 \mathrm{~Hz}, 1 \mathrm{H}), 5.30(\mathrm{dq}, J=10.4,1.2 \mathrm{~Hz}, 1 \mathrm{H}), 4.71(\mathrm{dt}, J=5.9,1.4 \mathrm{~Hz}, 2 \mathrm{H}), 2.31$ (s, 3H). ${ }^{13} \mathrm{C}$ NMR (126 MHz, Methanol-d $\left.d_{4}\right) \delta 169.6,156.0,142.2,134.1,133.1,129.2,127.5$, 123.3, 118.1, 118.1, 66.9, 18.0. UV ( $\lambda \max \mathrm{nm}): 268$; IR $\left(v_{\max } \mathrm{cm}^{-1}\right) 3287,3089,2966,2872,2663$, 2545, 1685, 1241; HRMS (ESI) calcd for $\mathrm{C}_{12} \mathrm{H}_{12} \mathrm{NO}_{4}[\mathrm{M}-\mathrm{H}]^{+}:$234.0772, found: 234.0776.<smiles>C=CCOC(=O)Nc1ccc(C(=O)O)cc1Cl</smiles>

\section{4-(((allyloxy)carbonyl)amino)-3-chlorobenzoic acid (8b):}

Using the general procedure for alloc protection, compound $\mathbf{8 b}$ was obtained as a white solid in 92\% yield. ${ }^{1} \mathrm{H}$ NMR (500 MHz, Chloroform- $d$ ) $\delta 11.74(\mathrm{~s}, 1 \mathrm{H}), 8.36(\mathrm{~d}, J=8.7 \mathrm{~Hz}, 1 \mathrm{H}), 8.12(\mathrm{~d}$, $J=1.9 \mathrm{~Hz}, 1 \mathrm{H}), 8.02(\mathrm{dd}, J=8.8,2.0 \mathrm{~Hz}, 1 \mathrm{H}), 7.45(\mathrm{~s}, 1 \mathrm{H}), 5.99(\mathrm{ddt}, J=17.1,10.3,5.9 \mathrm{~Hz}, 1 \mathrm{H})$, $5.41(\mathrm{dq}, J=17.2,1.5 \mathrm{~Hz}, 1 \mathrm{H}), 5.32(\mathrm{dq}, J=10.4,1.2 \mathrm{~Hz}, 1 \mathrm{H}), 4.72(\mathrm{dt}, J=5.9,1.4 \mathrm{~Hz}, 2 \mathrm{H}) .{ }^{13} \mathrm{C}$ NMR (126 MHz, Chloroform-d) $\delta 170.4,152.6,139.7,131.9,131.3,130.3,124.3,121.6,119.3$, 118.7, 66.8. UV ( $\lambda \max \mathrm{nm}): 270 ; \mathrm{IR}\left(\nu_{\max } \mathrm{cm}^{-1}\right) 3320,3082,2982,2950,2827,2651,2537,1703$, 1681, 1229, 557; HRMS (ESI) calcd for $\mathrm{C}_{11} \mathrm{H}_{9} \mathrm{ClNO}_{4}[\mathrm{M}-\mathrm{H}]^{+}:$254.0226, found: 254.0229 . 


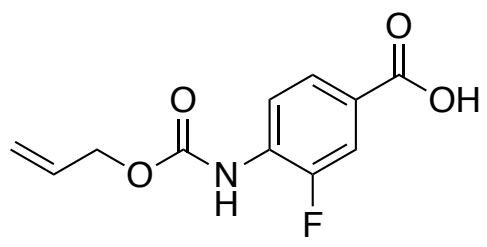

4-(((allyloxy)carbonyl)amino)-3-fluorobenzoic acid (8c):

Using the general procedure for alloc protection, compound $\mathbf{8 c}$ was obtained as a white solid in $89 \%$ yield. ${ }^{1} \mathrm{H}$ NMR (400 MHz, Chloroform- $d$ ) $\delta 8.28(\mathrm{t}, J=8.2 \mathrm{~Hz}, 1 \mathrm{H}), 7.95-7.88(\mathrm{~m}, 1 \mathrm{H})$, $7.80(\mathrm{dd}, J=11.5,2.0 \mathrm{~Hz}, 1 \mathrm{H}), 7.12(\mathrm{~d}, J=2.7 \mathrm{~Hz}, 1 \mathrm{H}), 5.98(\mathrm{ddt}, J=17.0,10.3,5.8 \mathrm{~Hz}, 1 \mathrm{H})$, $5.45-5.36(\mathrm{~m}, 1 \mathrm{H}), 5.36-5.26(\mathrm{~m}, 1 \mathrm{H}), 4.72(\mathrm{dt}, J=5.9,1.3 \mathrm{~Hz}, 2 \mathrm{H}) .{ }^{13} \mathrm{C} \mathrm{NMR}(101 \mathrm{MHz}$ DMSO-d $\left.{ }_{6}\right) \delta 166.1,166.0,153.6,153.3,151.2,132.9,130.9,130.8,126.6,126.5,125.9,125.8$, 122.1, 117.8, 116.3, 116.1, 65.3. ${ }^{13} \mathrm{C}$ NMR (101 MHz, DMSO- $\left.d_{6}\right) \delta 166.1(\mathrm{~d}, J=2.5 \mathrm{~Hz}), 153.3$, $152.4(\mathrm{~d}, J=246.3 \mathrm{~Hz}), 132.9,130.8(\mathrm{~d}, J=11.4 \mathrm{~Hz}), 126.6(\mathrm{~d}, J=6.3 \mathrm{~Hz}), 125.9(\mathrm{~d}, J=3.2 \mathrm{~Hz})$, 122.1, 117.8, $116.2(\mathrm{~d}, J=20.7 \mathrm{~Hz}), 65.3$. UV ( $\lambda \max \mathrm{nm}): 264$; IR $\left(v_{\max } \mathrm{cm}^{-1}\right) 3339,3067,2960$, 2846, 2673, 2561, 1715, 1617, 1237, 765; HRMS (ESI) calcd for $\mathrm{C}_{11} \mathrm{H}_{9} \mathrm{FNO}_{4}[\mathrm{M}-\mathrm{H}]^{+}:$: 238.0521, found: 238.0523 .<smiles>C=CCOC(=O)Nc1ccc(C(=O)O)c(F)c1</smiles>

\section{4-(((allyloxy)carbonyl)amino)-2-fluorobenzoic acid (8d):}

Using the general procedure for alloc protection, compound $\mathbf{8 d}$ was obtained as a white solid in 90\% yield. ${ }^{1} \mathrm{H}$ NMR (400 MHz, DMSO-d $\left.d_{6}\right) \delta 12.94(\mathrm{~s}, 1 \mathrm{H}), 10.32(\mathrm{~s}, 1 \mathrm{H}), 7.81(\mathrm{t}, J=8.6 \mathrm{~Hz}, 1 \mathrm{H})$, 7.44 (dd, $J=13.7,2.1 \mathrm{~Hz}, 1 \mathrm{H}), 7.29$ (dd, $J=8.7,2.1 \mathrm{~Hz}, 1 \mathrm{H}), 5.99$ (ddt, $J=17.3,10.7,5.5 \mathrm{~Hz}$, $1 \mathrm{H}), 5.37(\mathrm{dq}, J=17.3,1.7 \mathrm{~Hz}, 1 \mathrm{H}), 5.26(\mathrm{dq}, J=10.5,1.5 \mathrm{~Hz}, 1 \mathrm{H}), 4.64(\mathrm{dt}, J=5.5,1.5 \mathrm{~Hz}, 2 \mathrm{H})$. ${ }^{13} \mathrm{C}$ NMR $\left(101 \mathrm{MHz}, \mathrm{DMSO}-d_{6}\right) \delta 164.6,162.0(\mathrm{~d}, J=255.5 \mathrm{~Hz}), 153.0,145.0(\mathrm{~d}, J=10.9 \mathrm{~Hz})$, 
133.0, $132.9(\mathrm{~d}, J=6.5 \mathrm{~Hz}), 118.0,113.5(\mathrm{~d}, J=27.0 \mathrm{~Hz}), 112.3(\mathrm{~d}, J=9.7 \mathrm{~Hz}), 105.2(\mathrm{~d}, J=27.8$ Hz), 65.2. UV ( $\lambda \max \mathrm{nm}): 264$; IR $\left(v_{\max } \mathrm{cm}^{-1}\right) 3421,3373,3105,3071,2947,2884,2677,2578$, 1728, 1682, 1223, 763, 596; HRMS (ESI) calcd for $\mathrm{C}_{11} \mathrm{H}_{9} \mathrm{FNO}_{4}[\mathrm{M}-\mathrm{H}]^{+}: 238.0521$, found: 238.0526.<smiles>C=CCOC(=O)Nc1ccc(C(=O)O)c(Cl)c1</smiles>

\section{4-(((allyloxy)carbonyl)amino)-2-chlorobenzoic acid (8e):}

Using the general procedure for alloc protection, compound 8a was obtained as a white solid in 83\% yield. ${ }^{1} \mathrm{H}$ NMR (400 MHz, DMSO- $\left.d_{6}\right) \delta 13.07(\mathrm{~s}, 1 \mathrm{H}), 10.24(\mathrm{~s}, 1 \mathrm{H}), 7.82(\mathrm{~d}, J=8.6 \mathrm{~Hz}$, $1 \mathrm{H}), 7.68(\mathrm{~d}, J=2.1 \mathrm{~Hz}, 1 \mathrm{H}), 7.46(\mathrm{dd}, J=8.7,2.2 \mathrm{~Hz}, 1 \mathrm{H}), 5.99(\mathrm{ddt}, J=17.2,10.8,5.5 \mathrm{~Hz}, 1 \mathrm{H})$, $5.37(\mathrm{dq}, J=17.2,1.7 \mathrm{~Hz}, 1 \mathrm{H}), 5.26(\mathrm{dq}, J=10.5,1.4 \mathrm{~Hz}, 1 \mathrm{H}), 4.64(\mathrm{dt}, J=5.5,1.5 \mathrm{~Hz}, 2 \mathrm{H}) .{ }^{13} \mathrm{C}$ NMR (101 MHz, DMSO-d $)$ ) $165.9,153.0,143.1,133.3,132.9,132.6,123.6,119.1,118.0,116.0$, 65.2. UV ( $\lambda \max \mathrm{nm}): 268$; IR $\left(v_{\max } \mathrm{cm}^{-1}\right) 3362,3082,2987,2892,2653,2547,1703,1600,1215$, 658; HRMS (ESI) calcd for $\mathrm{C}_{11} \mathrm{H}_{9} \mathrm{ClNO}_{4}[\mathrm{M}-\mathrm{H}]^{+}:$254.0226, found: 254.0237 .

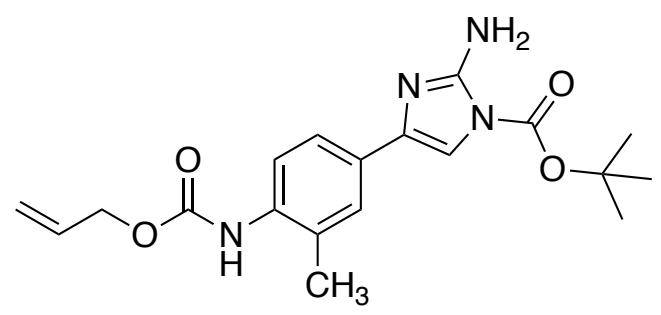

tert-butyl 4-(4-(((allyloxy)carbonyl)amino)-3-methylphenyl)-2-amino-1H-imidazole-1carboxylate (9a):

Using compound 8a in the general procedures for $\alpha$-bromo-ketone production and Boc-guanidine cyclization, compound 9a was obtained as a blue-green solid in $27 \%$ yield. ${ }^{1} \mathrm{H}$ NMR (400 MHz, 
Methanol- $\left.d_{4}\right) \delta 7.55-7.33(\mathrm{~m}, 3 \mathrm{H}), 7.15(\mathrm{~s}, 1 \mathrm{H}), 6.00(\mathrm{ddt}, J=17.2,10.7,5.5 \mathrm{~Hz}, 1 \mathrm{H}), 5.42-$ $5.30(\mathrm{~m}, 1 \mathrm{H}), 5.23(\mathrm{dq}, J=10.4,1.4 \mathrm{~Hz}, 1 \mathrm{H}), 4.63(\mathrm{dt}, J=5.5,1.5 \mathrm{~Hz}, 2 \mathrm{H}), 2.26(\mathrm{~s}, 3 \mathrm{H}), 1.63(\mathrm{~s}$, 9H). ${ }^{13} \mathrm{C}$ NMR (101 MHz, DMSO-d 6 ) $\delta 154.1,150.4,149.0,136.7,135.1,133.5,131.3,130.0$, 126.6, 124.5, 122.5, 117.4, 105.7, 84.6, 64.7, 27.6, 17.9. UV ( $\lambda \max \mathrm{nm}): 226$; IR $\left(v_{\max } \mathrm{cm}^{-1}\right) 3449$, 3292, 2979, 2928, 1730, 1353, 1116; HRMS (ESI) calcd for $\mathrm{C}_{19} \mathrm{H}_{25} \mathrm{~N}_{4} \mathrm{O}_{4}[\mathrm{M}+\mathrm{H}]^{+}$: 373.1870, found: 373.1879 .

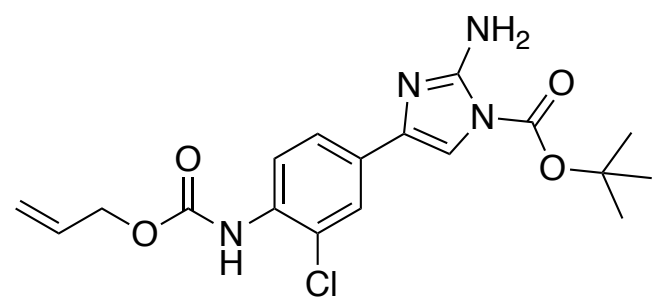

tert-butyl 4-(4-(((allyloxy)carbonyl)amino)-3-chlorophenyl)-2-amino-1H-imidazole-1carboxylate (9b):

Using compound $\mathbf{8 b}$ in the general procedures for $\alpha$-bromo-ketone production and Boc-guanidine cyclization, compound $9 \mathbf{b}$ was obtained as an off-white solid in 54\% yield. ${ }^{1} \mathrm{H}$ NMR (400 MHz, Chloroform- $d$ ) $\delta 8.15(\mathrm{~d}, J=8.7 \mathrm{~Hz}, 1 \mathrm{H}), 7.73(\mathrm{~d}, J=2.0 \mathrm{~Hz}, 1 \mathrm{H}), 7.56(\mathrm{dd}, J=8.7,2.0 \mathrm{~Hz}, 1 \mathrm{H})$, 7.20 (s, 1H), 7.06 (s, 1H), 5.99 (ddt, $J=17.2,10.4,5.8 \mathrm{~Hz}, 1 \mathrm{H}), 5.64$ (s, 2H), 5.39 (dq, $J=17.1$, $1.5 \mathrm{~Hz}, 1 \mathrm{H}), 5.29(\mathrm{dq}, J=10.5,1.3 \mathrm{~Hz}, 1 \mathrm{H}), 4.69(\mathrm{dt}, J=5.8,1.4 \mathrm{~Hz}, 2 \mathrm{H}), 1.62(\mathrm{~s}, 9 \mathrm{H}) .{ }^{13} \mathrm{C} \mathrm{NMR}$ $\left(101 \mathrm{MHz}, \mathrm{DMSO}-d_{6}\right) \delta 153.9,150.5,148.9,135.2,133.3,133.2,131.8,127.6,126.2,125.3$, 123.6, 117.5, 107.1, 84.8, 65.0, 27.6. UV ( $\lambda \max \mathrm{nm}): 316$; IR $\left(v_{\max } \mathrm{cm}^{-1}\right) 3388,3279,3104,2975$, 2932, 1734, 1158; HRMS (ESI) calcd for $\mathrm{C}_{18} \mathrm{H}_{22} \mathrm{ClN}_{4} \mathrm{O}_{4}[\mathrm{M}+\mathrm{H}]^{+}:$393.1324, found: 393.1314 . 


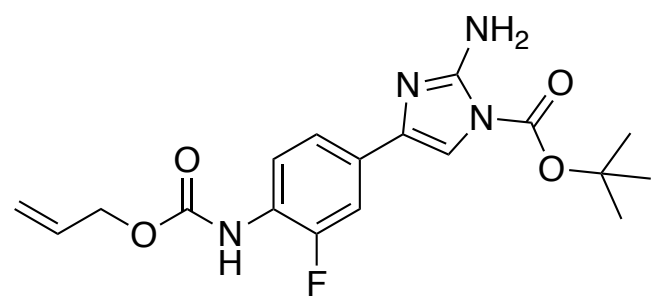

tert-butyl 4-(4-(((allyloxy)carbonyl)amino)-3-fluorophenyl)-2-amino-1H-imidazole-1carboxylate (9c):

Using compound $\mathbf{8 c}$ in the general procedures for $\alpha$-bromo-ketone production and Boc-guanidine cyclization, compound 9c was obtained as an off-white solid in $51 \%$ yield. ${ }^{1} \mathrm{H}$ NMR $(400 \mathrm{MHz}$, DMSO-d6) $\delta 9.40(\mathrm{~s}, 1 \mathrm{H}), 7.63-7.49(\mathrm{~m}, 3 \mathrm{H}), 7.42(\mathrm{~s}, 1 \mathrm{H}), 6.63(\mathrm{~s}, 2 \mathrm{H}), 5.97(\mathrm{ddt}, J=17.3,10.6$, $5.4 \mathrm{~Hz}, 1 \mathrm{H}), 5.36(\mathrm{dq}, J=17.2,1.7 \mathrm{~Hz}, 1 \mathrm{H}), 5.23(\mathrm{dq}, J=10.5,1.5 \mathrm{~Hz}, 1 \mathrm{H}), 4.60(\mathrm{dt}, J=5.4,1.5$ $\mathrm{Hz}, 2 \mathrm{H}), 1.58(\mathrm{~s}, 9 \mathrm{H}) .{ }^{13} \mathrm{C}$ NMR $\left(101 \mathrm{MHz}, \mathrm{DMSO}-d_{6}\right) \delta 156.0,153.6,151.8(\mathrm{~d}, J=266.1 \mathrm{~Hz})$, $149.3,136.1(\mathrm{~d}, J=2.5 \mathrm{~Hz}), 133.2,131.5(\mathrm{~d}, J=7.1 \mathrm{~Hz}), 124.9(\mathrm{~d}, J=12.0 \mathrm{~Hz}), 120.9(\mathrm{~d}, J=2.9$ $\mathrm{Hz}), 118.0,112.0(\mathrm{~d}, J=21.0 \mathrm{~Hz}), 107.3,85.2,65.4,28.0$. UV $(\lambda \max \mathrm{nm}): 308$; IR $\left(v_{\max } \mathrm{cm}^{-1}\right)$ 3417, 3344, 2975, 2936, 1736, 1596, 1212, 525; HRMS (ESI) calcd for $\mathrm{C}_{18} \mathrm{H}_{22} \mathrm{FN}_{4} \mathrm{O}_{4}[\mathrm{M}+\mathrm{H}]^{+}$: 377.1620, found: 377.1629 .

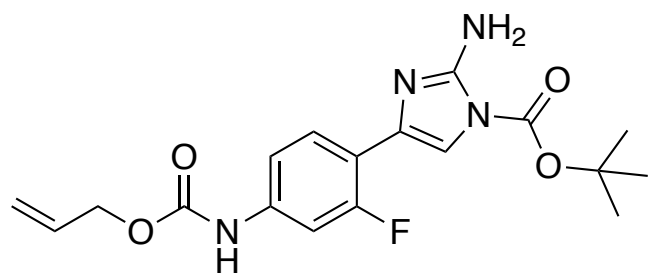

tert-butyl 4-(4-(((allyloxy)carbonyl)amino)-2-fluorophenyl)-2-amino-1H-imidazole-1carboxylate (9d):

Using compound $\mathbf{8 d}$ in the general procedures for $\alpha$-bromo-ketone production and Boc-guanidine cyclization, compound 9d was obtained as a white solid in 54\% yield. ${ }^{1} \mathrm{H}$ NMR (400 MHz, Chloroform- $d$ ) $\delta 7.87(\mathrm{t}, J=8.5 \mathrm{~Hz}, 1 \mathrm{H}), 7.47(\mathrm{~d}, J=13.4 \mathrm{~Hz}, 1 \mathrm{H}), 7.21(\mathrm{~d}, J=3.8 \mathrm{~Hz}, 1 \mathrm{H}), 6.97$ 
(dd, $J=8.5,2.2 \mathrm{~Hz}, 1 \mathrm{H}), 6.71(\mathrm{~s}, 1 \mathrm{H}), 5.97$ (ddt, $J=17.1,10.3,5.8 \mathrm{~Hz}, 1 \mathrm{H}), 5.67$ (s, 2H), 5.37 $(\mathrm{dq}, J=17.2,1.5 \mathrm{~Hz}, 1 \mathrm{H}), 5.28(\mathrm{dq}, J=10.4,1.3 \mathrm{~Hz}, 1 \mathrm{H}), 4.68(\mathrm{dt}, J=5.8,1.4 \mathrm{~Hz}, 2 \mathrm{H}), 1.62(\mathrm{~s}$, 9H). ${ }^{13} \mathrm{C}$ NMR (101 MHz, Chloroform- $d$ ) $\delta 160.2(\mathrm{~d}, J=248.3 \mathrm{~Hz}), 153.1,150.0,149.5,137.9(\mathrm{~d}$, $J=11.5 \mathrm{~Hz}), 132.4,131.0(\mathrm{~d}, J=2.5 \mathrm{~Hz}), 128.2(\mathrm{~d}, J=5.4 \mathrm{~Hz}), 118.6,116.2(\mathrm{~d}, J=13.3 \mathrm{~Hz})$ $114.3-113.9(\mathrm{~m}), 109.9$ (d, $J=15.4 \mathrm{~Hz}), 106.2(\mathrm{~d}, J=27.0 \mathrm{~Hz}), 85.6,66.2,28.1$. UV $(\lambda \max \mathrm{nm})$ : 302; IR $\left(v_{\max } \mathrm{cm}^{-1}\right) 341,3340,3119,2979,1733,1595,1396,1205,738$; HRMS (ESI) calcd for $\mathrm{C}_{18} \mathrm{H}_{22} \mathrm{FN}_{4} \mathrm{O}_{4}[\mathrm{M}+\mathrm{H}]^{+}: 377.1620$, found: 377.1631 .

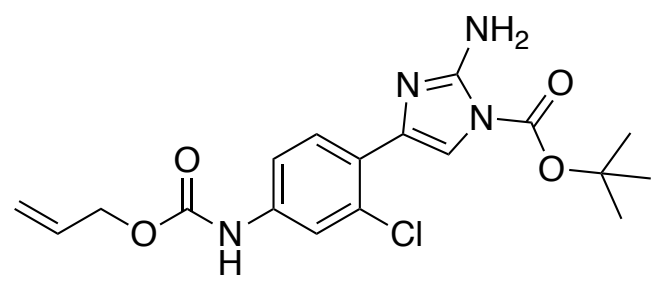

tert-butyl 4-(4-(((allyloxy)carbonyl)amino)-2-chlorophenyl)-2-amino-1H-imidazole-1carboxylate (9e):

Using compound $\mathbf{8 e}$ in the general procedures for $\alpha$-bromo-ketone production and Boc-guanidine cyclization, compound 9e was obtained as a white solid in 53\% yield. ${ }^{1} \mathrm{H}$ NMR (400 MHz, Chloroform- $d$ ) $\delta 7.86(\mathrm{~d}, J=8.6 \mathrm{~Hz}, 1 \mathrm{H}), 7.61(\mathrm{~s}, 1 \mathrm{H}), 7.44(\mathrm{~s}, 1 \mathrm{H}), 7.15(\mathrm{~d}, J=8.4 \mathrm{~Hz}, 1 \mathrm{H}), 7.00$ (s, 1H), $5.96(\mathrm{ddt}, J=17.3,10.4,5.7 \mathrm{~Hz}, 1 \mathrm{H}), 5.78(\mathrm{~s}, 2 \mathrm{H}), 5.37(\mathrm{dq}, J=17.2,1.5 \mathrm{~Hz}, 1 \mathrm{H}), 5.27$ (dq, $J=10.4,1.3 \mathrm{~Hz}, 1 \mathrm{H}), 4.67(\mathrm{dt}, J=5.8,1.4 \mathrm{~Hz}, 2 \mathrm{H}), 1.62$ (s, 9H). ${ }^{13} \mathrm{C}$ NMR (101 MHz, DMSO$\left.d_{6}\right) \delta 153.1,149.5,148.7,138.7,133.1,133.1,130.0,129.7,125.3,119.0,117.9,116.7,109.0$, 85.0, 64.9, 27.5. UV ( $\lambda \max \mathrm{nm}): 228$; IR $\left(v_{\max } \mathrm{cm}^{-1}\right) 3436,3294,3223,3185,2987,2934,1735$, 1705, 1149, 736; HRMS (ESI) calcd for $\mathrm{C}_{18} \mathrm{H}_{22} \mathrm{ClN}_{4} \mathrm{O}_{4}[\mathrm{M}+\mathrm{H}]^{+}$: 393.1324, found: 393.1312 . 
<smiles>Cc1cc(-c2c[nH]c(N)n2)ccc1NC(=O)c1cc(Cl)cc(Cl)c1</smiles>

$N$-(4-(2-amino-1H-imidazol-4-yl)-2-methylphenyl)-3,5-dichlorobenzamide hydrochloride (10a):

Using compound 9a in the general procedures for alloc deprotection, amide formation, and Boc deprotection, compound 10a was obtained as a white solid in $89 \%$ yield. ${ }^{1} \mathrm{H}$ NMR (400 MHz, DMSO-d $)_{6} \delta 12.73(\mathrm{~s}, 1 \mathrm{H}), 12.06(\mathrm{~s}, 1 \mathrm{H}), 10.19(\mathrm{~s}, 1 \mathrm{H}), 8.00(\mathrm{~d}, J=1.9 \mathrm{~Hz}, 2 \mathrm{H}), 7.90(\mathrm{t}, J=1.9$ $\mathrm{Hz}, 1 \mathrm{H}), 7.60(\mathrm{~d}, J=2.2 \mathrm{~Hz}, 1 \mathrm{H}), 7.55-7.44(\mathrm{~m}, 3 \mathrm{H}), 7.44-7.37(\mathrm{~m}, 2 \mathrm{H}), 2.26(\mathrm{~s}, 3 \mathrm{H}) ;{ }^{13} \mathrm{C}$ NMR $\left(101 \mathrm{MHz}, \mathrm{DMSO}-d_{6}\right) \delta 162.8,147.7,137.6,135.6,134.4,134.3,131.0,126.9,126.6,126.2$, 126.1, 125.7, 122.0, 109.4, 18.0. UV ( $\lambda \max \mathrm{nm}): 226$; IR $\left(v_{\max } \mathrm{cm}^{-1}\right) 3404,3258,3121,3080$, 3062, 2919, 2773, 2743, 1680, 1566, 1243, 780; HRMS (ESI) calcd for $\mathrm{C}_{17} \mathrm{H}_{15} \mathrm{Cl}_{2} \mathrm{~N}_{4} \mathrm{O}[\mathrm{M}+\mathrm{H}]^{+}$: 361.0617, found: 361.0628 .<smiles>Nc1nc(-c2ccc(NC(=O)c3cc(Cl)cc(Cl)c3)c(Cl)c2)c[nH]1</smiles>

$N$-(4-(2-amino-1H-imidazol-4-yl)-2-chlorophenyl)-3,5-dichlorobenzamide hydrochloride (10b):

Using compound $\mathbf{9 b}$ in the general procedures for alloc deprotection, amide formation, and Boc deprotection, compound 10b was obtained as a white solid in 93\% yield. ${ }^{1} \mathrm{H}$ NMR (400 MHz, 
Methanol- $\left.d_{4}\right) \delta 7.94(\mathrm{~d}, J=1.8 \mathrm{~Hz}, 2 \mathrm{H}), 7.83-7.78(\mathrm{~m}, 2 \mathrm{H}), 7.74(\mathrm{t}, J=1.9 \mathrm{~Hz}, 1 \mathrm{H}), 7.59(\mathrm{dd}, J$ $=8.4,2.1 \mathrm{~Hz}, 1 \mathrm{H}), 7.28(\mathrm{~s}, 1 \mathrm{H}) .{ }^{13} \mathrm{C} \mathrm{NMR}\left(101 \mathrm{MHz}, \mathrm{DMSO}-d_{6}\right) \delta$ 162.9, 147.9, 142.0, 137.0, $134.5,133.7,131.4,130.2,128.9,127.5,126.6,125.0,123.2,110.8$. UV ( $\lambda \max n m): 224 ;$ IR ( $v_{\max }$ $\mathrm{cm}^{-1}$ ) 3289, 3118, 3039, 3004, 1691, 1644, 720; HRMS (ESI) calcd for $\mathrm{C}_{16} \mathrm{H}_{12} \mathrm{Cl}_{3} \mathrm{~N}_{4} \mathrm{O}[\mathrm{M}+\mathrm{H}]^{+}$: 381.0071, found: 381.0080 .<smiles>Nc1nc(-c2ccc(NC(=O)c3cc(Cl)cc(Cl)c3)c(F)c2)c[nH]1</smiles>

$N$-(4-(2-amino-1H-imidazol-4-yl)-2-fluorophenyl)-3,5-dichlorobenzamide hydrochloride (10c):

Using compound $\mathbf{9 c}$ in the general procedures for alloc deprotection, amide formation, and Boc deprotection, compound 10c was obtained as a white solid in $98 \%$ yield. ${ }^{1} \mathrm{H}$ NMR $(500 \mathrm{MHz}$, DMSO-d $d_{6} \delta 12.95(\mathrm{~s}, 1 \mathrm{H}), 12.19(\mathrm{~s}, 1 \mathrm{H}), 10.50(\mathrm{~s}, 1 \mathrm{H}), 8.00(\mathrm{~d}, J=1.9 \mathrm{~Hz}, 2 \mathrm{H}), 7.91(\mathrm{t}, J=1.9$ $\mathrm{Hz}, 1 \mathrm{H}), 7.73-7.66(\mathrm{~m}, 2 \mathrm{H}), 7.57(\mathrm{~s}, 2 \mathrm{H}), 7.54(\mathrm{dd}, J=8.3,2.0 \mathrm{~Hz}, 1 \mathrm{H}), 7.50(\mathrm{~s}, 1 \mathrm{H}) .{ }^{13} \mathrm{C} \mathrm{NMR}$ $\left(126 \mathrm{MHz}, \mathrm{DMSO}-d_{6}\right) \delta 162.9,155.6(\mathrm{~d}, J=247.1 \mathrm{~Hz}), 147.8,137.0,134.4,131.3,127.2(\mathrm{~d}, J=$ $2.5 \mathrm{~Hz}), 126.9$ (d, $J=8.6 \mathrm{~Hz}), 126.7,125.2$ (d, $J=2.6 \mathrm{~Hz}), 124.6$ (d, $J=12.6 \mathrm{~Hz}), 120.1$ (d, $J=$ 3.1 Hz), $111.8(\mathrm{~d}, J=22.6 \mathrm{~Hz}), 110.6 . \mathrm{UV}(\lambda \max \mathrm{nm}): 320$; IR $\left(v_{\max } \mathrm{cm}^{-1}\right) 3421,3355,3293$, 3211, 3153, 3076, 3043, 1663, 1519, 703; HRMS (ESI) calcd for $\mathrm{C}_{16} \mathrm{H}_{12} \mathrm{Cl}_{2} \mathrm{FN}_{4} \mathrm{O}[\mathrm{M}+\mathrm{H}]^{+}$: 365.0367, found: 365.0359 . 


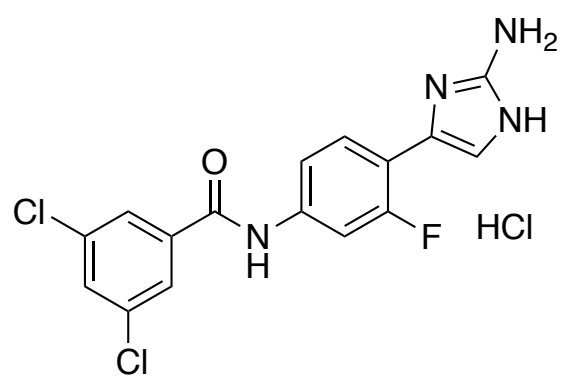

\section{$N$-(4-(2-amino-1H-imidazol-4-yl)-3-fluorophenyl)-3,5-dichlorobenzamide hydrochloride} (10d):

Using compound 9d in the general procedures for alloc deprotection, amide formation, and Boc deprotection, compound 10d was obtained as a tan solid in 98\% yield. ${ }^{1} \mathrm{H}$ NMR (400 $\mathrm{MHz}$, DMSO-d $\left.{ }_{6}\right) \delta 12.57(\mathrm{~s}, 1 \mathrm{H}), 12.17(\mathrm{~s}, 1 \mathrm{H}), 10.74(\mathrm{~s}, 1 \mathrm{H}), 7.99(\mathrm{~d}, J=1.9 \mathrm{~Hz}, 2 \mathrm{H}), 7.92(\mathrm{t}, J=1.9$ $\mathrm{Hz}, 1 \mathrm{H}), 7.87(\mathrm{dd}, J=13.8,2.0 \mathrm{~Hz}, 1 \mathrm{H}), 7.72(\mathrm{t}, J=8.6 \mathrm{~Hz}, 1 \mathrm{H}), 7.65$ (dd, $J=8.7,2.0 \mathrm{~Hz}, 1 \mathrm{H})$, $7.47(\mathrm{~s}, 2 \mathrm{H}), 7.21(\mathrm{~d}, J=2.3 \mathrm{~Hz}, 1 \mathrm{H}) .{ }^{13} \mathrm{C}$ NMR $\left(126 \mathrm{MHz}, \mathrm{DMSO}-d_{6}\right) \delta 163.1,158.0(\mathrm{~d}, J=246.3$ Hz), 147.6, 139.7 (d, $J=11.3 \mathrm{~Hz}), 137.5,134.4,131.3,126.7$ (d, $J=18.1 \mathrm{~Hz}), 126.6,120.4$ (d, $J$ $=2.1 \mathrm{~Hz}), 116.3(\mathrm{~d}, J=2.9 \mathrm{~Hz}), 111.8(\mathrm{~d}, J=11.0 \mathrm{~Hz}), 111.2(\mathrm{~d}, J=12.9 \mathrm{~Hz}), 107.7(\mathrm{~d}, J=26.7$ Hz). UV ( $\lambda \max \mathrm{nm}): 322$; IR $\left(v_{\max } \mathrm{cm}^{-1}\right) 3443,3237,3181,3065,1687,797,660 ;$ HRMS (ESI) calcd for $\mathrm{C}_{16} \mathrm{H}_{12} \mathrm{Cl}_{2} \mathrm{FN}_{4} \mathrm{O}[\mathrm{M}+\mathrm{H}]^{+}: 365.0367$, found: 365.0378 .<smiles>Nc1nc(-c2ccc(NC(=O)c3cc(Cl)cc(Cl)c3)cc2Cl)c[nH]1</smiles>

$\mathrm{N}$-(4-(2-amino-1H-imidazol-4-yl)-3-chlorophenyl)-3,5-dichlorobenzamide hydrochloride (10e): 
Using compound $\mathbf{9 e}$ in the general procedures for alloc deprotection, amide formation, and Boc deprotection, compound 10e was obtained as a white solid in 94\% yield. ${ }^{1} \mathrm{H}$ NMR (400 MHz, Methanol- $\left.d_{4}\right) \delta 8.07(\mathrm{~d}, J=2.1 \mathrm{~Hz}, 1 \mathrm{H}), 7.93(\mathrm{~d}, J=1.9 \mathrm{~Hz}, 2 \mathrm{H}), 7.79(\mathrm{dd}, J=8.6,2.2 \mathrm{~Hz}, 1 \mathrm{H})$, $7.72(\mathrm{t}, J=1.9 \mathrm{~Hz}, 1 \mathrm{H}), 7.54(\mathrm{~d}, J=8.6 \mathrm{~Hz}, 1 \mathrm{H}), 7.16(\mathrm{~s}, 1 \mathrm{H}) .{ }^{13} \mathrm{C}$ NMR $\left(101 \mathrm{MHz}\right.$, Methanol- $\left.d_{4}\right)$ $\delta 165.7,148.9,141.3,139.0,136.6,133.3,132.7,130.9,127.5,125.2,123.4,123.1,120.4,113.5$. UV ( $\lambda \max \mathrm{nm}): 204$; IR $\left(v_{\max } \mathrm{cm}^{-1}\right) 3474,3238,3204,3135,1682,1564,663$; HRMS (ESI) calcd for $\mathrm{C}_{16} \mathrm{H}_{12} \mathrm{Cl}_{3} \mathrm{~N}_{4} \mathrm{O}[\mathrm{M}+\mathrm{H}]^{+}: 381.0071$, found: 381.0082 .

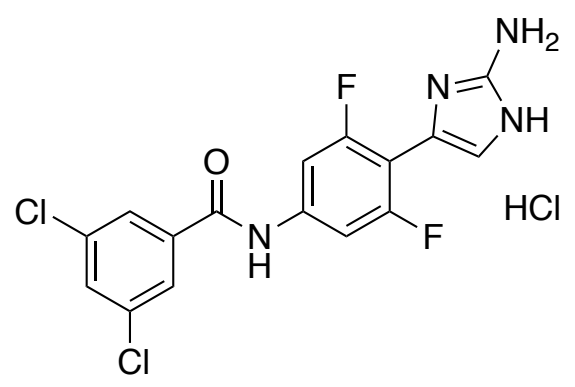

$N$-(4-(2-amino-1H-imidazol-4-yl)-3,5-difluorophenyl)-3,5-dichlorobenzamide hydrochloride (13):

Using compound 11 in the general procedures for amide formation, saponification, $\alpha$-bromoketone production, Boc-guanidine cyclization, and Boc deprotection, compound $\mathbf{1 3}$ was obtained as a white solid in $92 \%$ yield. ${ }^{1} \mathrm{H}$ NMR (400 MHz, DMSO- $\left.d_{6}\right) \delta 12.36(\mathrm{~s}, 2 \mathrm{H}), 11.08(\mathrm{~s}, 1 \mathrm{H}), 8.04$ (d, $J=1.9 \mathrm{~Hz}, 2 \mathrm{H}), 7.92$ (t, $J=1.9 \mathrm{~Hz}, 1 \mathrm{H}), 7.75(\mathrm{~d}, J=11.1 \mathrm{~Hz}, 2 \mathrm{H}), 7.57$ (s, 2H), $7.21(\mathrm{~s}, 1 \mathrm{H})$. ${ }^{13} \mathrm{C}$ NMR (101 MHz, DMSO- $\left.d_{6}\right) \delta 163.4,158.6(\mathrm{dd}, J=246.5,9.2 \mathrm{~Hz}), 147.6,140.4(\mathrm{t}, J=14.6$ Hz), 137.1, 134.5, 131.5, 126.7, 113.9, 103.8 (d, $J=8.3 \mathrm{~Hz}), 103.5$ (d, $J=8.0 \mathrm{~Hz}), 100.9$ (t, $J=$ $17.9 \mathrm{~Hz})$. UV ( $\lambda \max \mathrm{nm}): 322$; IR $\left(v_{\max } \mathrm{cm}^{-1}\right) 3306,3203,3150,3070,1687,801,669$; HRMS (ESI) calcd for $\mathrm{C}_{16} \mathrm{H}_{11} \mathrm{Cl}_{2} \mathrm{~F}_{2} \mathrm{~N}_{4} \mathrm{O}[\mathrm{M}+\mathrm{H}]^{+}: 383.0272$, found: 383.0272 . 


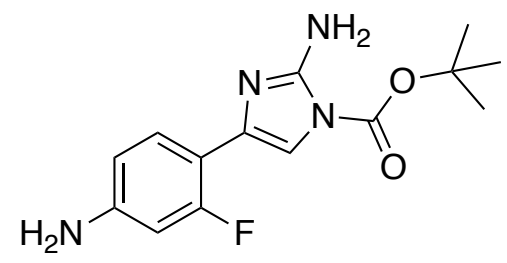

tert-butyl 2-amino-4-(4-amino-2-fluorophenyl)-1H-imidazole-1-carboxylate (14):

Using compound 9d in the general procedures for alloc deprotection, compound $\mathbf{1 4}$ was obtained as an orange solid in 98\% yield. ${ }^{1} \mathrm{H}$ NMR $\left(400 \mathrm{MHz}\right.$, Methanol- $\left.d_{4}\right) \delta 7.53(\mathrm{t}, J=8.6 \mathrm{~Hz}, 1 \mathrm{H}), 6.99$ $(\mathrm{d}, J=3.9 \mathrm{~Hz}, 1 \mathrm{H}), 6.50(\mathrm{dd}, J=8.4,2.2 \mathrm{~Hz}, 1 \mathrm{H}), 6.43(\mathrm{dd}, J=13.7,2.2 \mathrm{~Hz}, 1 \mathrm{H}), 1.62(\mathrm{~s}, 9 \mathrm{H})$. ${ }^{13} \mathrm{C}$ NMR (101 MHz, Methanol- $\left.d_{4}\right) \delta 163.6(\mathrm{~d}, J=245.8 \mathrm{~Hz}), 152.1,150.7,150.5(\mathrm{~d}, J=11.6 \mathrm{~Hz})$, $132.9(\mathrm{~d}, J=2.2 \mathrm{~Hz}), 129.3(\mathrm{~d}, J=5.8 \mathrm{~Hz}), 111.8(\mathrm{~d}, J=39.0 \mathrm{~Hz}), 110.7(\mathrm{~d}, J=13.5 \mathrm{~Hz}), 108.6$ $(\mathrm{d}, J=15.1 \mathrm{~Hz}), 102.6(\mathrm{~d}, J=25.2 \mathrm{~Hz}), 86.4,28.1 . \mathrm{UV}(\lambda \max \mathrm{nm}): 322 ; \mathrm{IR}\left(v_{\max } \mathrm{cm}^{-1}\right) 3457$, 3346, 3209, 2927, 2873, 1732, 1618, 1119, 695; HRMS (ESI) calcd for $\mathrm{C}_{14} \mathrm{H}_{18} \mathrm{FN}_{4} \mathrm{O}_{2}[\mathrm{M}+\mathrm{H}]^{+}$: 293.1408, found: 293.1413.<smiles>Nc1nc(-c2ccc(NC(=O)c3cc(Br)cc(Br)c3)cc2F)c[nH]1</smiles>

\section{$N$-(4-(2-amino-1H-imidazol-4-yl)-3-fluorophenyl)-3,5-dibromobenzamide hydrochloride} (15a):

Using compound $\mathbf{1 4}$ in the general procedures for amide formation and Boc deprotection, compound 15a was obtained as a tan solid in $83 \%$ yield. ${ }^{1} \mathrm{H}$ NMR (400 MHz, DMSO- $\left.d_{6}\right) \delta 12.87$ (s, 1H), $12.27(\mathrm{~s}, 1 \mathrm{H}), 10.82(\mathrm{~s}, 1 \mathrm{H}), 8.17(\mathrm{~d}, J=1.7 \mathrm{~Hz}, 2 \mathrm{H}), 8.12(\mathrm{t}, J=1.7 \mathrm{~Hz}, 1 \mathrm{H}), 7.89$ (dd, $J$ $=13.8,2.0 \mathrm{~Hz}, 1 \mathrm{H}), 7.75(\mathrm{t}, J=8.6 \mathrm{~Hz}, 1 \mathrm{H}), 7.67(\mathrm{dd}, J=8.7,2.0 \mathrm{~Hz}, 1 \mathrm{H}), 7.51(\mathrm{~s}, 2 \mathrm{H}), 7.19(\mathrm{~d}$, $J=2.3 \mathrm{~Hz}, 1 \mathrm{H}) .{ }^{13} \mathrm{C}$ NMR $\left(101 \mathrm{MHz}, \mathrm{DMSO}-d_{6}\right) \delta 162.9,158.0(\mathrm{~d}, J=246.6 \mathrm{~Hz}), 147.6,139.7$ 
(d, $J=11.2 \mathrm{~Hz}), 137.9,136.6,129.8,126.7$ (d, $J=4.2 \mathrm{~Hz}), 122.7,120.3(\mathrm{~d}, J=1.9 \mathrm{~Hz}), 116.3(\mathrm{~d}$, $J=2.8 \mathrm{~Hz}), 111.8(\mathrm{~d}, J=11.0 \mathrm{~Hz}), 111.2(\mathrm{~d}, J=12.9 \mathrm{~Hz}), 107.7(\mathrm{~d}, J=26.5 \mathrm{~Hz}) . \mathrm{UV}(\lambda \max \mathrm{nm}):$ 210; IR $\left(v_{\max } \mathrm{cm}^{-1}\right) 3362,3246,3172,3149,3070,3018,1687,1660,1517,1140,659$; HRMS (ESI) calcd for $\mathrm{C}_{16} \mathrm{H}_{12} \mathrm{Br}_{2} \mathrm{FN}_{4} \mathrm{O}[\mathrm{M}+\mathrm{H}]^{+}$: 452.9356, found: 452.9338 .

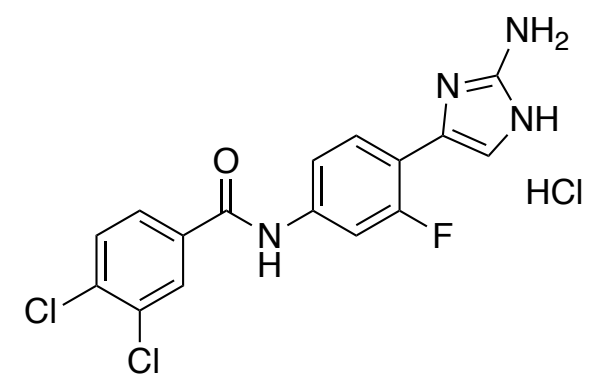

$\mathrm{N}$-(4-(2-amino-1H-imidazol-4-yl)-3-fluorophenyl)-3,4-dichlorobenzamide hydrochloride (15b):

Using compound $\mathbf{1 4}$ in the general procedures for amide formation and Boc deprotection, compound $\mathbf{1 5 b}$ was obtained as a white solid in $96 \%$ yield. ${ }^{1} \mathrm{H}$ NMR (400 MHz, DMSO- $\left.d_{6}\right) \delta$ $12.91(\mathrm{~s}, 1 \mathrm{H}), 12.28(\mathrm{~s}, 1 \mathrm{H}), 10.85(\mathrm{~s}, 1 \mathrm{H}), 8.27(\mathrm{~d}, J=2.1 \mathrm{~Hz}, 1 \mathrm{H}), 7.98(\mathrm{dd}, J=8.4,2.1 \mathrm{~Hz}, 1 \mathrm{H})$, $7.92(\mathrm{dd}, J=13.9,2.0 \mathrm{~Hz}, 1 \mathrm{H}), 7.84(\mathrm{~d}, J=8.4 \mathrm{~Hz}, 1 \mathrm{H}), 7.75(\mathrm{t}, J=8.6 \mathrm{~Hz}, 1 \mathrm{H}), 7.69$ (dd, $J=8.7$, $2.0 \mathrm{~Hz}, 1 \mathrm{H}), 7.52(\mathrm{~s}, 2 \mathrm{H}), 7.19(\mathrm{~d}, J=2.3 \mathrm{~Hz}, 1 \mathrm{H}) .{ }^{13} \mathrm{C} \mathrm{NMR}\left(101 \mathrm{MHz}, \mathrm{DMSO}-d_{6}\right) \delta 163.5,158.0$ (d, $J=246.3 \mathrm{~Hz}), 147.6,139.9(\mathrm{~d}, J=11.4 \mathrm{~Hz}), 134.7(\mathrm{~d}, J=15.8 \mathrm{~Hz}), 131.4,130.9,129.8,128.2$, 126.7, 126.7, 120.3, $116.3(\mathrm{~d}, J=2.6 \mathrm{~Hz}), 111.7$ (d, $J=11.5 \mathrm{~Hz}), 111.1(\mathrm{~d}, J=13.1 \mathrm{~Hz}), 107.6(\mathrm{~d}$, $J=26.7 \mathrm{~Hz}) . \mathrm{UV}(\lambda \max \mathrm{nm}): 322 ; \mathrm{IR}\left(v_{\max } \mathrm{cm}^{-1}\right) 3464,3324,3273,3132,3064,1682,780,677$; HRMS (ESI) calcd for $\mathrm{C}_{16} \mathrm{H}_{12} \mathrm{Cl}_{2} \mathrm{FN}_{4} \mathrm{O}[\mathrm{M}+\mathrm{H}]^{+}: 365.0367$, found: 365.0369 . 


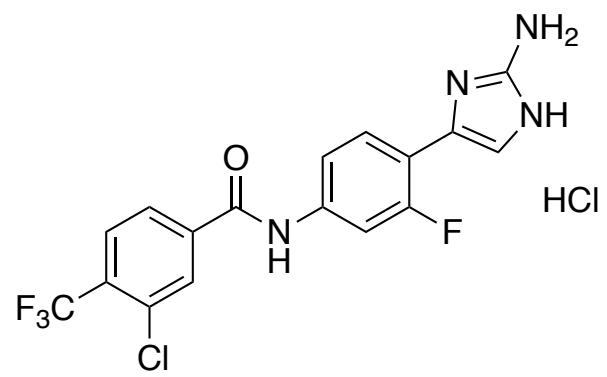

\section{N-(4-(2-amino-1H-imidazol-4-yl)-3-fluorophenyl)-3-chloro-4-(trifluoromethyl)benzamide hydrochloride (17a):}

Using compound $\mathbf{1 6}$ in the general procedures for amide formation using EDC coupling, saponification, $\alpha$-bromo-ketone production, Boc-guanidine cyclization, and Boc deprotection, compound 17a was obtained as a white solid in 90\% yield. ${ }^{1} \mathrm{H}$ NMR $\left(400 \mathrm{MHz}, \mathrm{DMSO}-d_{6}\right) \delta 12.57$ (s, 1H), $10.86(\mathrm{~s}, 1 \mathrm{H}), 8.28(\mathrm{~s}, 1 \mathrm{H}), 8.13-8.01(\mathrm{~m}, 2 \mathrm{H}), 7.89(\mathrm{dd}, J=13.6,1.5 \mathrm{~Hz}, 1 \mathrm{H}), 7.73(\mathrm{t}, J$ $=8.6 \mathrm{~Hz}, 1 \mathrm{H}), 7.66(\mathrm{dd}, J=8.6,1.9 \mathrm{~Hz}, 1 \mathrm{H}), 7.47(\mathrm{~s}, 2 \mathrm{H}), 7.22(\mathrm{~d}, J=2.2 \mathrm{~Hz}, 1 \mathrm{H}) .{ }^{13} \mathrm{C} \mathrm{NMR}(126$ MHz, Methanol- $\left.d_{4}\right) \delta 165.7,160.3(\mathrm{~d}, J=247.0 \mathrm{~Hz}), 149.1,141.4(\mathrm{~d}, J=11.4 \mathrm{~Hz}), 140.9,133.5$ $(\mathrm{d}, J=2.0 \mathrm{~Hz}), 132.2-131.4(\mathrm{~m}), 129.2(\mathrm{q}, J=5.2 \mathrm{~Hz}), 127.7(\mathrm{~d}, J=4.0 \mathrm{~Hz}), 127.6,125.1,122.9$ $(\mathrm{d}, J=19.0 \mathrm{~Hz}), 122.8,117.7(\mathrm{~d}, J=3.0 \mathrm{~Hz}), 112.8(\mathrm{~d}, J=13.2 \mathrm{~Hz}), 112.6(\mathrm{~d}, J=10.7 \mathrm{~Hz}), 109.3$ (d, $J=27.2 \mathrm{~Hz})$. UV ( $\lambda \max \mathrm{nm}): 306$; $\mathrm{HRMS}(\mathrm{ESI})$ calcd for $\mathrm{C}_{17} \mathrm{H}_{12} \mathrm{ClF}_{4} \mathrm{~N}_{4} \mathrm{O}[\mathrm{M}+\mathrm{H}]^{+}: 399.0630$, found: 399.0634 .<smiles>Nc1nc(-c2ccc(NC(=O)c3ccc(Cl)c(C(F)(F)F)c3)cc2F)c[nH]1</smiles>

$N$-(4-(2-amino-1H-imidazol-4-yl)-3-fluorophenyl)-4-chloro-3-(trifluoromethyl)benzamide hydrochloride (17b): 
Using compound $\mathbf{1 6}$ in the general procedures for amide formation using EDC coupling, saponification, $\alpha$-bromo-ketone production, Boc-guanidine cyclization, and Boc deprotection, compound 17b was obtained as a white solid in $35 \%$ yield. ${ }^{1} \mathrm{H}$ NMR (500 MHz, DMSO- $\left.d_{6}\right) \delta$ $12.88(\mathrm{~s}, 1 \mathrm{H}), 12.27(\mathrm{~s}, 1 \mathrm{H}), 10.98(\mathrm{~s}, 1 \mathrm{H}), 8.41(\mathrm{~d}, J=2.2 \mathrm{~Hz}, 1 \mathrm{H}), 8.31$ (dd, $J=8.4,2.2 \mathrm{~Hz}, 1 \mathrm{H})$, $7.97-7.89(\mathrm{~m}, 2 \mathrm{H}), 7.76(\mathrm{t}, J=8.7 \mathrm{~Hz}, 1 \mathrm{H}), 7.69(\mathrm{dd}, J=8.7,2.0 \mathrm{~Hz}, 1 \mathrm{H}), 7.52(\mathrm{~s}, 2 \mathrm{H}), 7.20(\mathrm{~d}$, $J=2.3 \mathrm{~Hz}, 1 \mathrm{H}) .{ }^{13} \mathrm{C}$ NMR (126 MHz, DMSO- $\left.d_{6}\right) \delta 163.5,158.0(\mathrm{~d}, J=246.5 \mathrm{~Hz}), 147.6,139.8$ (d, $J=11.4 \mathrm{~Hz}), 134.3(\mathrm{~d}, J=2.0 \mathrm{~Hz}), 133.6(\mathrm{~d}, J=5.1 \mathrm{~Hz}), 132.0,127.3(\mathrm{q}, J=5.2 \mathrm{~Hz}), 127.0-$ $126.6(\mathrm{~m}), 123.7,121.6,120.3(\mathrm{~d}, J=1.8 \mathrm{~Hz}), 116.4(\mathrm{~d}, J=2.9 \mathrm{~Hz}), 111.8(\mathrm{~d}, J=11.3 \mathrm{~Hz}), 111.2$ $(\mathrm{d}, J=13.2 \mathrm{~Hz}), 107.7(\mathrm{~d}, J=26.7 \mathrm{~Hz}) . \mathrm{UV}(\lambda \max \mathrm{nm})$ : 306; HRMS (ESI) calcd for $\mathrm{C}_{17} \mathrm{H}_{12} \mathrm{ClF}_{4} \mathrm{~N}_{4} \mathrm{O}[\mathrm{M}+\mathrm{H}]^{+}:$399.0630, found: 399.0633 .<smiles>Nc1nc(-c2ccc(NC(=O)Nc3cc(Br)cc(Br)c3)cc2)c[nH]1</smiles>

\section{1-(4-(2-amino-1H-imidazol-4-yl)phenyl)-3-(3,5-dibromophenyl)urea hydrochloride (20a):}

To a solution of compound 3 (1 eq, $0.21 \mathrm{mmol})$ dissolved in DCM $(12 \mathrm{~mL})$ was added sodium carbonate (1.6 eq, $0.34 \mathrm{mmol})$ dissolved in $\mathrm{dI}$ water $(12 \mathrm{~mL})$. After the solution was stirred for 5 min, triphosgene (0.33 eq, $0.07 \mathrm{mmol})$ dissolved in DCM $(2 \mathrm{~mL})$ was added to the flask. After the solution was stirred for $0.5 \mathrm{~h}, 3,5$-dibromoaniline $(1.3 \mathrm{eq}, 0.27 \mathrm{mmol})$ dissolved in DCM (2 mL) was added dropwise and allowed to stir for an additional $2 \mathrm{~h}$. The mixture was then separated, and the aqueous layer was washed twice with DCM. The organics were combined, dried with $\mathrm{MgSO}_{4}$, and concentrated under reduced pressure. The resulting solid was purified using flash chromatography $(0-33 \%$ EtOAc in hexanes). The collected urea product was used in the general 
procedure for Boc deprotection to obtain compound 20a as a tan solid in $87 \%$ yield. ${ }^{1} \mathrm{H}$ NMR (400 MHz, Methanol- $\left.d_{4}\right) \delta 7.69(\mathrm{~d}, J=1.7 \mathrm{~Hz}, 2 \mathrm{H}), 7.58-7.47(\mathrm{~m}, 4 \mathrm{H}), 7.34(\mathrm{t}, J=1.7 \mathrm{~Hz}, 1 \mathrm{H}), 7.08$ (s, 1H). ${ }^{13} \mathrm{C}$ NMR (101 MHz, Methanol- $\left.d_{4}\right) \delta 154.3,149.1,143.3,140.6,128.9,128.5,126.2$, 123.8, 123.4, 121.2, 120.5, 109.0. UV ( $\lambda \max \mathrm{nm}): 228$; IR $\left(v_{\max } \mathrm{cm}^{-1}\right) 3272,3258,3133,3043$, 1672, 1511, 664; HRMS (ESI) calcd for $\mathrm{C}_{16} \mathrm{H}_{14} \mathrm{Br}_{2} \mathrm{~N}_{5} \mathrm{O}[\mathrm{M}+\mathrm{H}]^{+}$: 449.9560, found: 449.9542.<smiles>Nc1nc(-c2ccc(NC(=O)Nc3cc(Cl)cc(Cl)c3)cc2)c[nH]1</smiles>

\section{1-(4-(2-amino-1H-imidazol-4-yl)phenyl)-3-(3,5-dichlorophenyl)urea hydrochloride (20b):}

The above compound was synthesized in a similar manner to compound 20a, followed by using the general procedure for Boc deprotection to obtain $20 \mathrm{~b}$ as a tan solid in $99 \%$ yield. ${ }^{1} \mathrm{H}$ NMR $\left(400 \mathrm{MHz}\right.$, Methanol- $\left.d_{4}\right) \delta 7.58-7.50(\mathrm{~m}, 4 \mathrm{H}), 7.50(\mathrm{~d}, J=1.6 \mathrm{~Hz}, 2 \mathrm{H}), 7.08(\mathrm{~s}, 1 \mathrm{H}), 7.07(\mathrm{t}, J=$ $1.9 \mathrm{~Hz}, 1 \mathrm{H}) .{ }^{13} \mathrm{C}$ NMR (101 MHz, DMSO- $\left.d_{6}\right) \delta 152.3,147.5,142.3,139.1,134.2,126.5,125.0$, 121.6, 120.8, 118.3, 115.9, 108.3. UV ( $\lambda \max \mathrm{nm}): 308$; IR $\left(v_{\max } \mathrm{cm}^{-1}\right) 3258,3150,3039,1674$, 1513, 665; HRMS (ESI) calcd for $\mathrm{C}_{16} \mathrm{H}_{14} \mathrm{Cl}_{2} \mathrm{~N}_{5} \mathrm{O}[\mathrm{M}+\mathrm{H}]^{+}$: 362.0570, found: 362.0574 .<smiles>Nc1nc(-c2ccc(NC(=O)Nc3ccc(Cl)c(Cl)c3)cc2)c[nH]1</smiles>

\section{1-(4-(2-amino-1H-imidazol-4-yl)phenyl)-3-(3,4-dichlorophenyl)urea hydrochloride (21c):}

The above compound was synthesized in a similar manner to compound 20a, followed by using the general procedure for Boc deprotection to obtain 20c as a white solid in $99 \%$ yield. ${ }^{1} \mathrm{H}$ NMR $\left(400 \mathrm{MHz}\right.$, Methanol- $\left.d_{4}\right) \delta 7.81(\mathrm{~d}, J=2.5 \mathrm{~Hz}, 1 \mathrm{H}), 7.55(\mathrm{~d}, J=8.9 \mathrm{~Hz}, 2 \mathrm{H}), 7.50(\mathrm{~d}, J=8.8 \mathrm{~Hz}$, 
2H), $7.41(\mathrm{~d}, J=8.8 \mathrm{~Hz}, 1 \mathrm{H}), 7.30(\mathrm{dd}, J=8.8,2.5 \mathrm{~Hz}, 1 \mathrm{H}), 7.07(\mathrm{~s}, 1 \mathrm{H}) .{ }^{13} \mathrm{C} \mathrm{NMR}(126 \mathrm{MHz}$, Methanol- $\left.d_{4}\right) \delta 154.5,149.1,140.7,140.6,133.3,131.5,128.9,126.2,126.2,123.2,121.3,120.5$, 119.6, 108.9. UV $(\lambda \max \mathrm{nm})$ : 332; (ESI) calcd for $\mathrm{C}_{16} \mathrm{H}_{14} \mathrm{Cl}_{2} \mathrm{~N}_{5} \mathrm{O}[\mathrm{M}+\mathrm{H}]^{+}: 362.0570$, found: 362.0573. 
${ }^{1} \mathrm{H}$ and ${ }^{13} \mathrm{C}$ Nuclear Magnetic Resonance Spectra

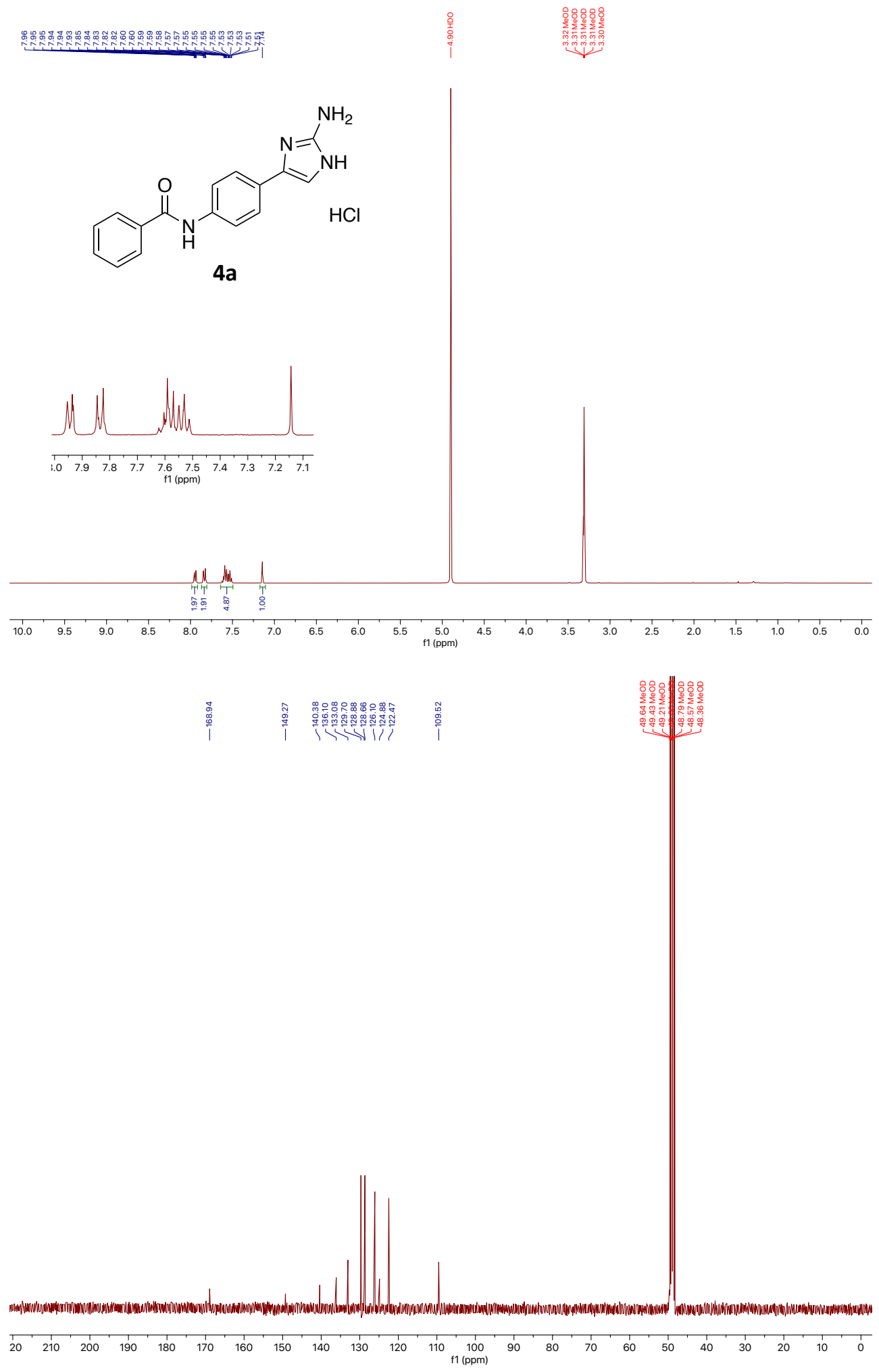



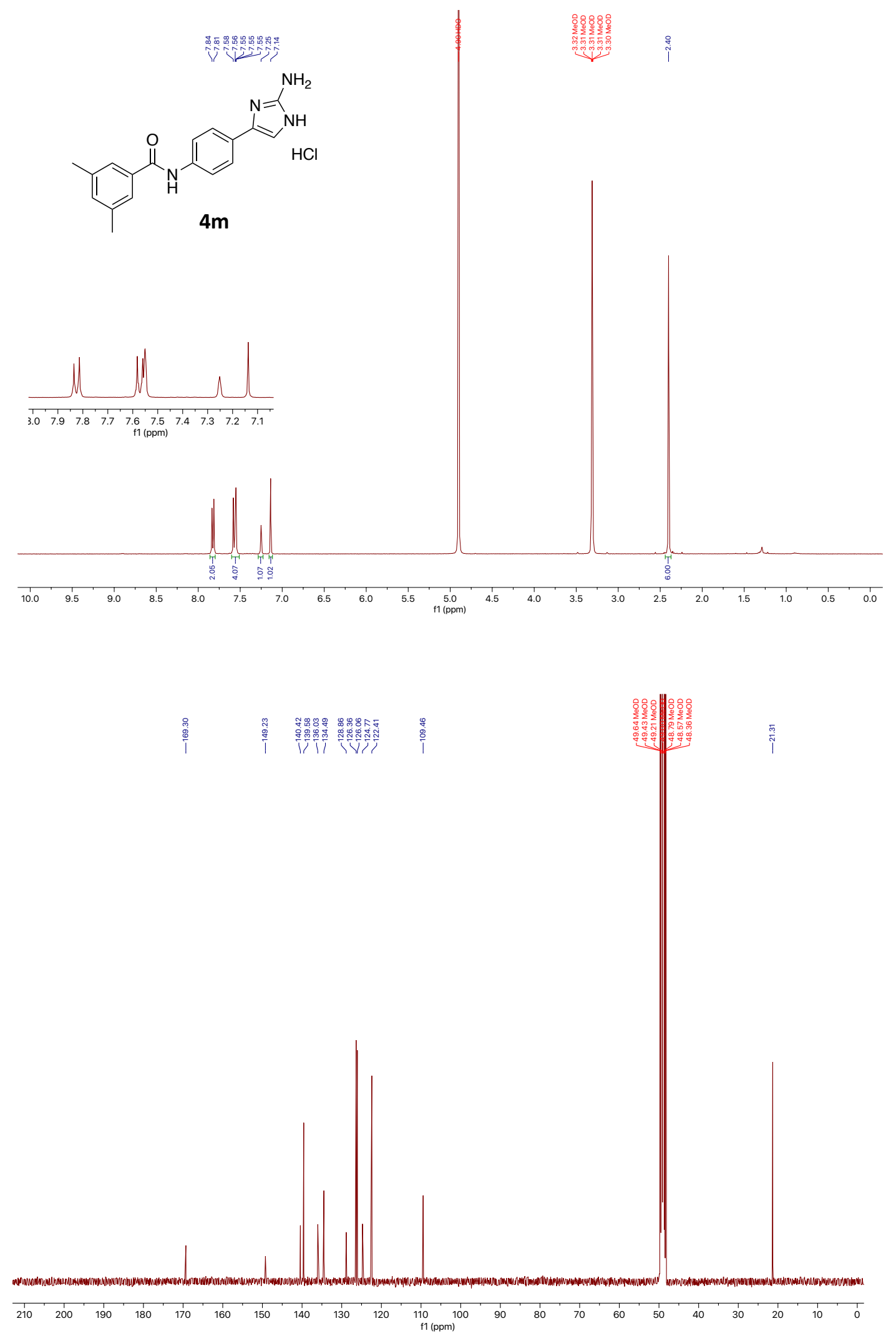

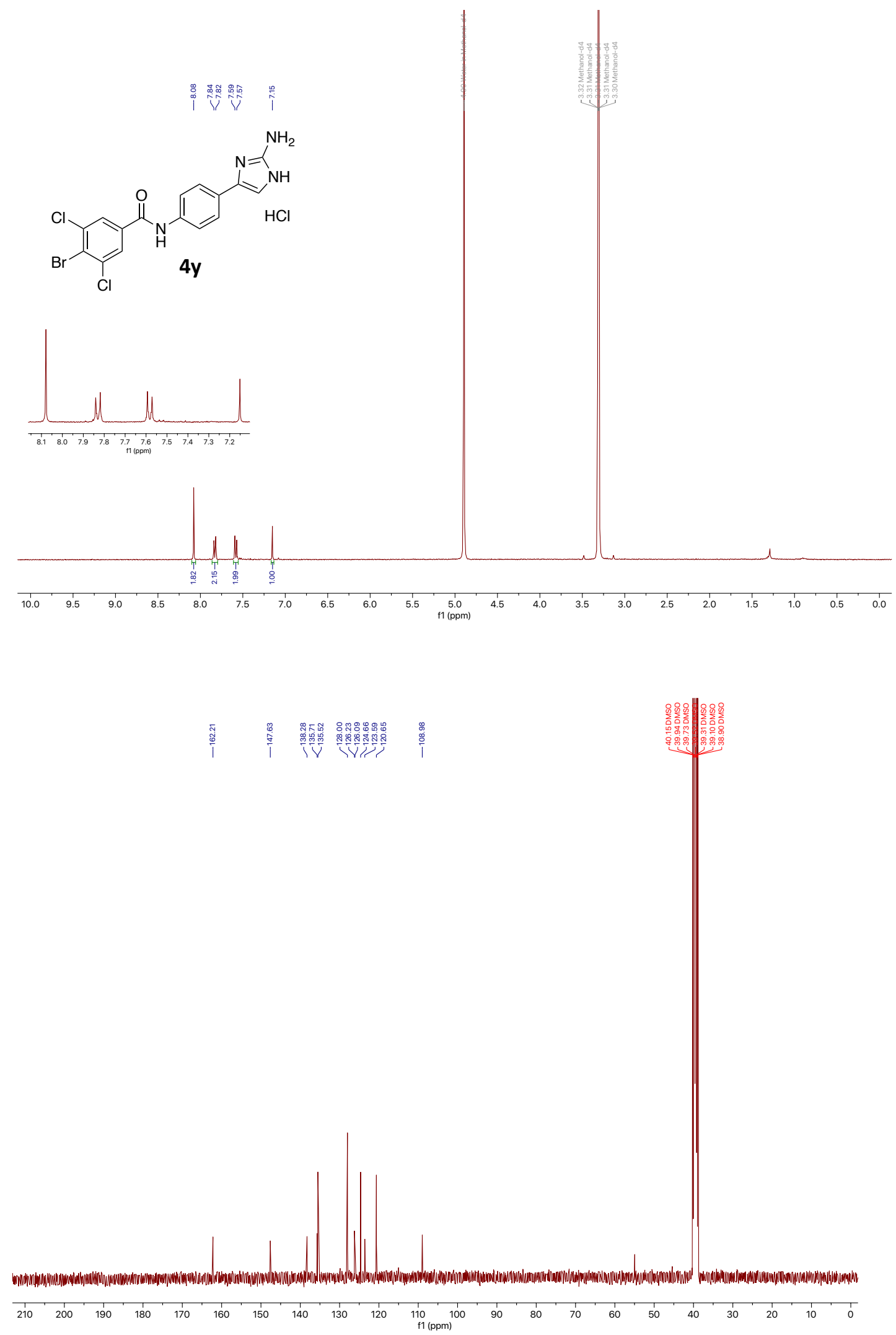

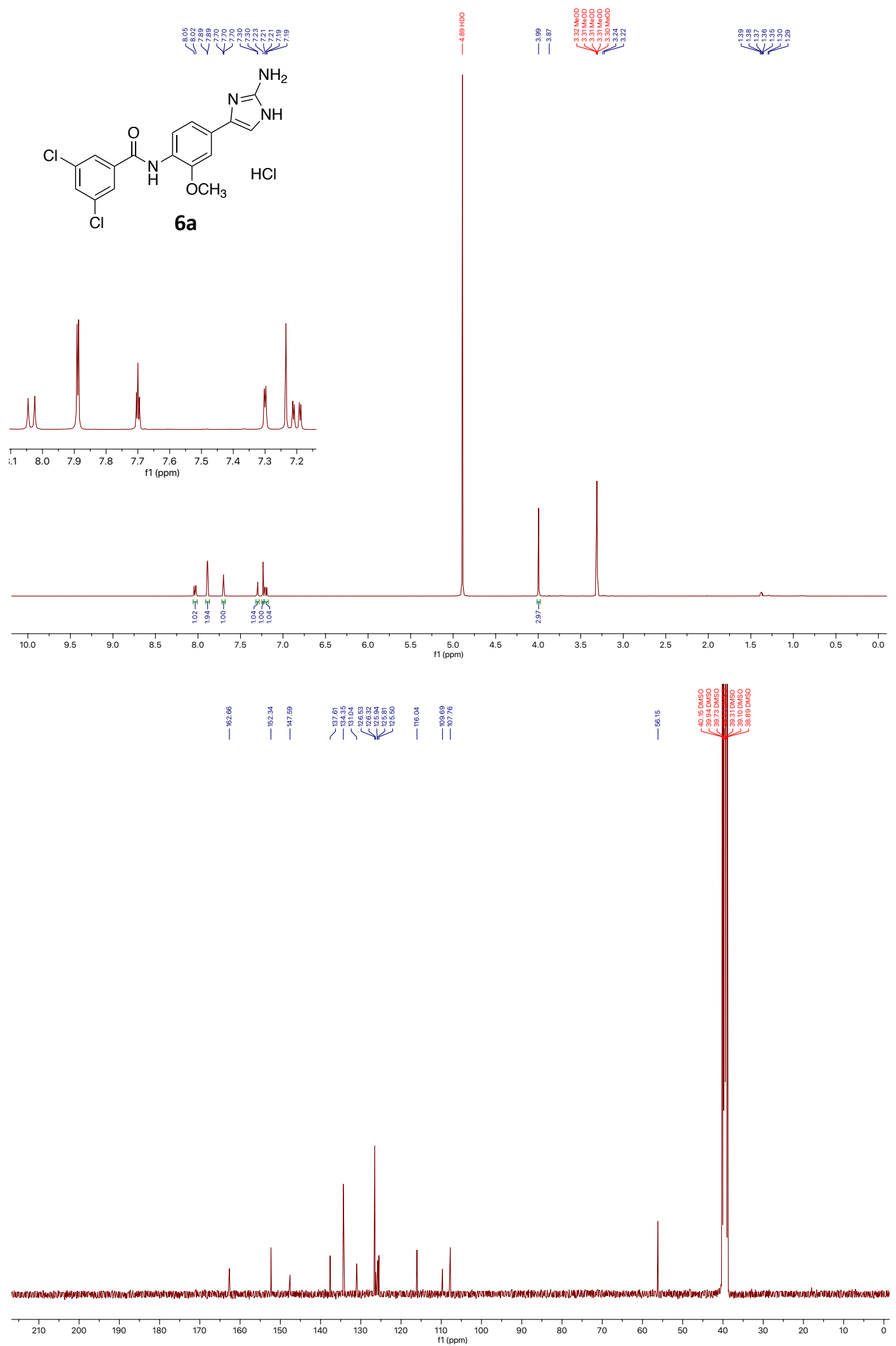

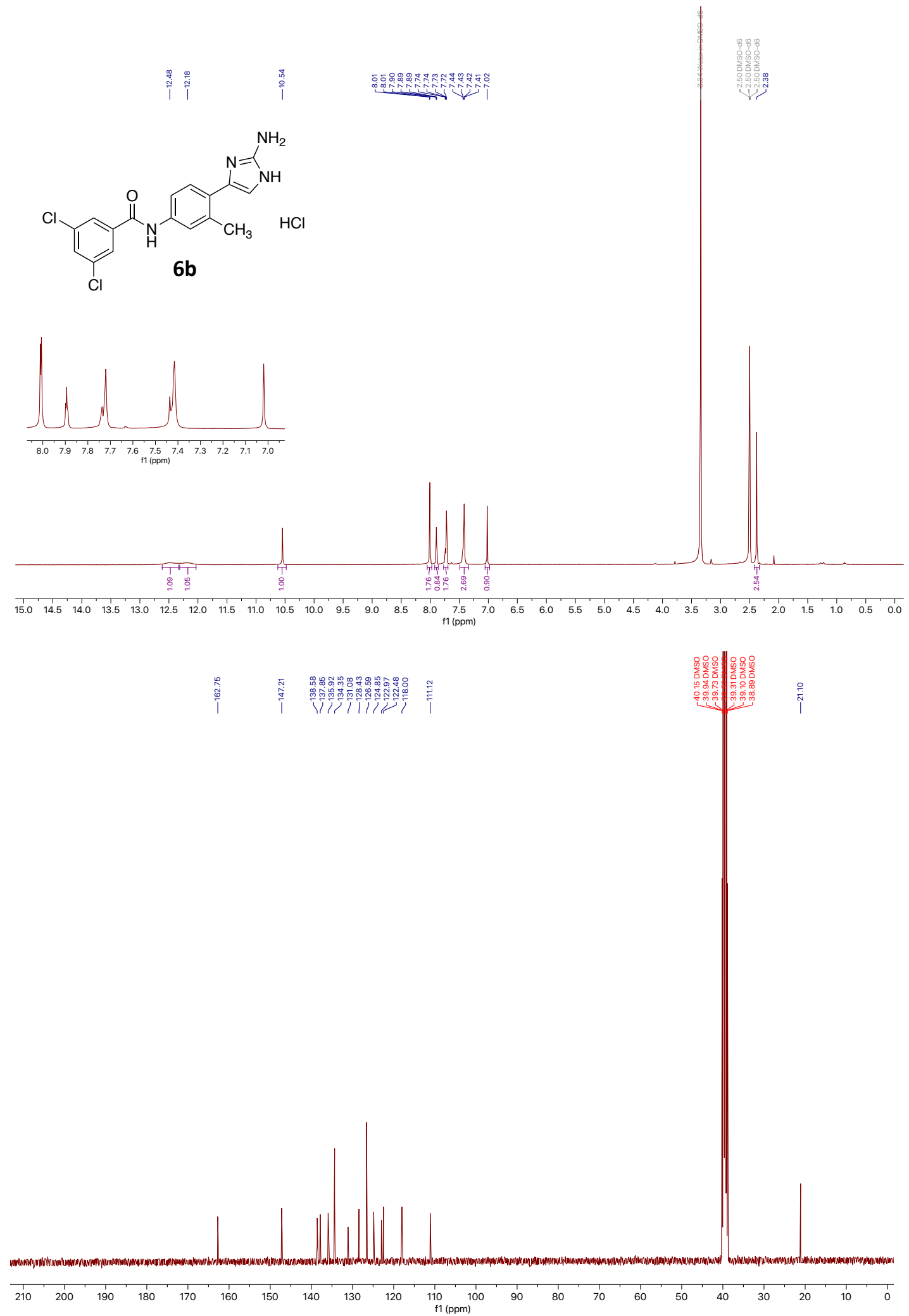

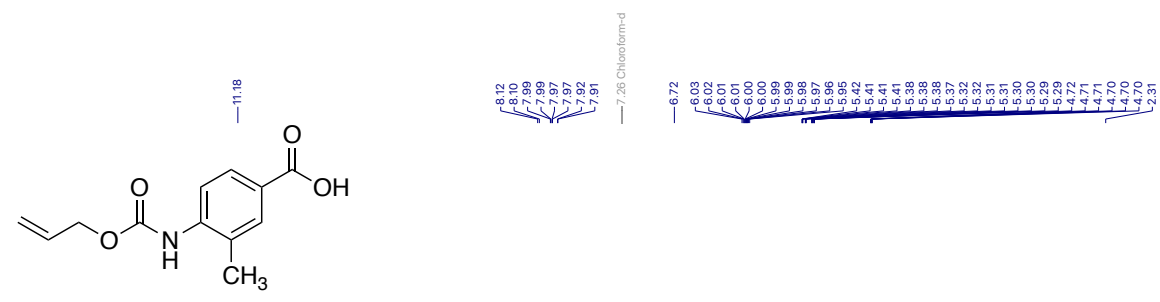

$8 a$
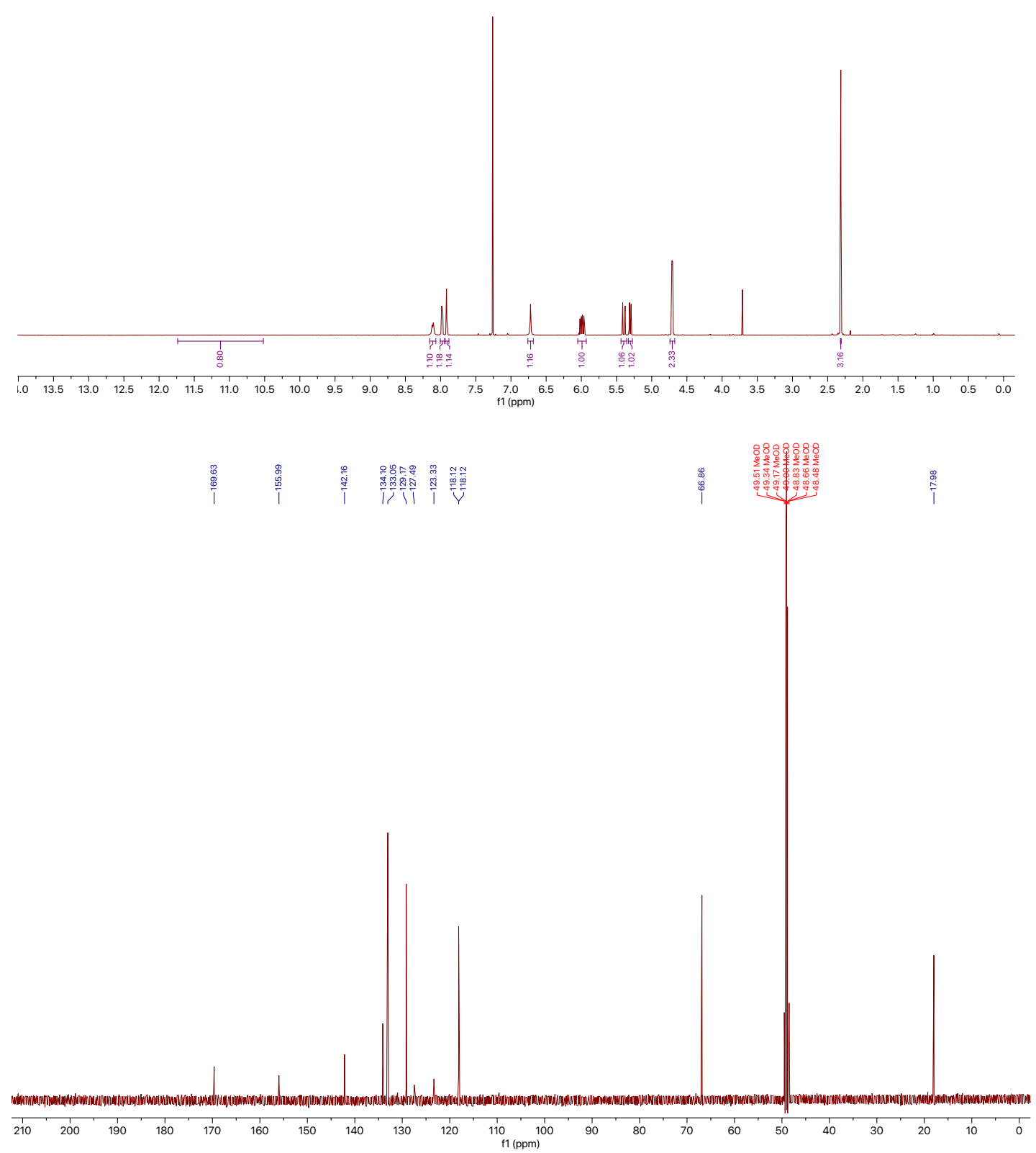

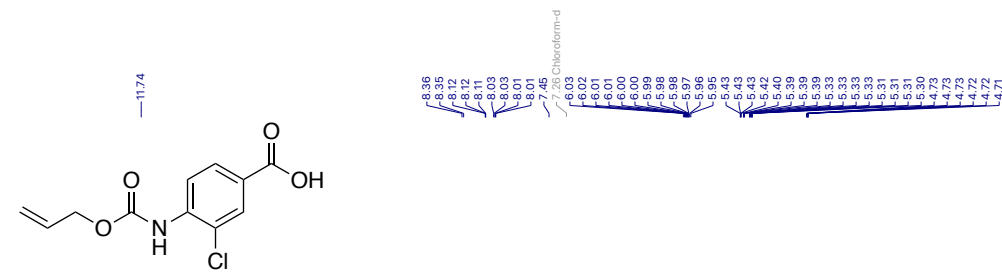

$8 b$
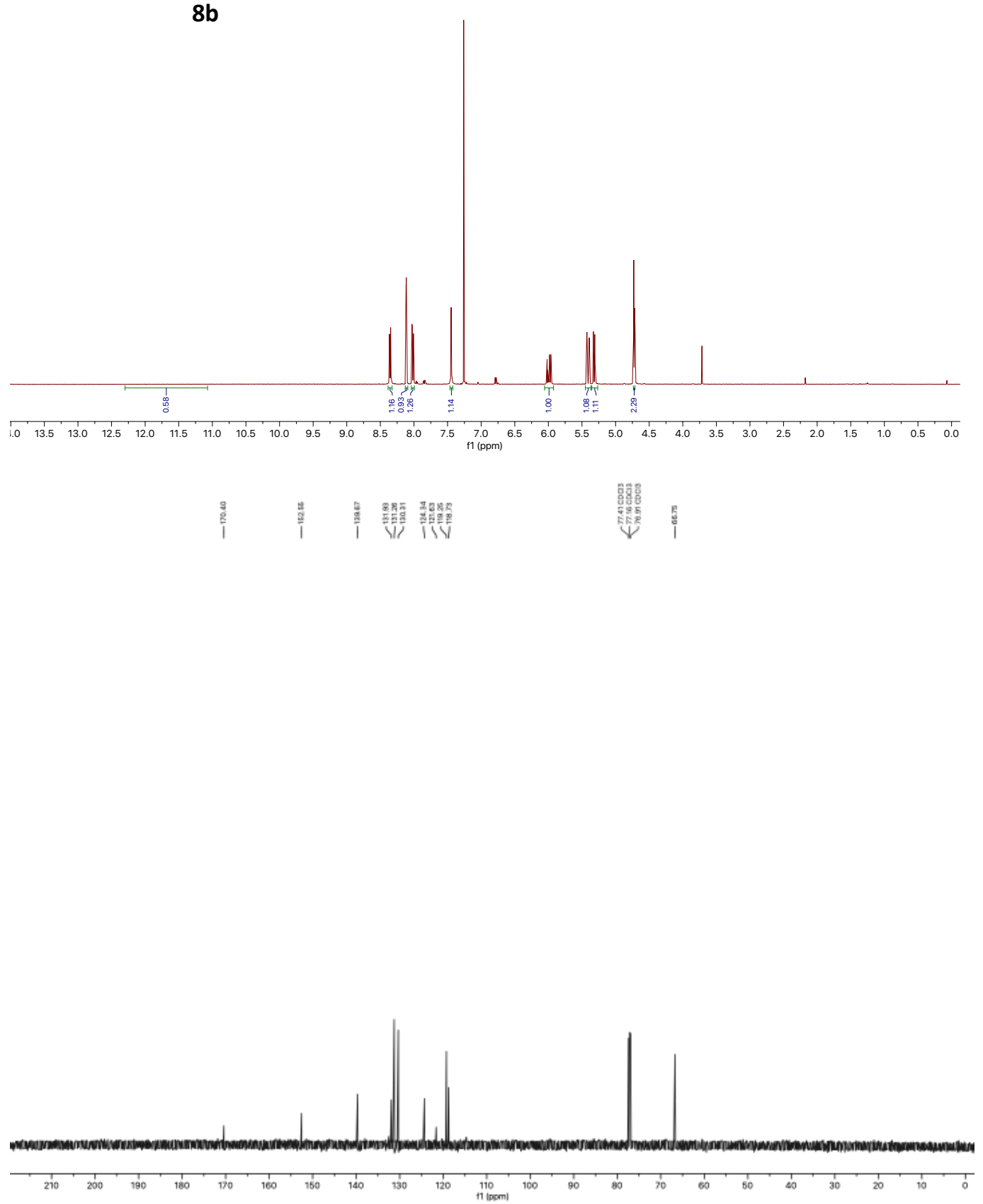

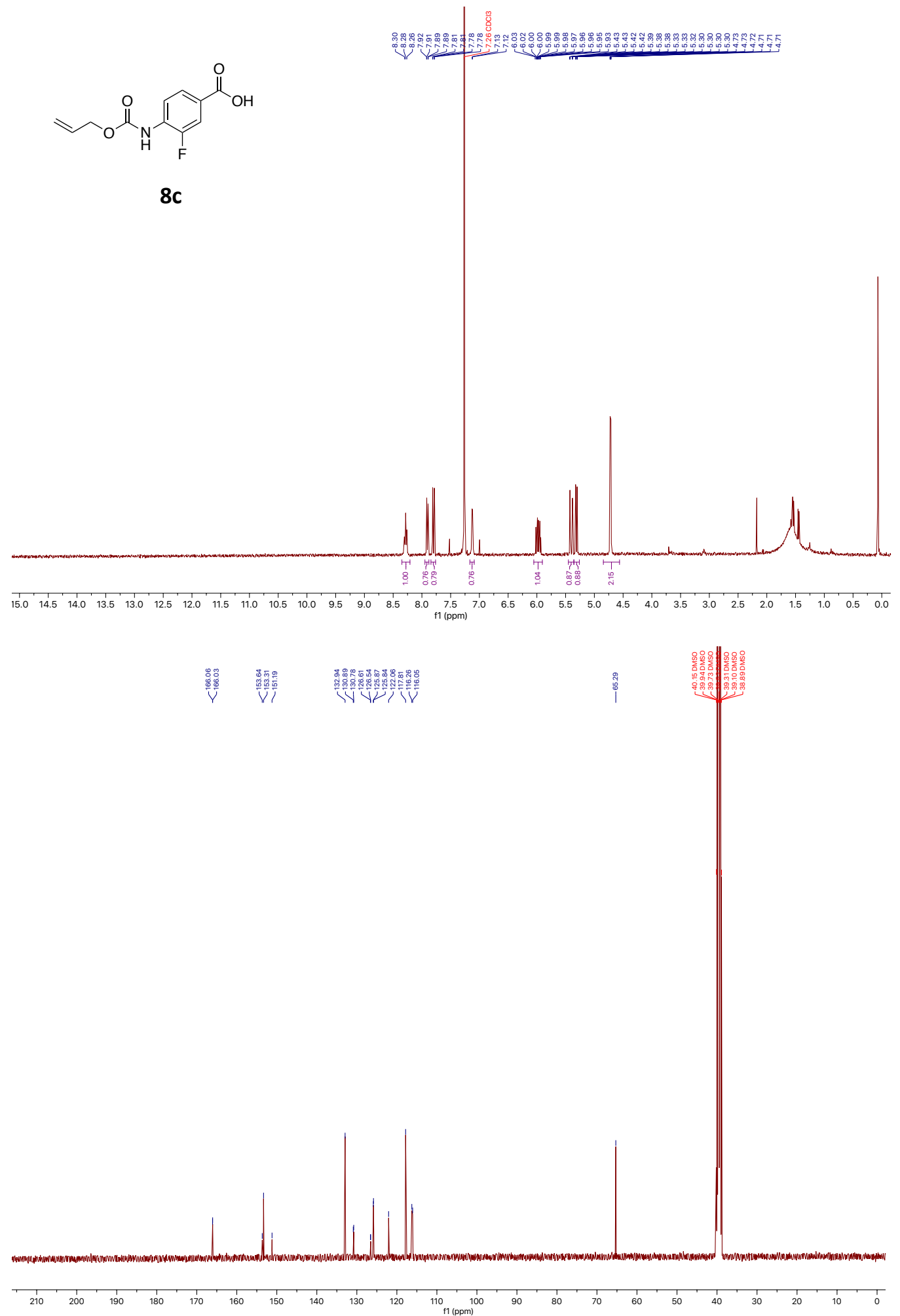


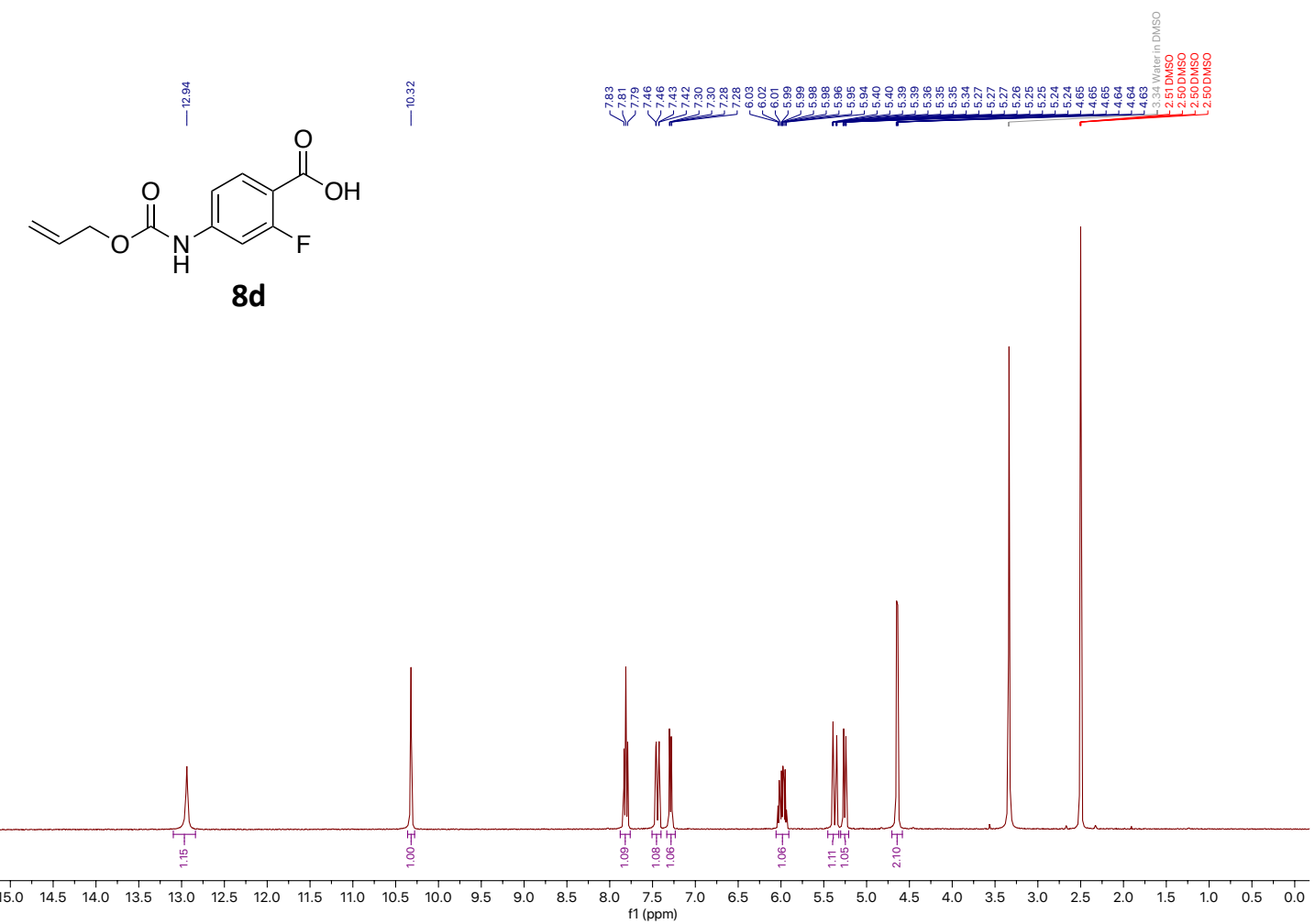

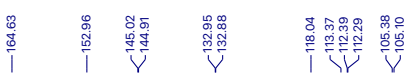

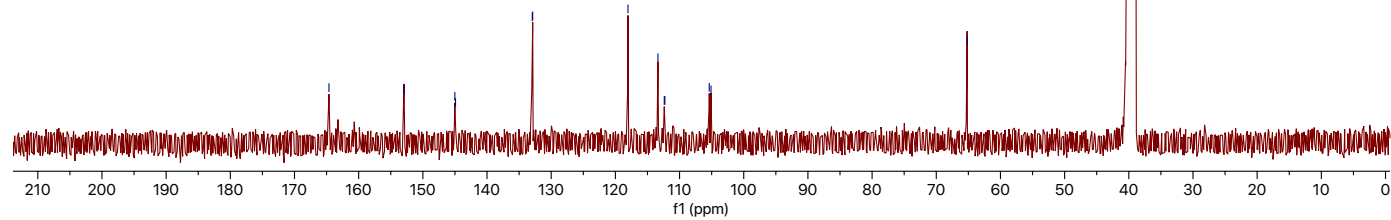



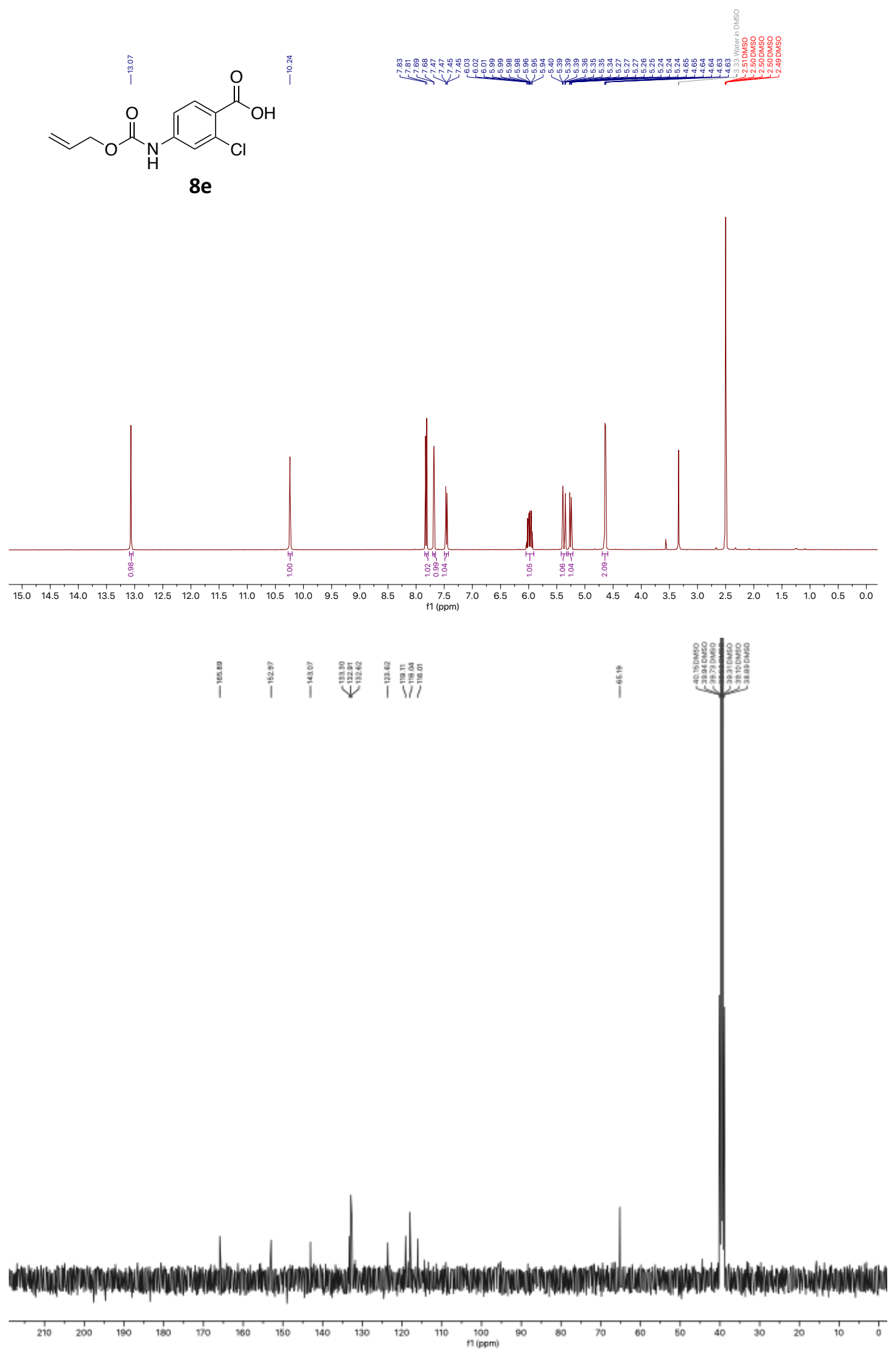

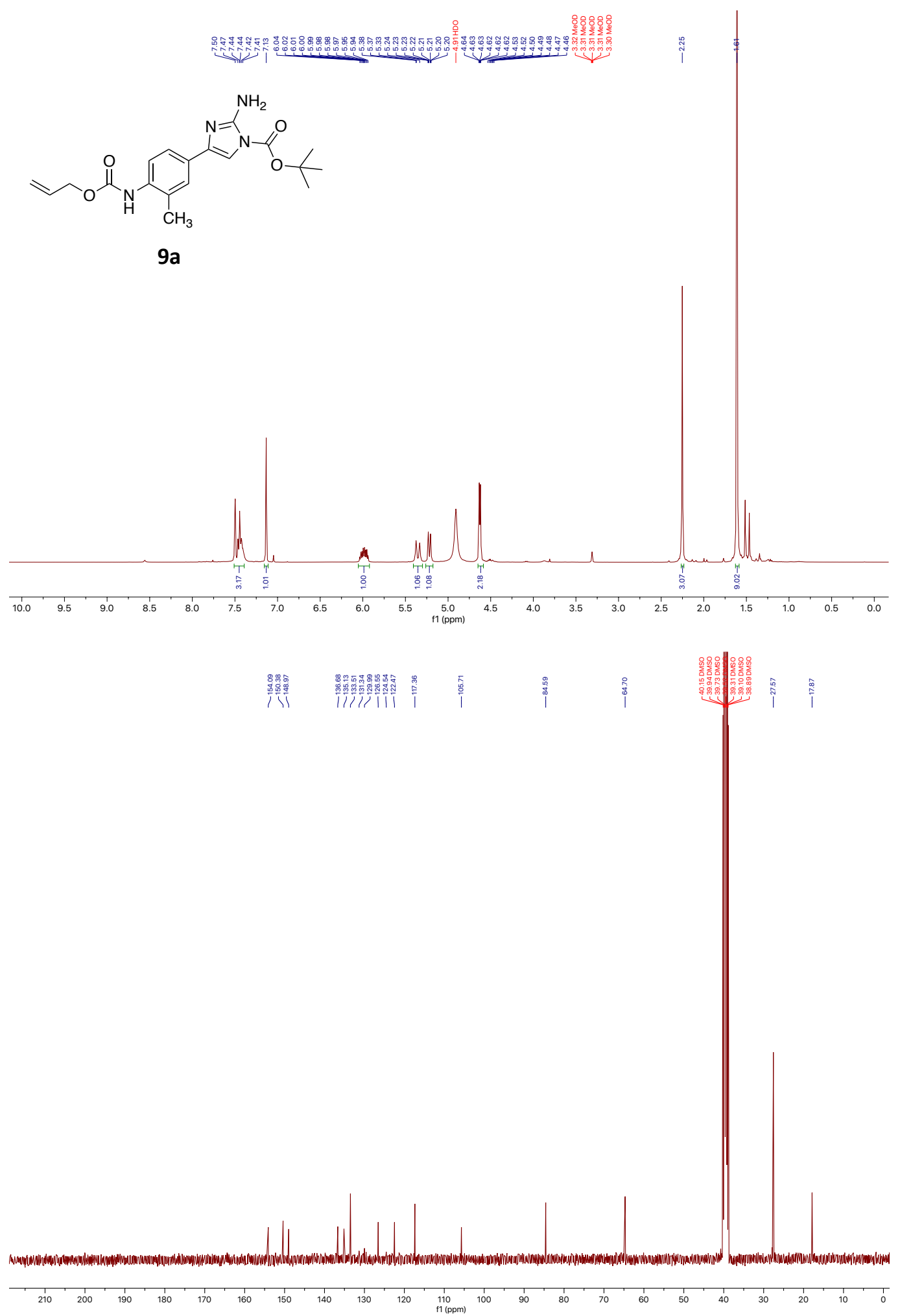


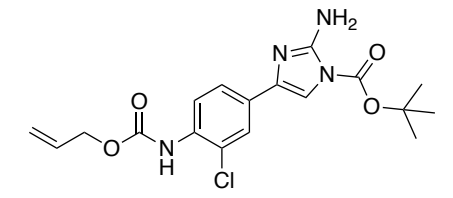

$9 b$
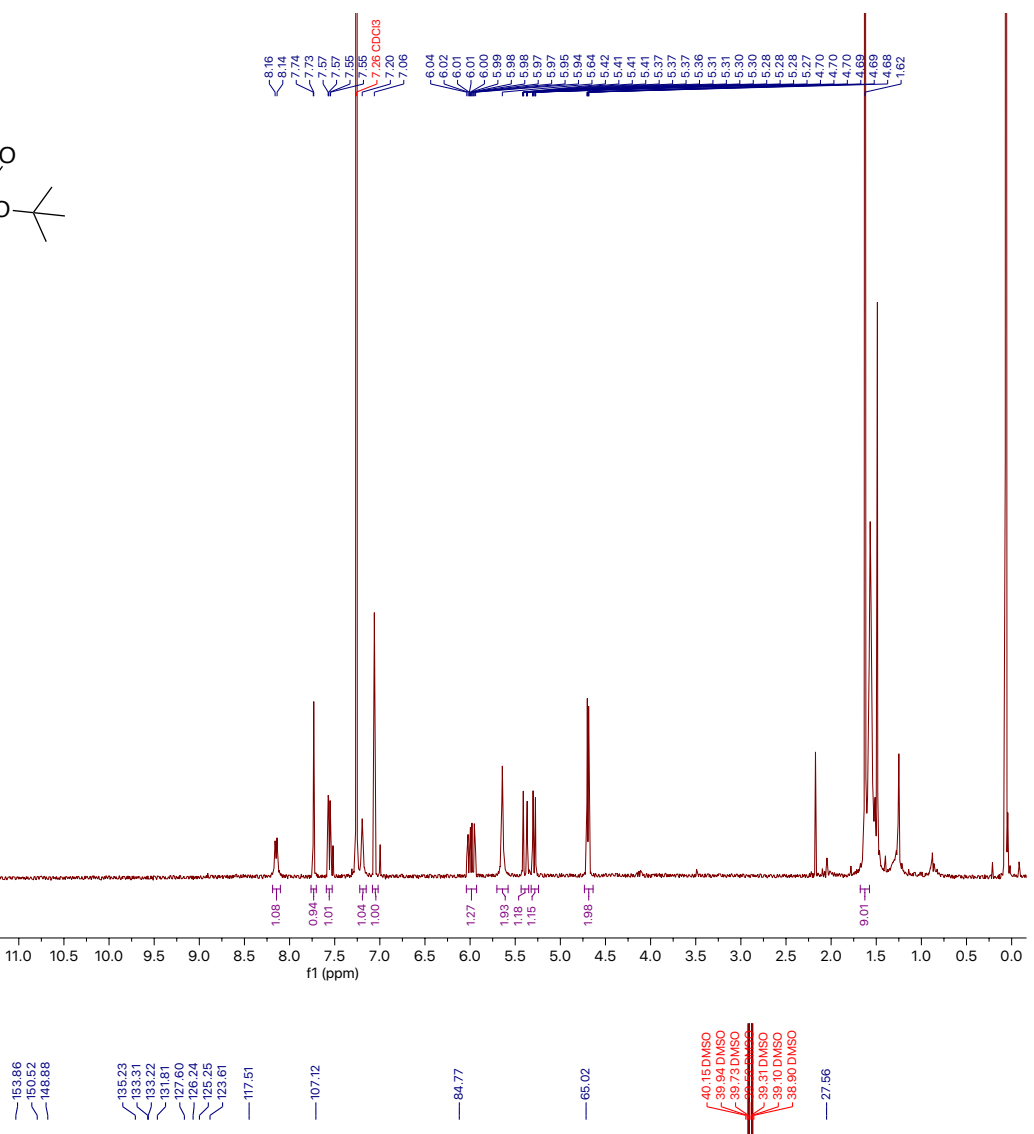

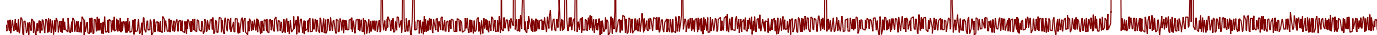

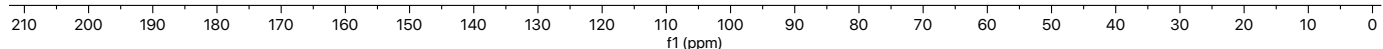



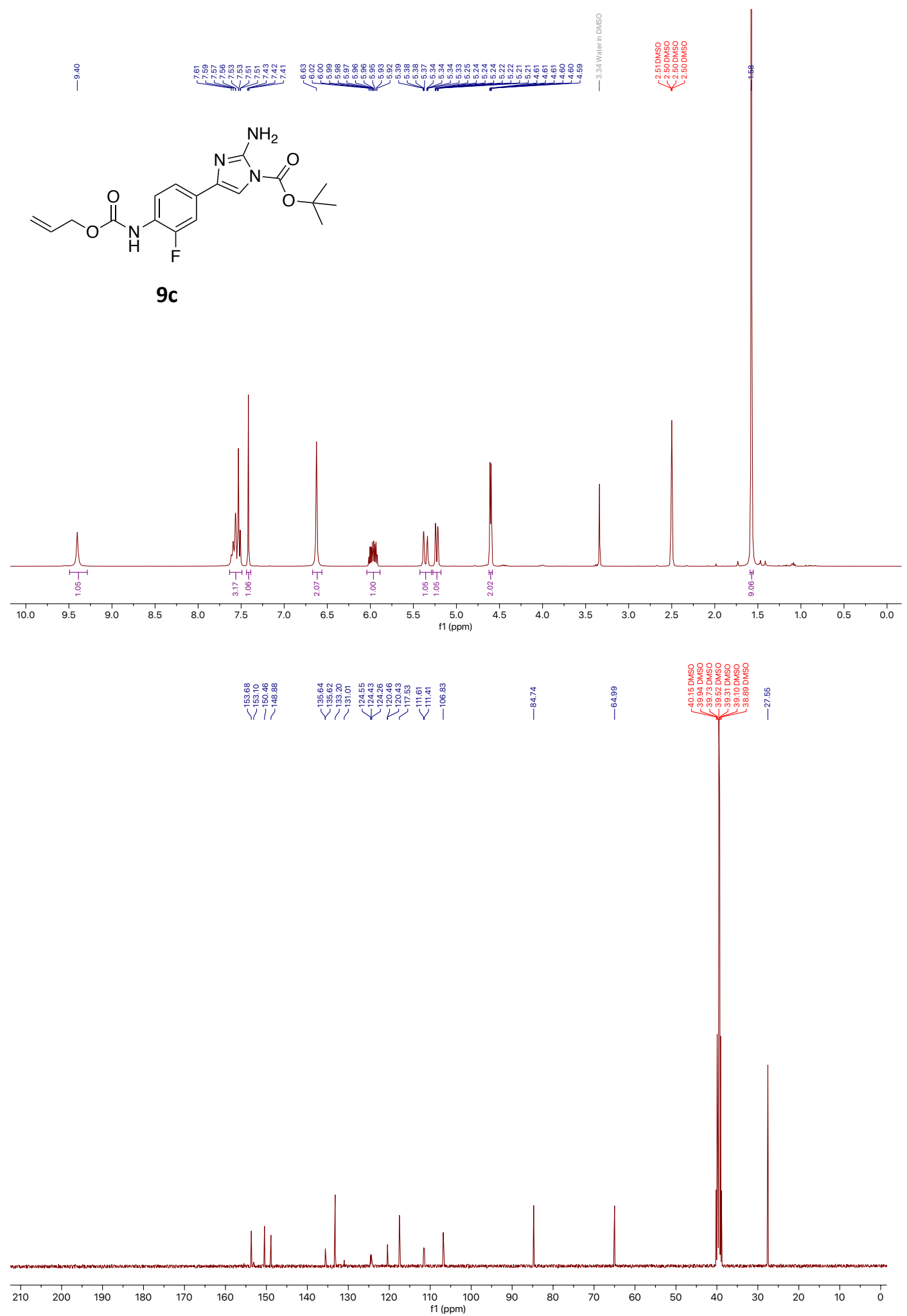

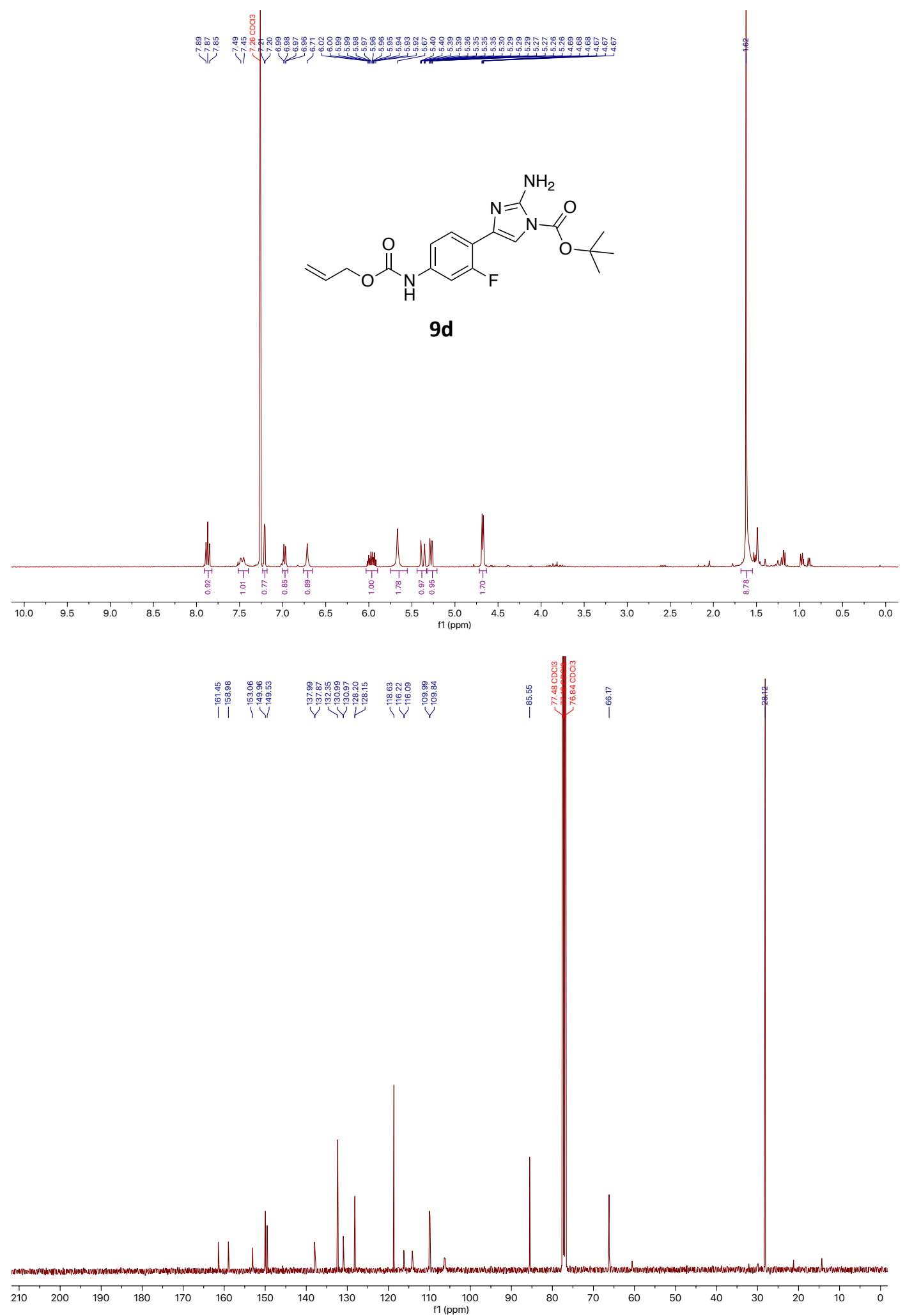

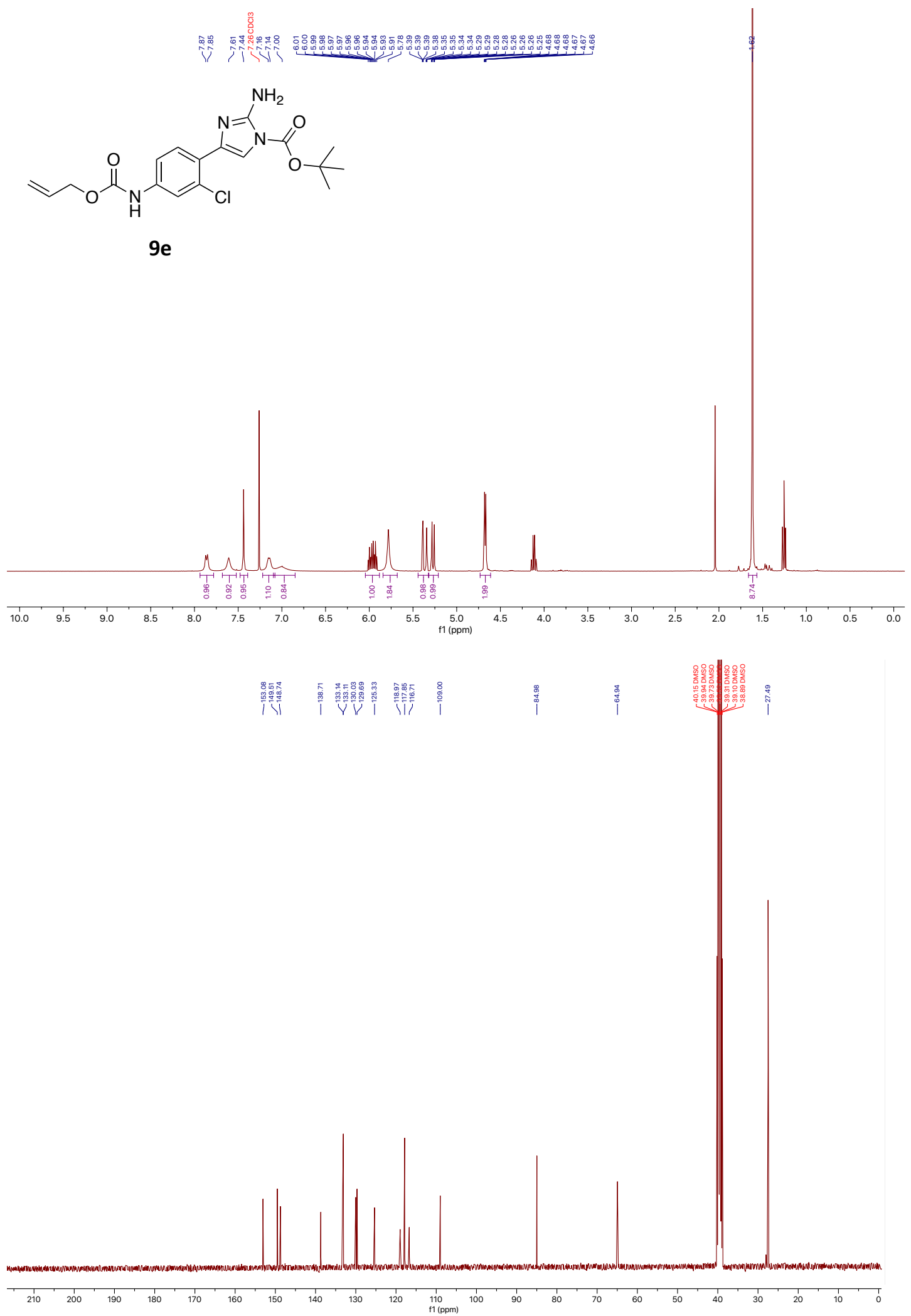


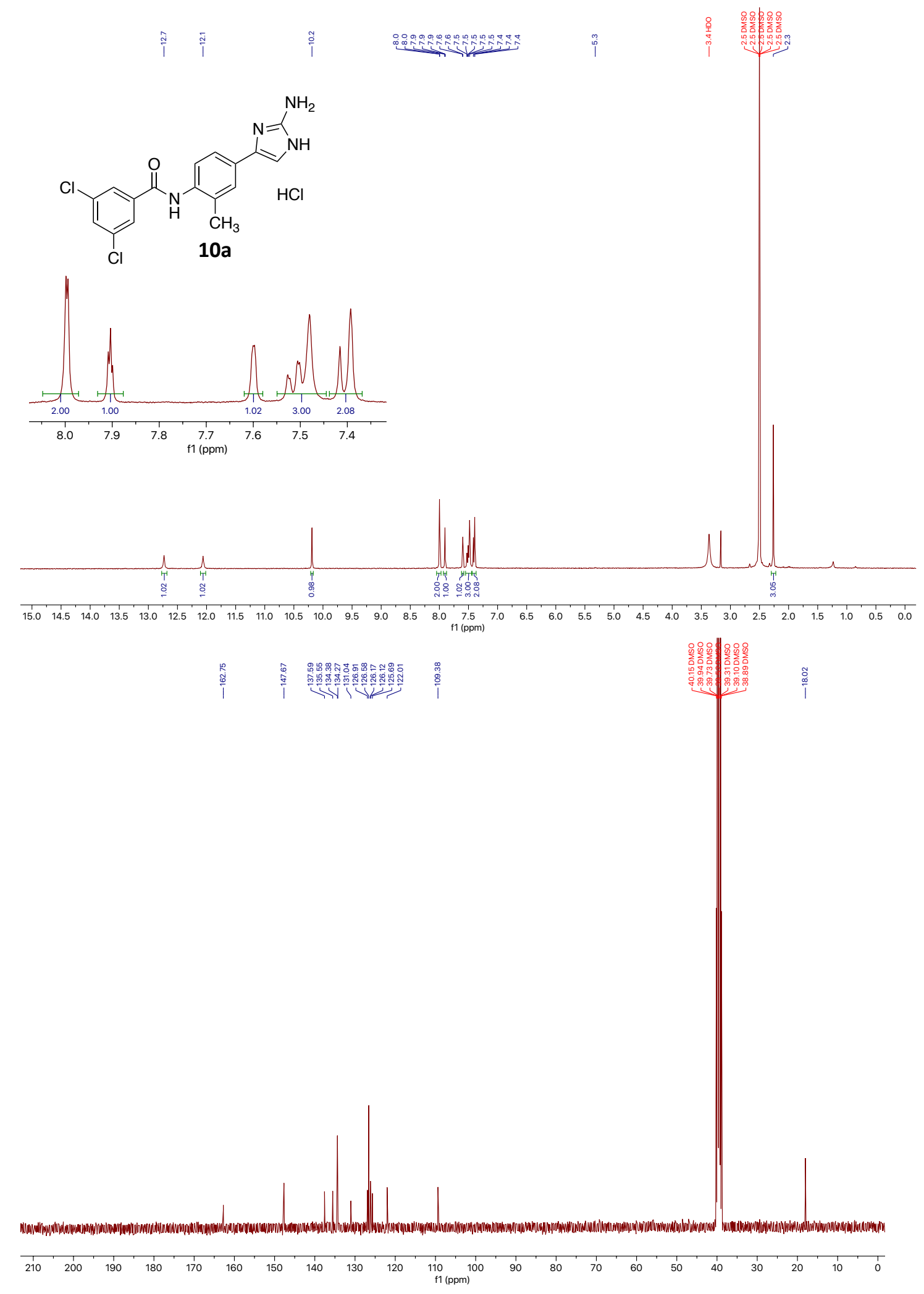



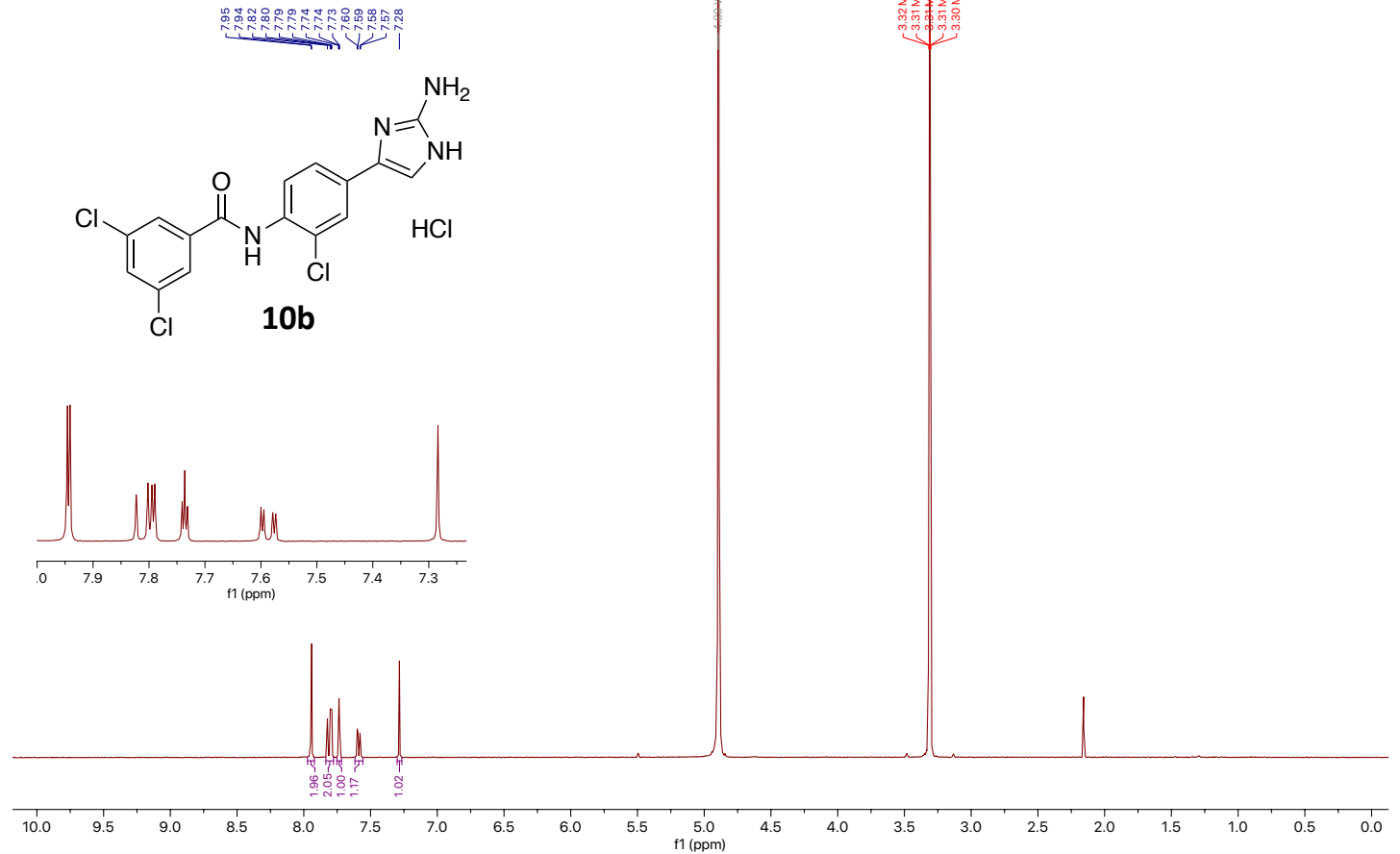

$$
\text { I l }
$$

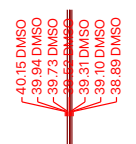

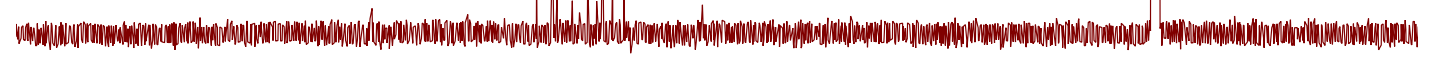

\begin{tabular}{llllllllllllllllllllll}
\hline 210 & 200 & 190 & 180 & 170 & 160 & 150 & 140 & 130 & 120 & 110 & $\begin{array}{c}100 \\
\mathrm{f} 1(\mathrm{ppm})\end{array}$ & 90 & 80 & 70 & 60 & 50 & 40 & 30 & 20 & 10 & 0
\end{tabular}



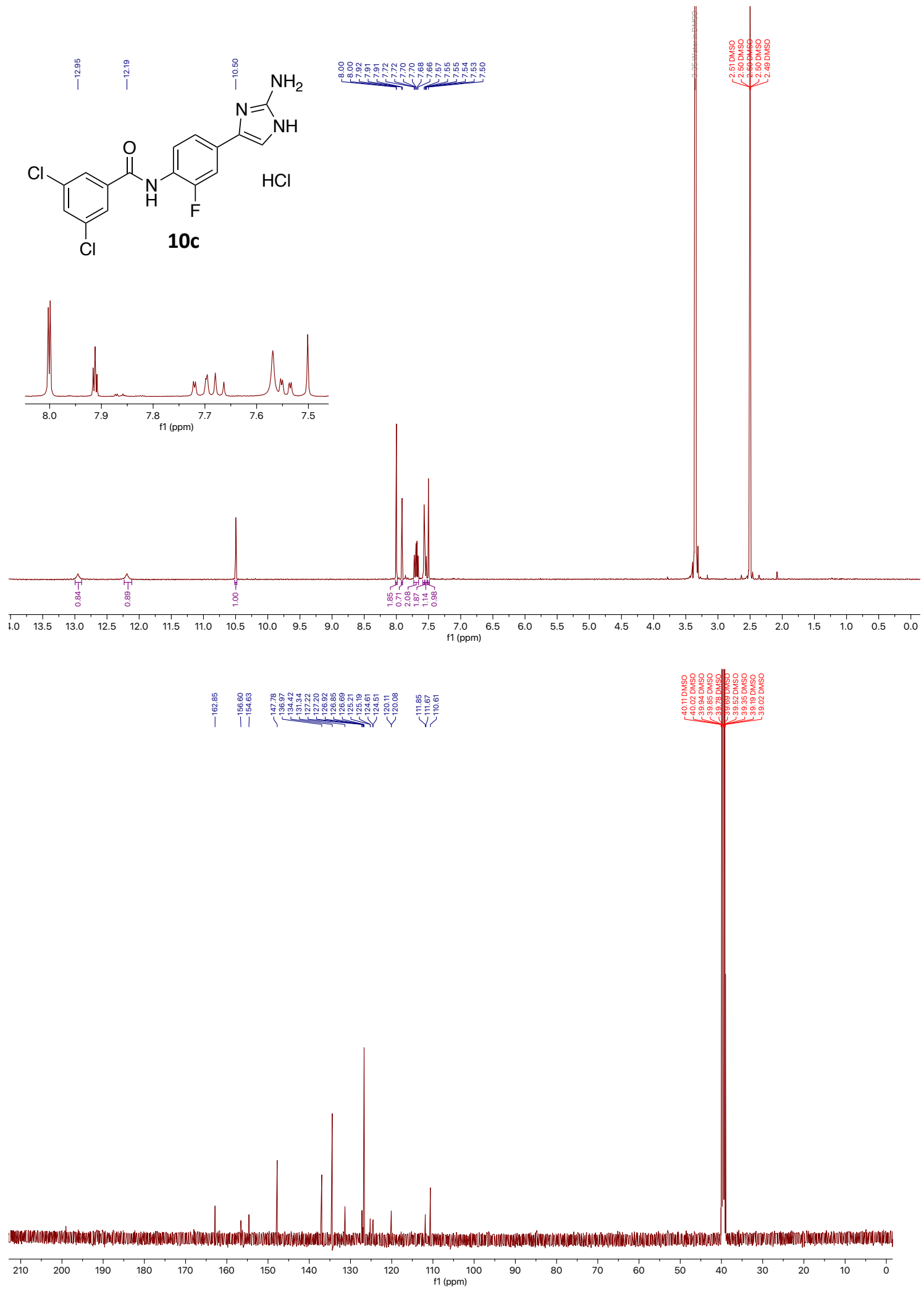

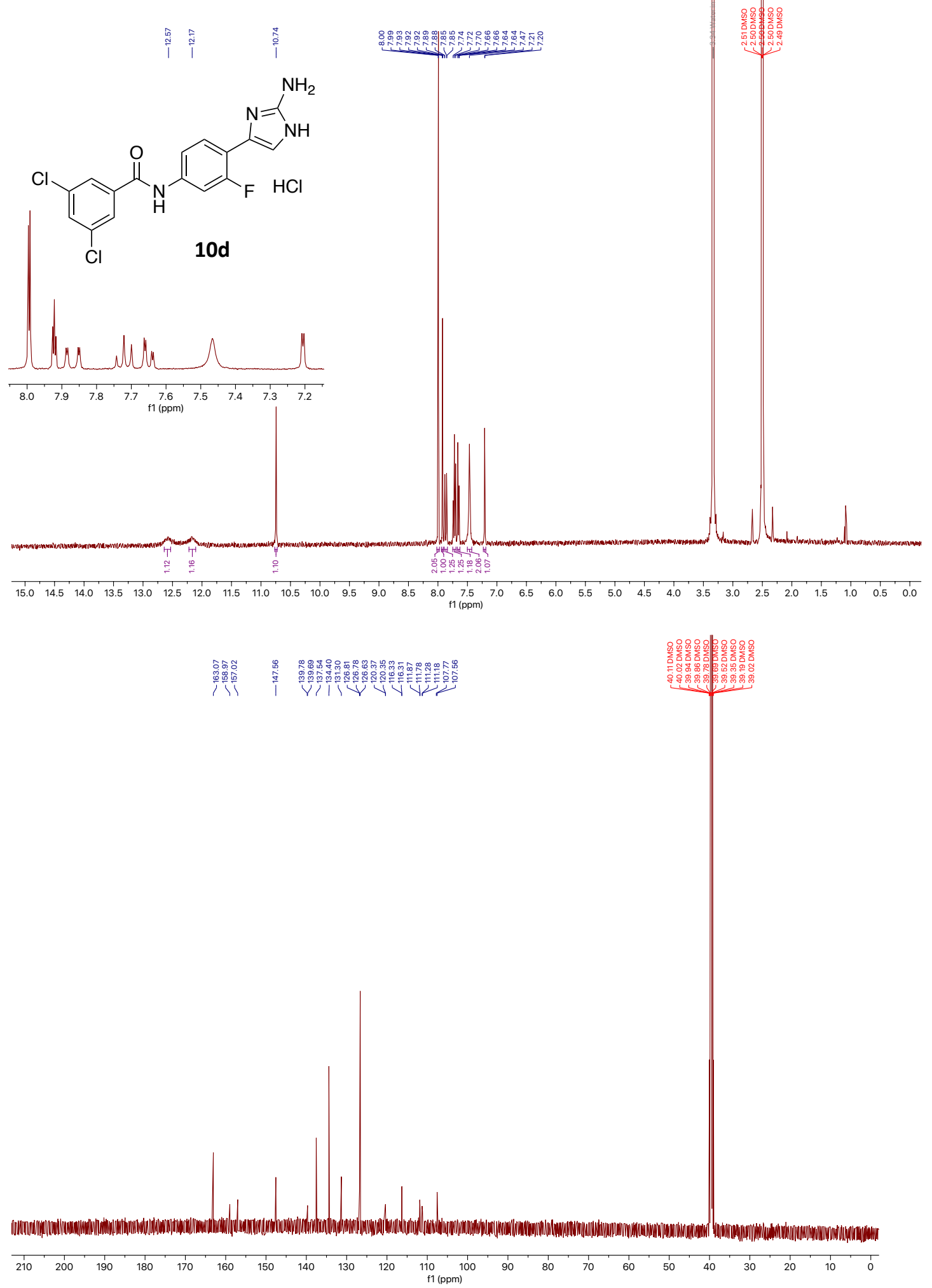

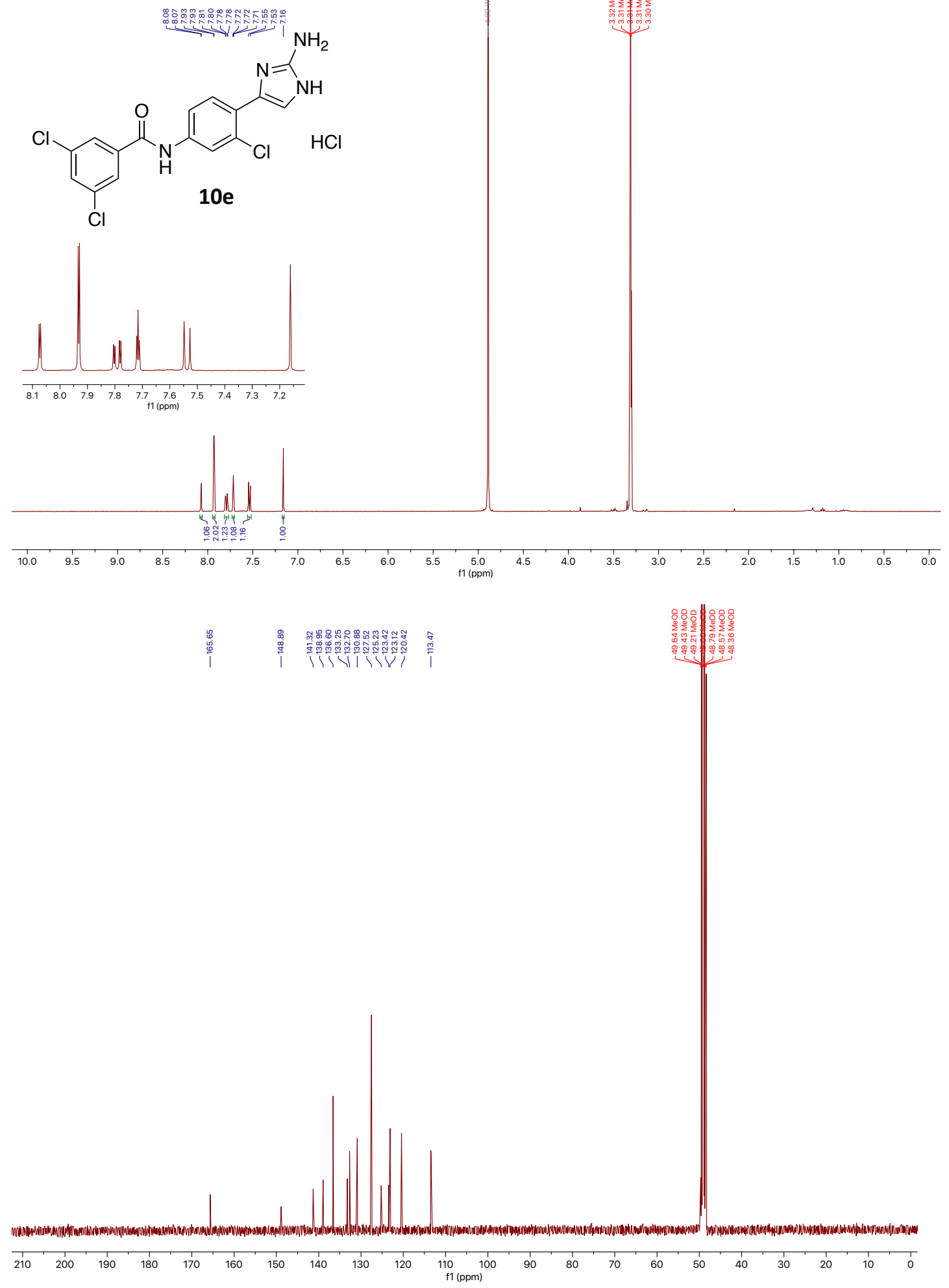

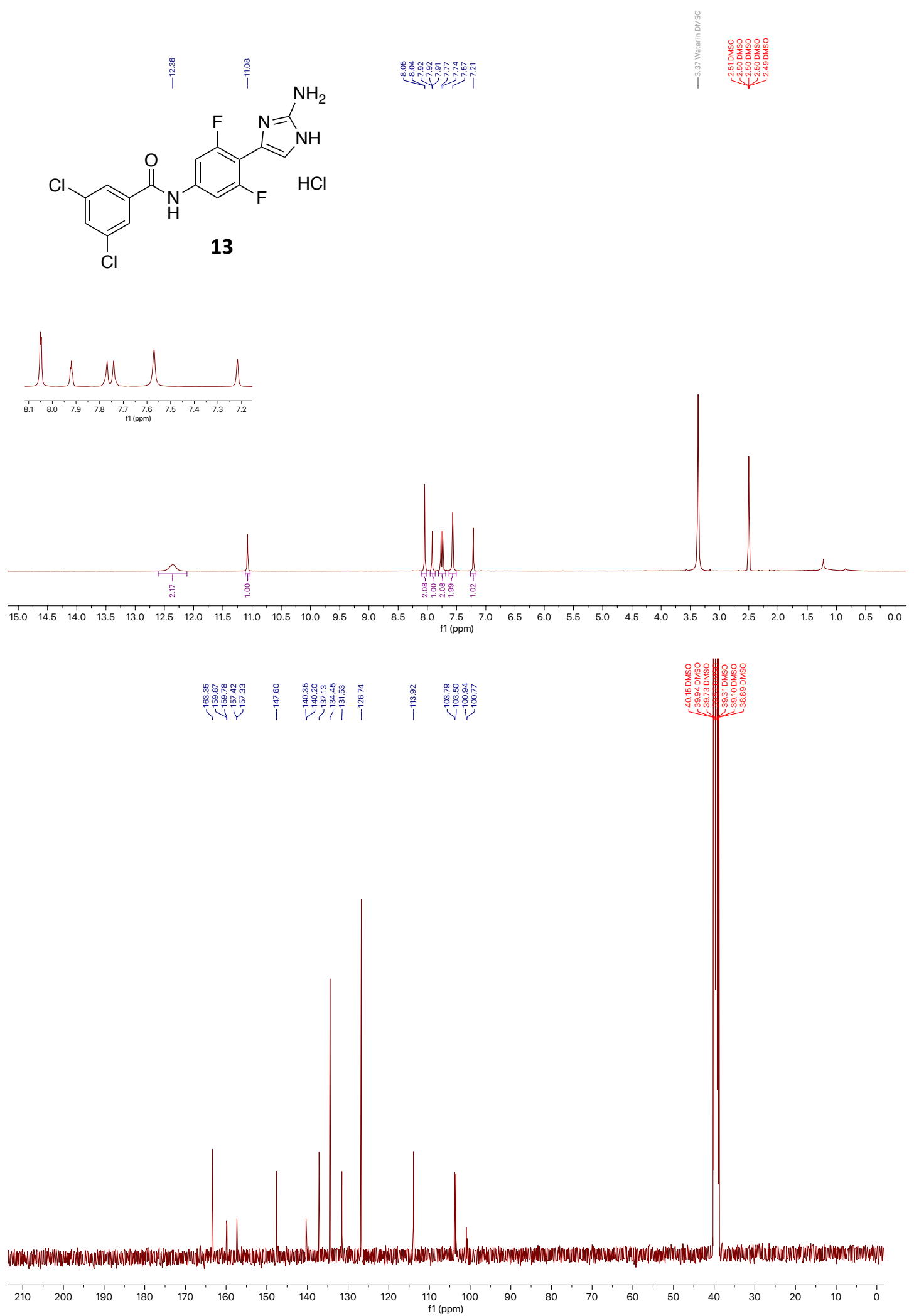


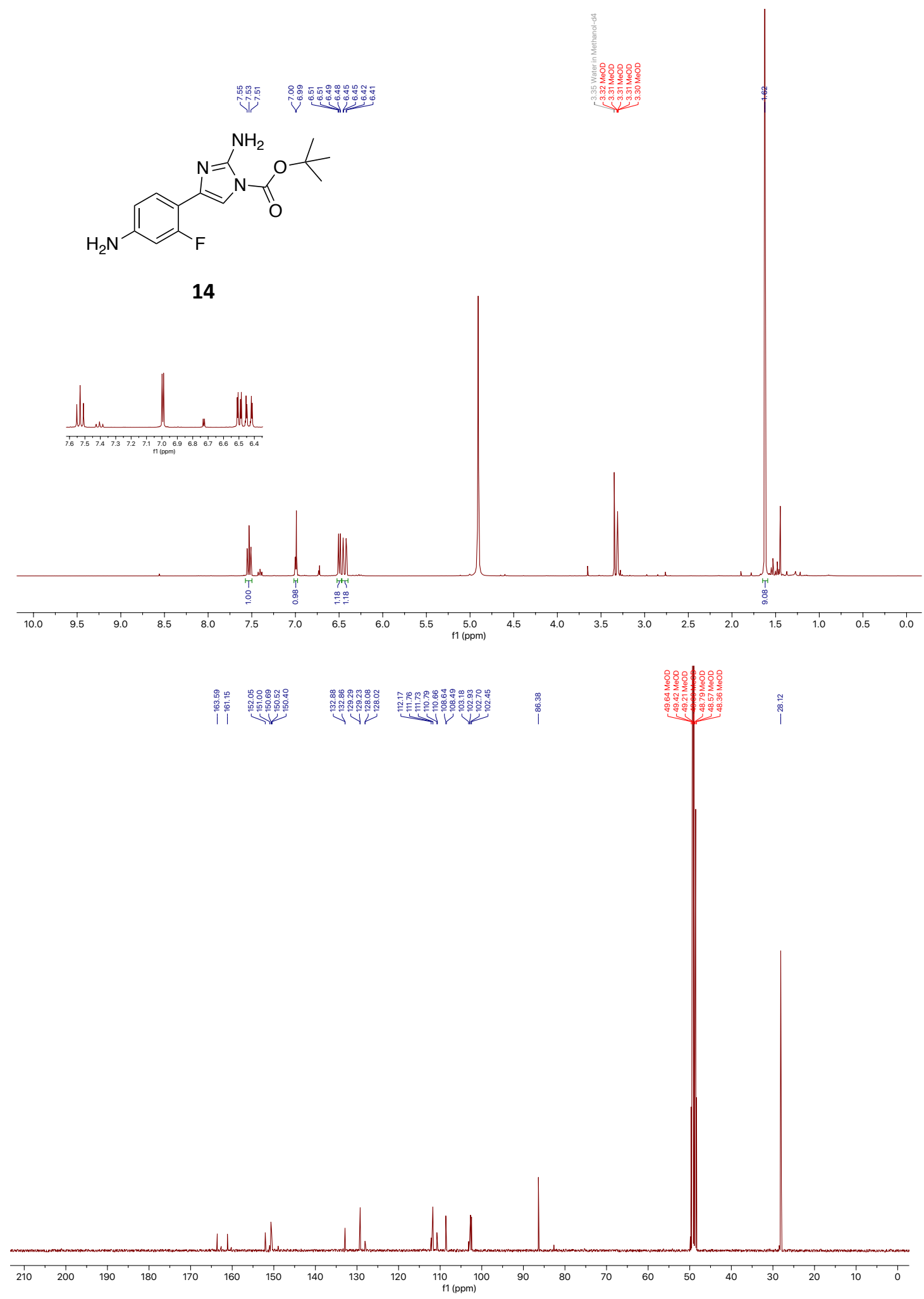




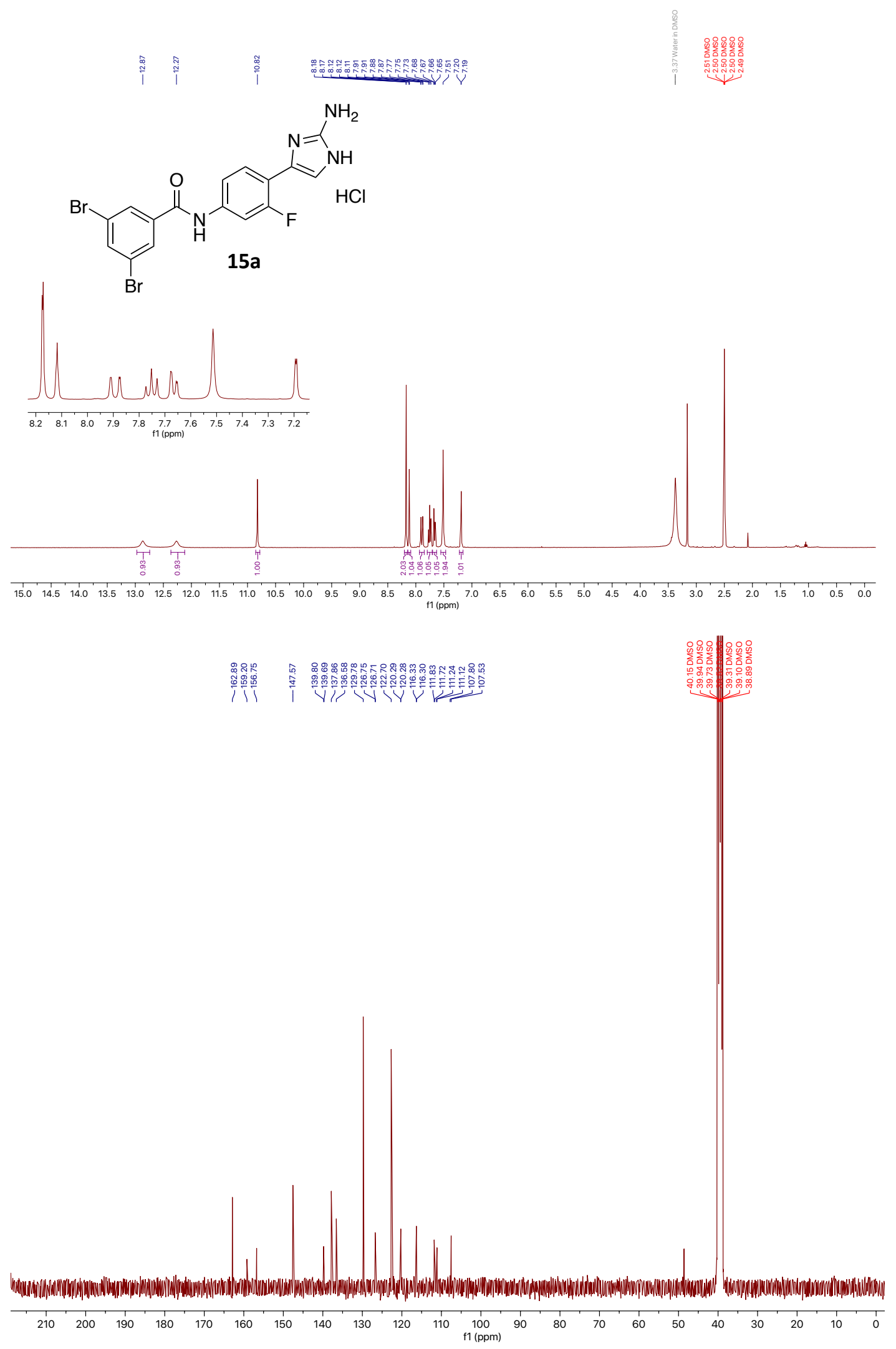



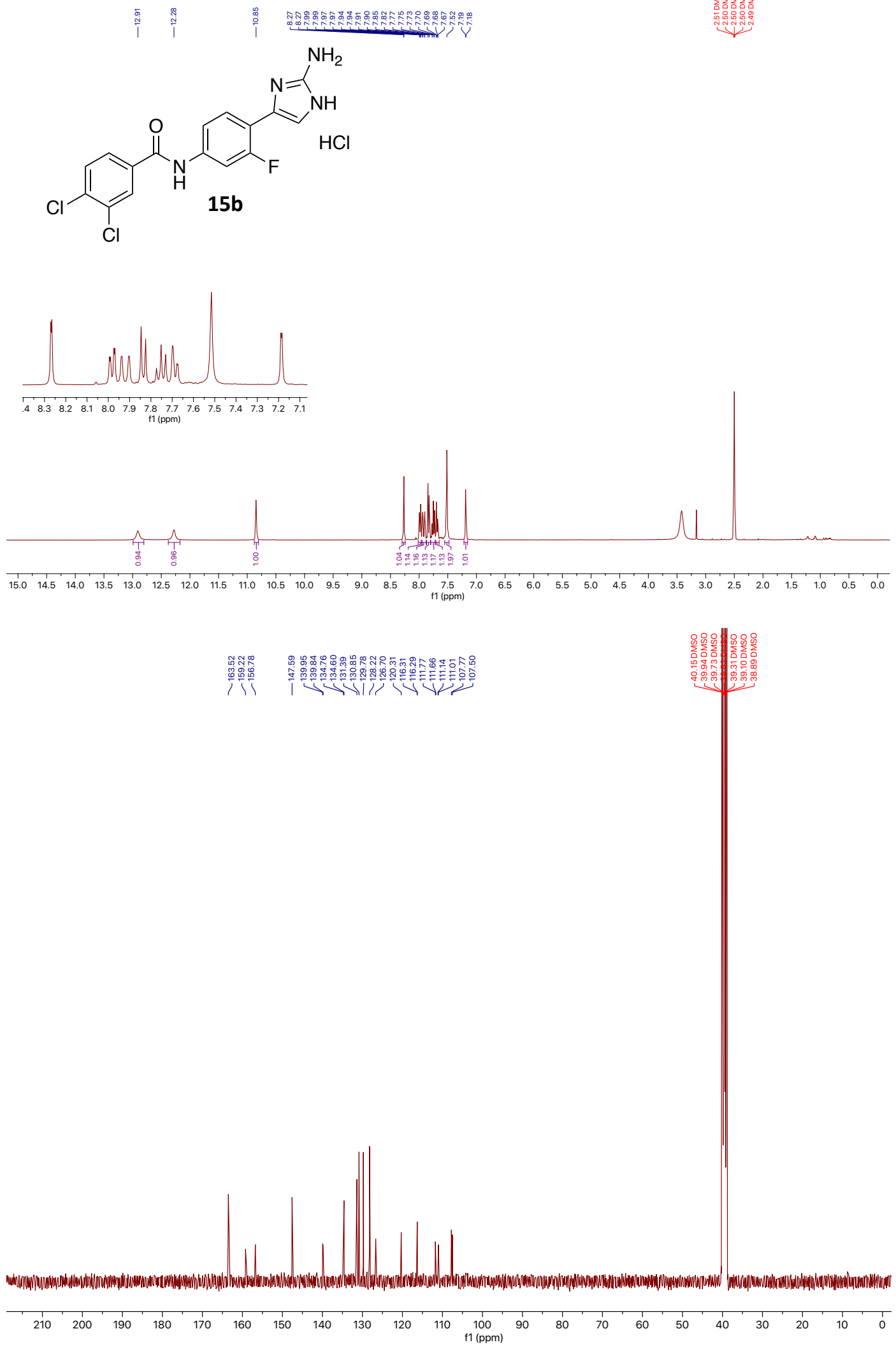


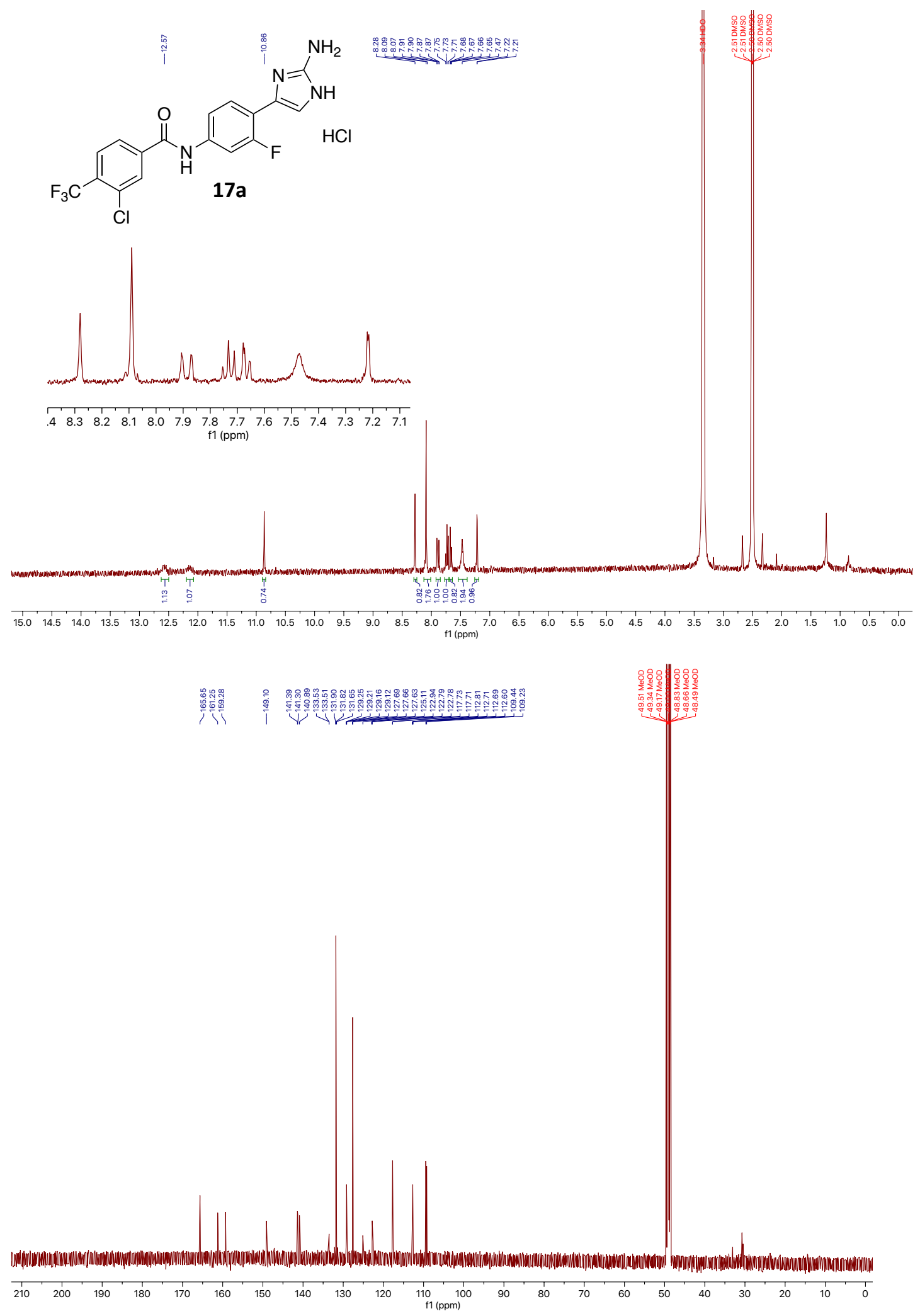



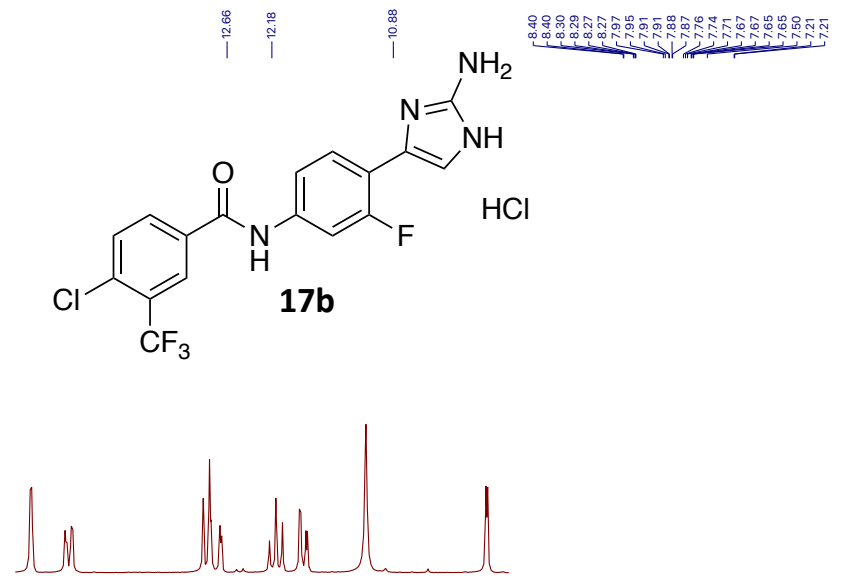

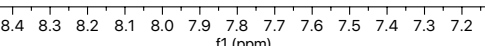
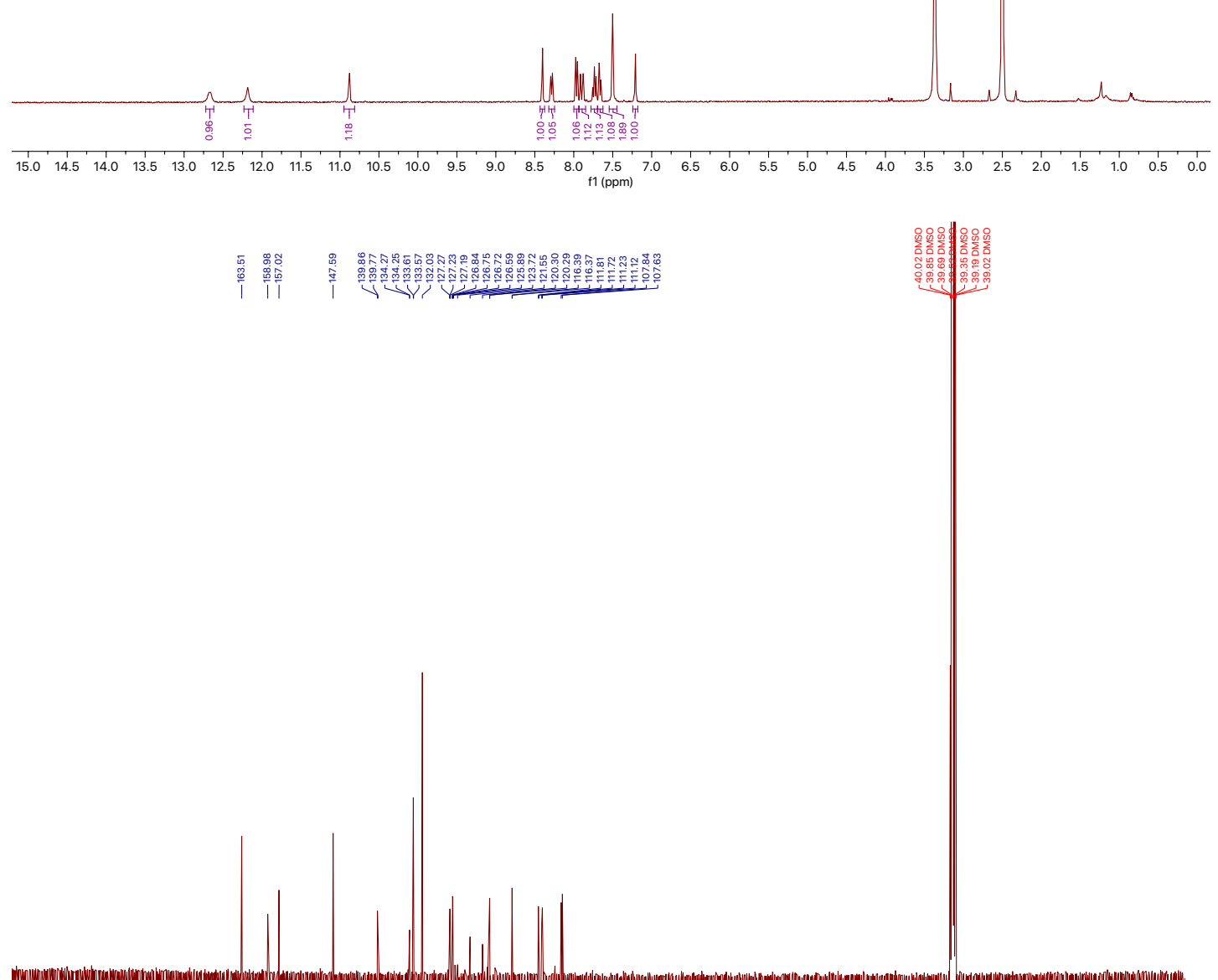

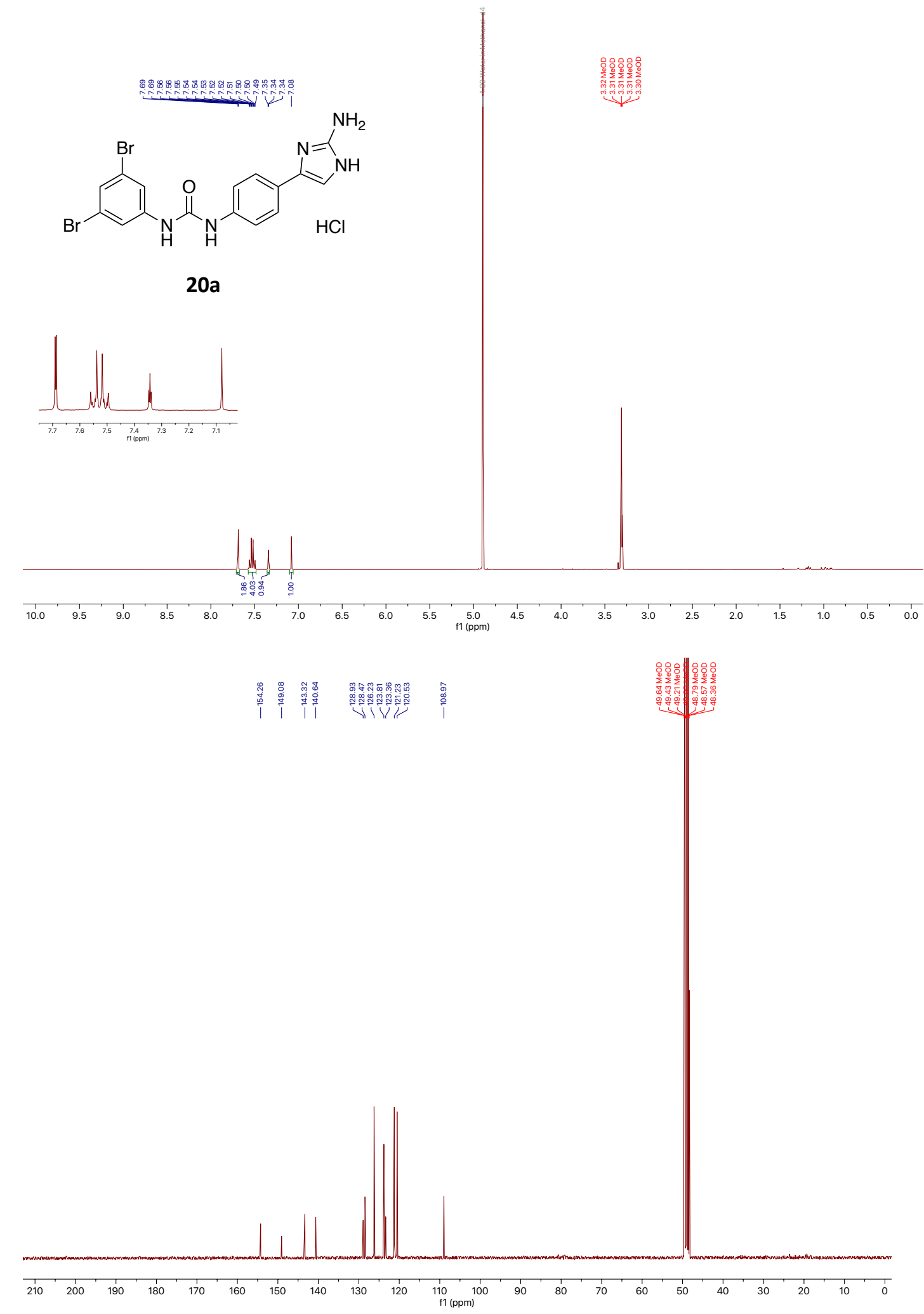

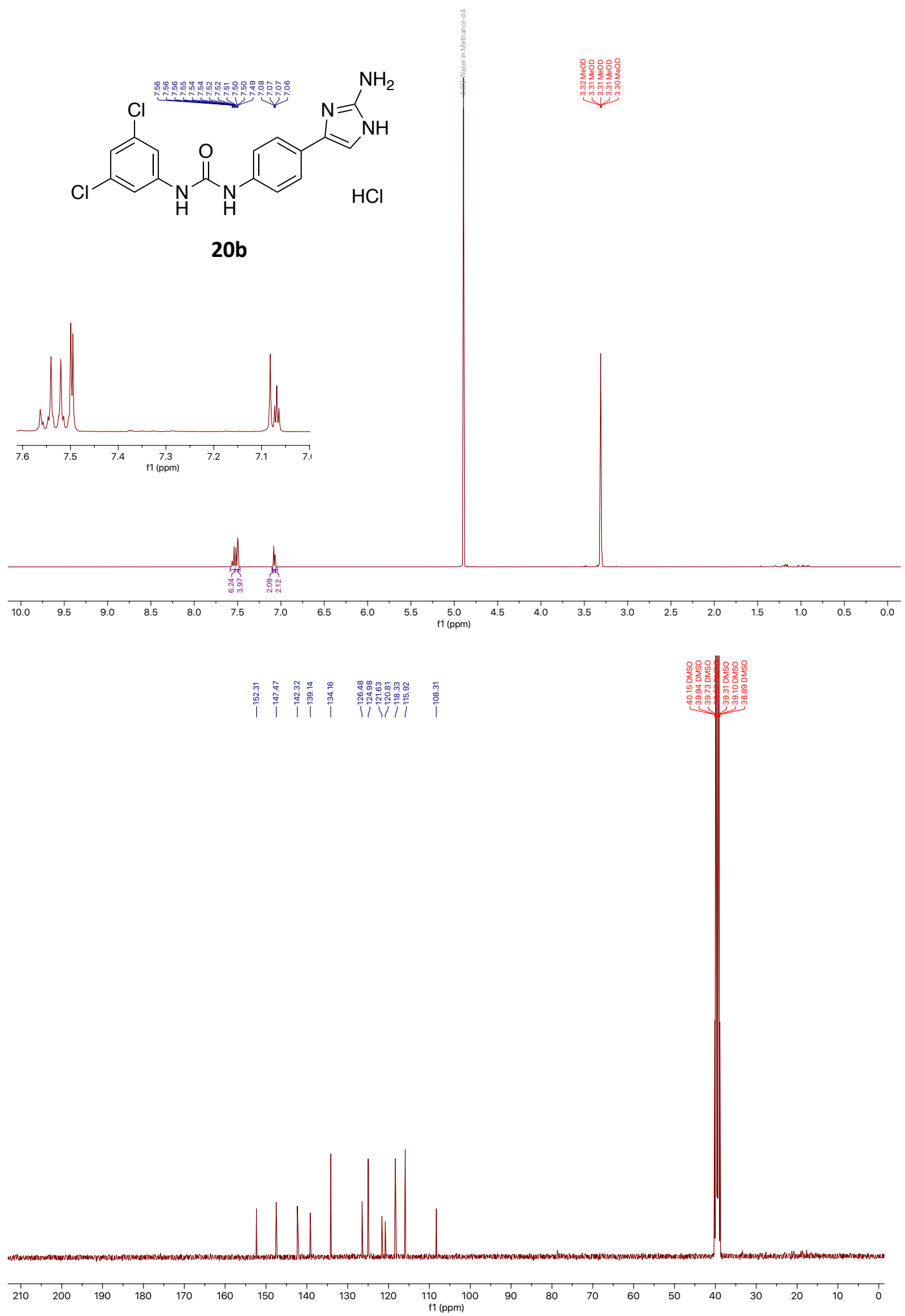

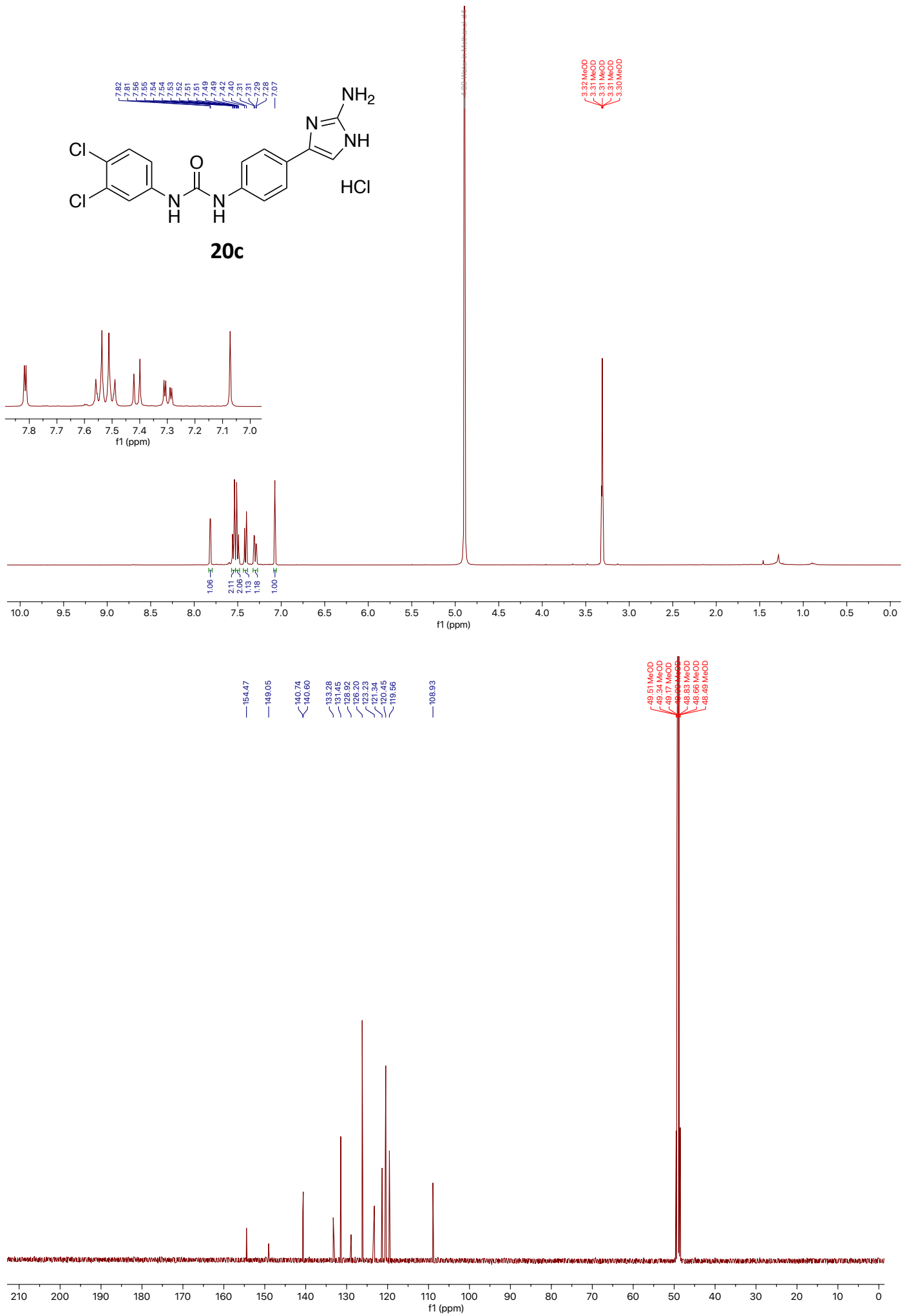


\section{Bibliography}

1. Brackett, C. M.; Melander, R. J.; An, I. H.; Krishnamurthy, A.; Thompson, R. J.; Cavanagh, J.; Melander, C., Small-Molecule suppression of beta-lactam resistance in multidrug-resistant Gram-negative pathogens. J Med Chem 2014, 57 (17), 7450-8. 